\title{
Ultrasound-assisted surface-modification of wood particulates for improved wood/plastic composites
}

\author{
Wei-Ping Chang \\ West Virginia University
}

Follow this and additional works at: https://researchrepository.wvu.edu/etd

\section{Recommended Citation}

Chang, Wei-Ping, "Ultrasound-assisted surface-modification of wood particulates for improved wood/ plastic composites" (2008). Graduate Theses, Dissertations, and Problem Reports. 1903.

https://researchrepository.wvu.edu/etd/1903

This Thesis is protected by copyright and/or related rights. It has been brought to you by the The Research Repository @ WVU with permission from the rights-holder(s). You are free to use this Thesis in any way that is permitted by the copyright and related rights legislation that applies to your use. For other uses you must obtain permission from the rights-holder(s) directly, unless additional rights are indicated by a Creative Commons license in the record and/ or on the work itself. This Thesis has been accepted for inclusion in WVU Graduate Theses, Dissertations, and Problem Reports collection by an authorized administrator of The Research Repository @ WVU. For more information, please contact researchrepository@mail.wvu.edu. 


\title{
Ultrasound-assisted surface-modification of wood particulates for improved wood/plastic composites
}

\author{
Wei-Ping Chang \\ Thesis Submitted to \\ College of Engineering and Mineral Resources \\ West Virginia University

\begin{abstract}
IN PARTIAL FULFILLMENT OF THE
REQUIREMENTS FOR THE DEGREE OF

MASTER OF SCIENCE IN CHEMICAL ENGINEERING
\end{abstract} \\ Dr. Rakesh K. Gupta, Chair \\ Dr. Charter D. Stinespring \\ Dr. John W. Zondlo \\ Department of Chemical Engineering \\ Morgantown, West Virginia \\ 2008
}




\section{ABSTRACT \\ Ultrasound-assisted surface-modification of wood particulates for improved wood/plastic composites}

\section{Wei-Ping Chang}

The combined effects of alkali and ultrasound treatment of wood flour on the mechanical properties of polypropylene-based wood/plastic composites (WPCs) were examined. FTIR measurements confirmed that the alkali treatment removed both hemicellulose and lignin from the wood, and there was an increase in the number of hydroxyl groups on the cellulose surface. This process was promoted by the application of ultrasound. Mechanical testing of injection-molded WPC samples revealed that alkali treatment improved both composite strength and modulus when polypropylene grafted with maleic acid was used as a coupling agent. The strength increase is due to improved adhesion between the fiber and matrix, while improved modulus is due to the removal of lignin and hemicellulose that are not as stiff as cellulose. Polarized optical microscopy showed the presence of well-defined polymer crystals on the surface of the modified wood, and this is also responsible for the improved mechanical properties. It is conclusively demonstrated that the combination of chemical treatment of wood and ultrasound assistance is more effective in improving the mechanical properties of the composites than the use of chemical treatment alone. 


\section{Table of Contents}

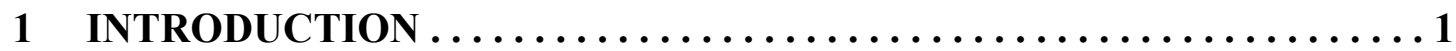

1.1 The importance of WPC and its application $\ldots \ldots \ldots \ldots \ldots \ldots$

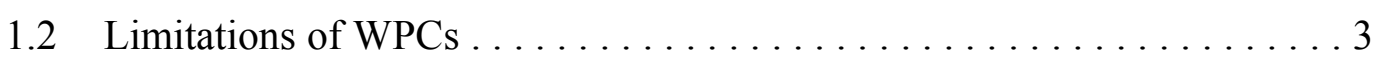

1.3 The surface modification of wood fiber $\ldots \ldots \ldots \ldots \ldots \ldots \ldots$

1.4 Research objectives . . . . . . . . . . . . . . . . . . . . 6

2 LITERATURE REVIEW ....................... 7

2.1 Wood fiber and its chemical composition $\ldots \ldots \ldots \ldots \ldots \ldots \ldots$

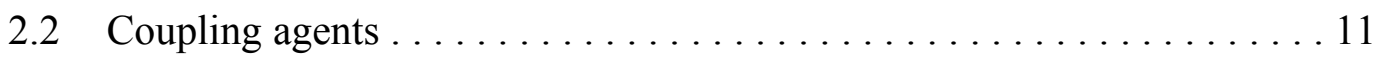

2.2.1 Graft copolymerization $\ldots \ldots \ldots \ldots \ldots \ldots \ldots \ldots \ldots \ldots \ldots \ldots \ldots \ldots \ldots \ldots$

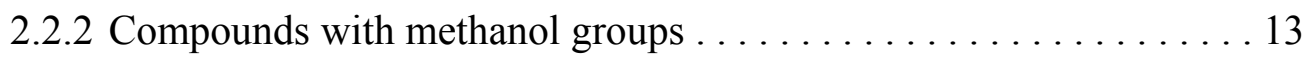

2.2 .3 Organosilanes . . . . . . . . . . . . . . . . . 13

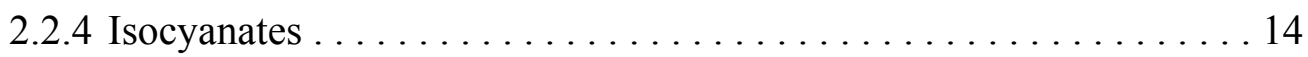

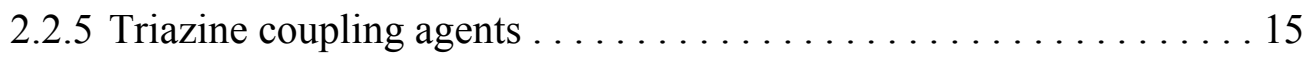

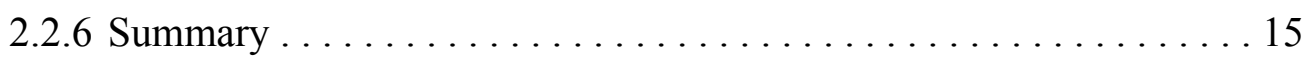

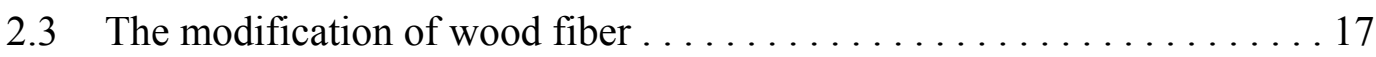

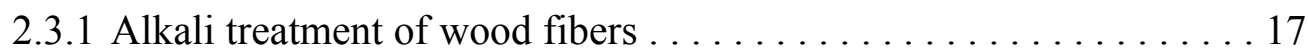

2.3.2 Ultrasound treatment of wood fiber . . . . . . . . . . . 23

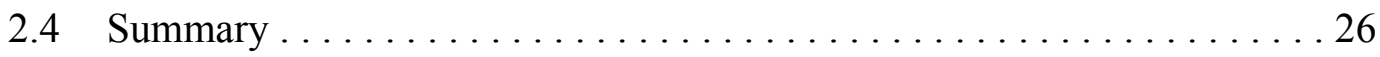

3 MTERIALS AND EXPERIMENTS .................. 28

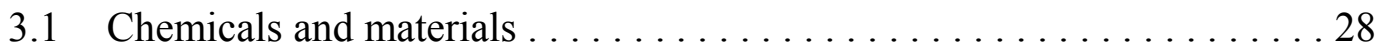

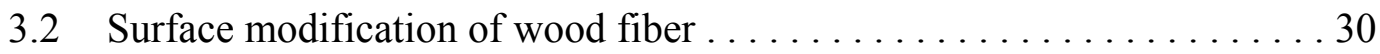

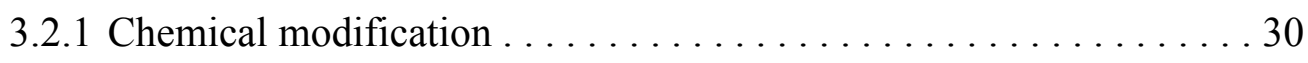

3.2.2 Chemical modification with ultrasound assistant . . . . . . . . 31

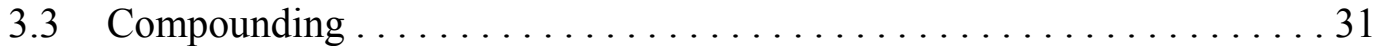

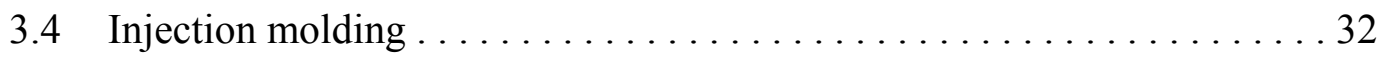

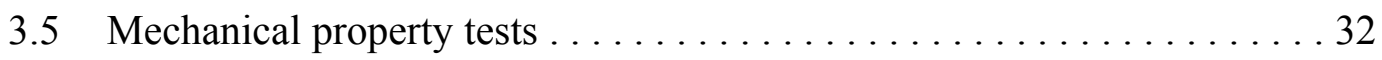

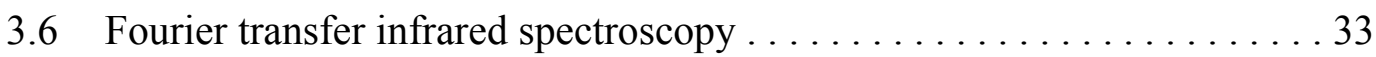

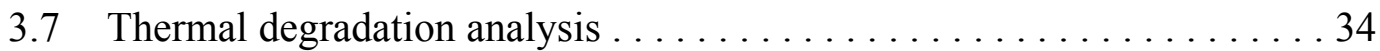

$3.8 \quad$ SEM . . . . . . . . . . . . . . . . . . . . . . 34

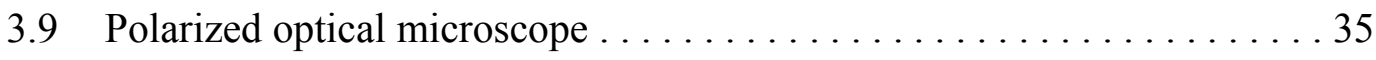

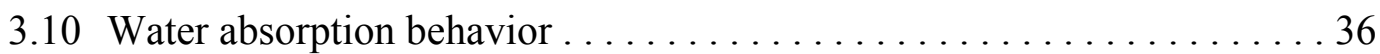

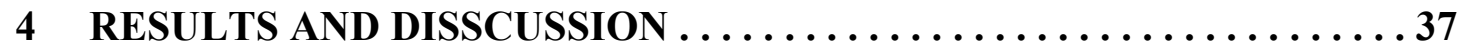

4.1 Characterization of modified wood fibers . . . . . . . . . 37

4.1.1 Fourier transfer infrared spectroscopy (FTIR) . . . . . . . . . 37

4.1.2 Scanning Electron Microscope $(\mathrm{SEM}) \ldots \ldots \ldots \ldots \ldots \ldots \ldots$

4.1 .3 Particle Size Analysis . . . . . . . . . . . . . . . . . . 45

4.1.4 Thermal Degradation Analysis (TGA) of wood fibers . . . . . . . . 47 
4.2 Characterization of wood plastic composites . . . . . . . . . . . . 49

4.2.1 Thermal degradation analysis of WPC . . . . . . . . . . . 49

4.2.2 Mechanical properties test . . . . . . . . . . . . 51

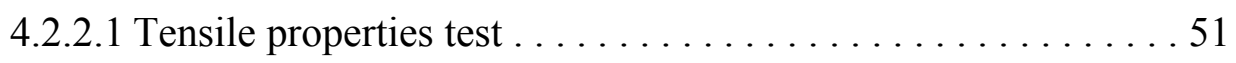

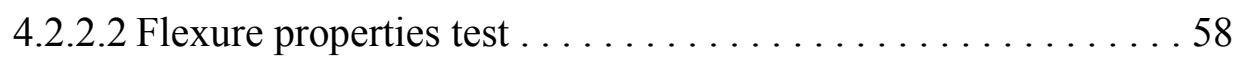

4.2.2.3 Impact properties test . . . . . . . . . . . . . 63

4.2.2.4 Summary of mechanical properties tests . . . . . . . 65

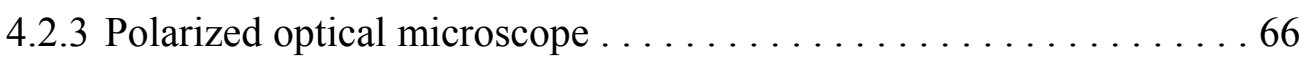

4.2 .4 Water absorption behavior . . . . . . . . . . . . . 69

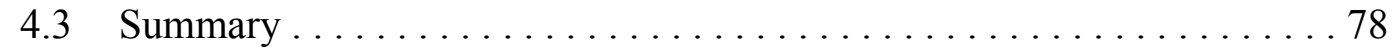

5 RECOMMENDATION FOR FUTURE WORK ............. 81

6 REFERENCES ............................ 83

APPEXDIX I ECONOMIC ANALYSIS ...................................... 87 


\section{INTRODUCTION}

1.1. The importance of WPC and its application

Wood plastic composites (commonly abbreviated as WPCs) are composites made by combining plastic and wood wastes. Their most widespread use is in outdoor decking, but they are also used for indoor furniture, window and door frames, molding and trim, park benches, railings and fences, and landscaping timbers. As a building material, WPC is still a very new material relative to the long history of natural lumbers. For WPC, a major advantage over wood is the ability to be molded to meet almost any desired shape. With up to $70 \%$ wood content, WPCs behave more like wood than plastic and can be shaped using conventional woodworking tools. At the same time, WPCs are moisture- and rot-resistant, although they are not as rigid as wood and may slightly deform in extremely hot weather.

According to a report by Jennifer Markarian [1], the global wood and fiber composites (WPC) market was 1.7 billion lbs in 2003 . Nearly $85 \%$ of the WPC market is in North America. Due to its aesthetic and low-maintenance advantages, WPC use is growing rapidly in wood-replacement applications. In North America, the WPC market is projected to have double digit growth till 2010.

Among various applications of WPCs, decking has nearly $65 \%$ share of the 
WPC market. Beside this, the WPC producers of North America are seeking to translate WPC into other building products, such as fencing, trim board, windows, and WPC sheet for replacing plywood. Also, roofing and siding are considered as possible applications of WPC. Figure 1-1 shows some applications of WPC.

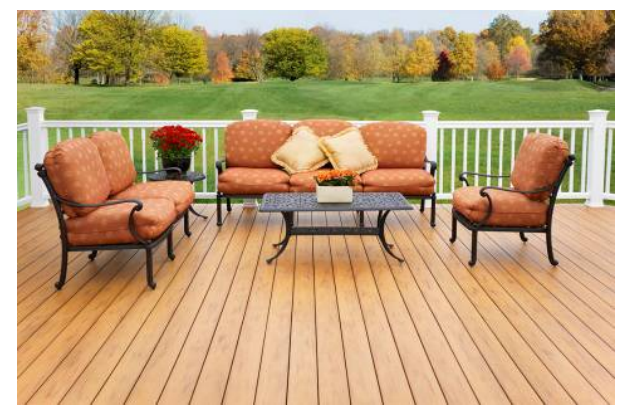

(a)

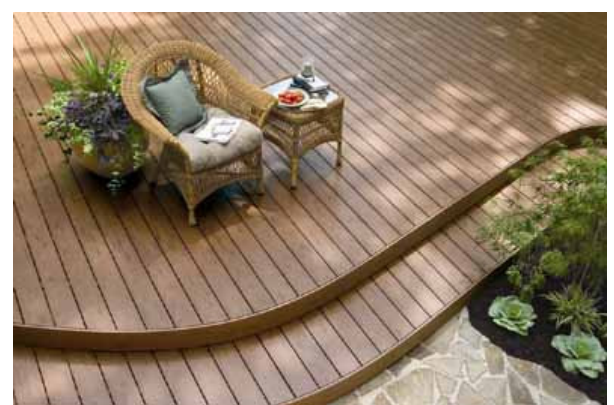

(b)

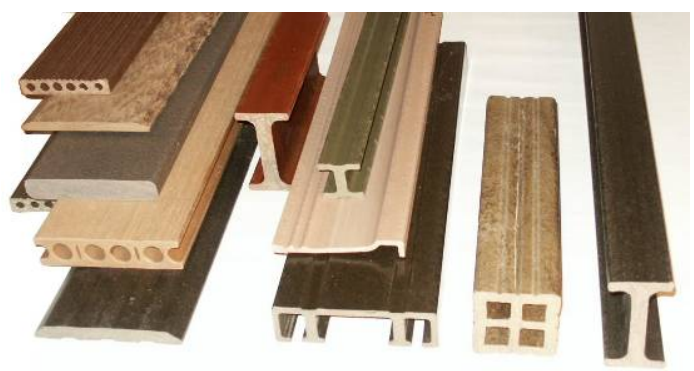

(c)

Figure 1-1 (a)WPC floor 1 (b)WPC floor 2 (c)WPC construction materials

Compared to treated wood and plastic products, WPCs have two major benefits that attract industry to investment: cost and environmental regulation. The cost of wood fiber is usually just one-tenth (maybe lower) of the plastic. For instance, for the same product, the cost of WPC (50\% wood fiber content) is just $55 \%$ of plastic. As the proportion of wood fiber increases, the cost continues going down. Another reason is environmental regulation. Recently, eco-awareness has become a major issue all over the world. People and governments are asking industry to produce a 
green-product. In addition, the recyclable wood fiber is a perfect fit for the green requirement. Due to these reasons, the increase of the WPC market is predictable.

\subsection{Limitations of WPCs}

Natural fibers are, in general, suitable to reinforce plastics due to their relatively high strength and stiffness and low density. But some handicaps still need to be overcome to produce good quality WPCs. First of all, the interface between the hydrophobic plastic and the hydrophilic wood is typically weak and fails to transfer stress. Therefore, the major barrier to the durability of WPCs is the lack of compatibility between plastics and wood. There has been much research to modify plastic or wood fibers to make them become compatible with each other, but the widely acceptable solution is still the use of coupling agents. In the case of WPCs, a coupling agent has two kinds of functional groups: one that will react with the hydroxyl groups on the wood fiber surface, and the other which is compatible with the polymer. Thus, the plastic and wood fiber can adhere to each other with the help of the coupling agent.

If strength is directly related to the load at fracture of a board, modulus is directly related to the deflection of the board under a certain load. Unlike the strength of composite boards, modulus of plastic-based composite boards can place limits on their installation. There are two main situations which cause the WPC 
boards not to pass the building code requirements: deck boards and stair tread at a certain span. The deflection is determined by the formula (1) (deck boards) and formula (2) (stair treads) [2].

$$
\begin{aligned}
& \mathrm{D}=\frac{5 \mathrm{WbL}^{4}}{384 \times 144 \times \mathrm{EI}} \ldots \ldots . \\
& \mathrm{D}=\frac{\mathrm{PL}^{3}}{48 \times \mathrm{EI}} \ldots \ldots \ldots \ldots \ldots
\end{aligned}
$$

$\mathrm{W}=$ uniformly distributed load

$\mathrm{D}=$ deflection (should not exceed $1 / 360$ span)

$\mathrm{b}=$ board width

$\mathrm{L}=$ support span, in inches

$\mathrm{E}=$ flexural modulus

$\mathrm{I}=$ moment of inertia

$\mathrm{P}=$ center point load

To pass the building code requirements of deflection, deflection D should not exceed $1 / 360$ span; if the span is 12 inches, D should be less than $12 / 360(0.033)$. Therefore, WPC with higher modulus allows for installation with longer span distance, or at a lower installation cost. Thus, increasing modulus of WPC is the main objective of this work.

In addition to the above, water absorption in finished WPC parts has also been a problem for WPCs. As mentioned before, most applications of WPCs are in building products. These products are used outdoors and often experience several freeze-thaw cycles which trend to weaken the composites. Therefore, controlling the water absorption of WPCs becomes very important for WPC applications. Unfortunately, 
the three major components of wood fiber (cellulose, lignin and hemicellulose) all have hydroxyl groups and other oxygen-containing groups in their structures. These structures will attract moisture through hydrogen bonding. Thus, surface modification seems like one solution of the water absorption in WPCs.

\subsection{The surface modification of wood fiber}

Wood fiber is primarily composed of cellulose, lignin, hemicellulose, and other minor constituents. Among these different materials, cellulose has the highest strength and stiffness. It seems, therefore, that pure cellulose has the potential to become a good reinforcement material for WPC. But for commercial purpose, the cost of pure cellulose is much higher than that of natural wood fiber. Therefore, using pure cellulose to be the reinforcement material has little commercial value in the WPC market, but increasing the ratio of cellulose in wood fiber still has its potential in WPC products.

To increase the proportion of cellulose in wood fiber, the best way is removing some of the non-cellulosic content from wood fiber. There are three major ways to remove non-cellulosic components: acid treatment, alkali treatment, and ultrasonic treatment.

Due to its high selectivity, acid treatment is usually performed for hemicellulose extraction. As far as alkali treatment is concerned, it has been found not only 
effective to eliminate hemicellulose but also be able to remove the lignin from the wood fibers. Thus, alkali treatment has become the most common way to eliminate the non-cellulosic part from wood fibers. Also, ultrasonic treatment is usually performed in conjunction with the other two kinds of chemical treatments, since it has been found that ultrasound has the ability to separate lignin and hemicellulose from wood fiber even without any chemicals being used. Even with added chemicals, ultrasound can assist in reducing the amount of chemical usage and shorten the reaction time. Thus, ultrasound treatment is a relatively environmentally friendly process, and its has great potential in commercial usage.

\subsection{Research objectives}

As discussed previously, due to factors of cost, eco-awareness, and esthetic requirement, WPC has an increasing market share. For satisfying the needs of the WPC market, a stronger, stiffer and cheaper WPC must be developed. Due to this reason, the present work is devoted to achieving the goals listed below:

- Increasing the modulus of WPC

- Reducing the moisture absorption of WPC

By means of choosing a proper coupling agent and applying surface modification, it hopes to solve the problems mentioned above, and then develop a better procedure to form WPC products. 


\section{LITERATURE REVIEW}

2.1 Wood fiber and its chemical composition

Dry wood is primarily composed of cellulose, lignin, hemicellulose, and minor amounts of other constituents. These include tannins and polyphenolics, coloring matter, essential oils, fats, resin, wax, and simple metabolic intermediates [3]. The actual composition of wood fibers varies between and within species, and, in general, only cellulose, lignin and hemicellulose are considered as the basic components of wood fiber.

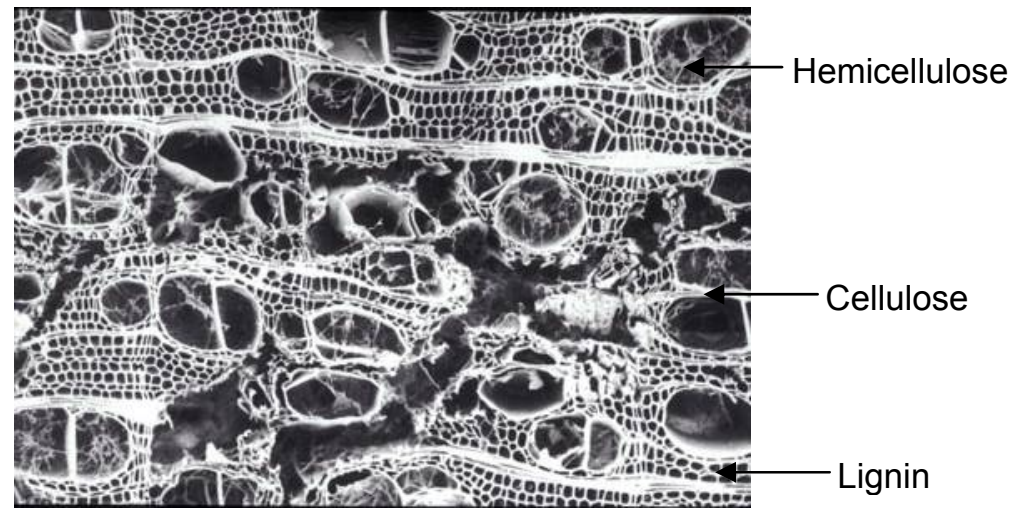

Figure 2-1 The cellulose, lignin and hemicellulose in wood fiber [3]

The major component of wood fiber is cellulose which constitutes approximately $50 \%$ of wood substance by weight. It is a high-molecular-weight linear polymer consisting of chains of 1 to more than $4 \beta$-linked glucose monomers [3]. Cellulose is the essential component of all plant-fibers. In 1838, Payen suggested that the cell wall of large numbers of plants consist of the same substance, to which he gave the name: cellulose [4]. Figure 2-2 shows the chemical structure of cellulose. The hydroxyl 
groups on the cellulose surface make wood fiber hydrophilic.

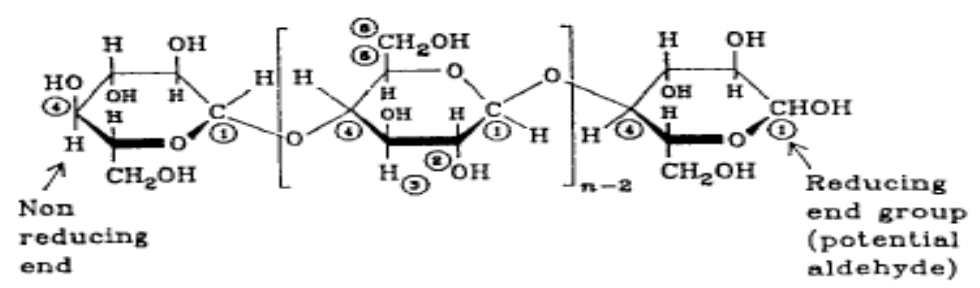

Figure 2-2 The molecular structure of cellulose [4]

The portion of lignin is $16 \%$ to $25 \%$ of the wood substance in hardwoods and $23 \%$ to $33 \%$ in softwoods [3]. Due to the fact that it binds individual cells together, lignin is usually called the cementing agent of wood substance. Lignin is a complex hydrocarbon polymer with both aliphatic and aromatic constituents [4]. Figure 2-3 shows the molecular structure of lignin. On a commercial scale, lignin is necessary to be removed for producing high-grade paper products.

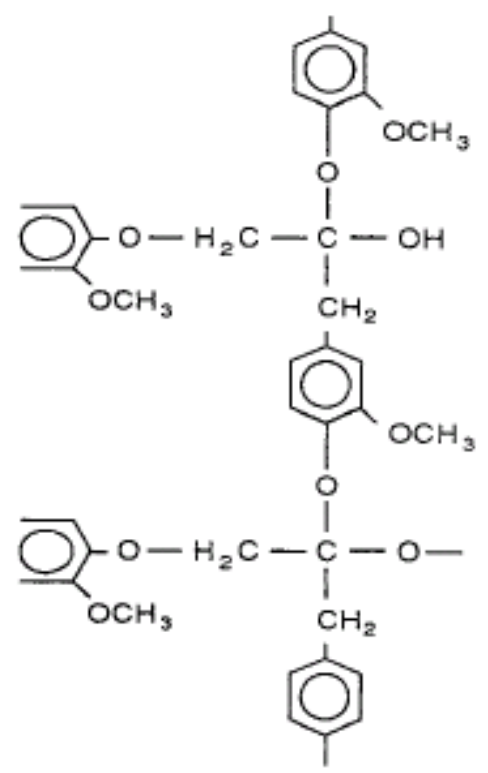

Figure 2-3 The molecular structure of lignin [4]

Hemicellulose are not a form of cellulose at all, and they differ from cellulose in three important aspects: [4] 
Hemicellulose contains several different sugar units, but cellulose contains only 1, 4-b-d-glucipyranose units.

Hemicellulose exhibits a considerable degree of chain branching, whereas cellulose is strictly a linear polymer.

The degree of polymerization of native cellulose is ten to one hundred times higher than that of hemicellulose.

Unlike cellulose, the constituents of hemicellulose differ from plant to plant; Figure 2-4 shows the molecular structure of hemicellulose.

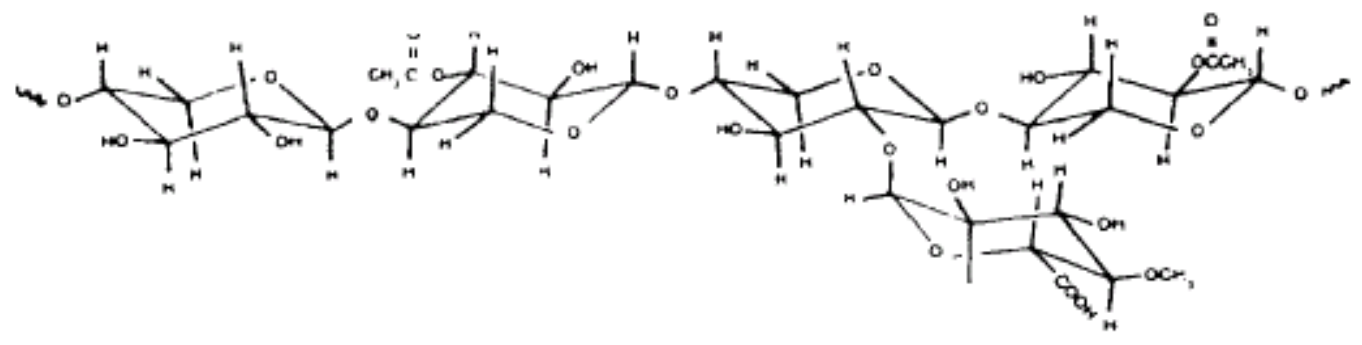

Figure 2-4 The molecular structure of hemicellulose [4]

Unlike the major components of wood, the minor materials are not structural components. Minor materials include both organic and inorganic materials. The organic extractives contribute to such wood properties as color, odor, taste, decay resistance, density and flammability. Extractive components may constitute roughly $5 \%$ to $30 \%$ of the wood substance, depending on species, growth conditions and so on.

The inorganic component of minor materials generally constitutes $0.2 \%$ to 1.0 $\%$ of the wood substance. Calcium, potassium, and magnesium are the more 
abundant elemental constituents. Trace amounts $(<100 \mathrm{ppm})$ of phosphorus, sodium, iron, silicon, manganese, copper, zinc and perhaps a few other elements are usually present. [4]

The moduli of cellulose-based materials are very different from one to another. For instance, the elastic modulus of bulk fibers such as wood is about $10 \mathrm{GPa}$. By chemical pulping processes, cellulose fiber can be separated from wood substance. Its modulus goes up to about $40 \mathrm{GPa}$. Such fibers can be further subdivided into micro fibrils by hydrolysis followed by mechanical disintegration. The modulus of micro fibrils could reach $70 \mathrm{GPa}$. According to theoretical calculations, the elastic modulus of cellulose chains can be as high as $250 \mathrm{GPa}$ [5]. Since the modulus of wood fiber $(40 \mathrm{GPa})$ is much higher than that of most plastics, increasing the modulus of plastic by compounding wood fiber with it seems an attractive prospect.

Natural fiber reinforced plastic is usually compared with glass fiber reinforced plastic. One disadvantage of natural fiber reinforced plastic is that the price of natural fiber is variable. Also the cost of natural fiber preparation and pretreatment is higher. But natural fibers offer some advantages over glass-fibers: [4]. These are:

$>$ Natural fibers are a renewable raw material and their availability is more or less unlimited.

$>$ The abrasive nature of natural fibers is much lower compared to that of 
glass-fibers, which leads to advantages with regard to technical, material recycling or processing of composite materials in general.

Natural fiber reinforced plastics have biodegradable polymers as matrix materials and are the most environmentally, friendly materials which can be composted at the end of their life cycle.

\subsection{Coupling agents}

A coupling agent is used to compatiblize wood fiber and the polymer matrix, and it is usually a copolymer, or possesses methanol groups, isocyanates, triazine, or organosilanes. The main purpose of adding a coupling agent is to enhance mechanical properties, primarily strength, of the WPC. The effect of the coupling agent is very different among various polymer matrixes.

Table 2-1 shows the influence of coupling agents on the mechanical properties of natural fiber reinforced plastics.

\begin{tabular}{|c|c|c|c|c|c|}
\hline \multirow[t]{2}{*}{ Fibre/matrix } & \multirow[t]{2}{*}{ Coupling agent } & \multicolumn{4}{|c|}{ Increase in properties (\%) } \\
\hline & & Tensile strength & Young's modulus & Compression strength & Impact energy \\
\hline \multicolumn{6}{|l|}{ Thermosets } \\
\hline Jute/EP & Acrylic acid & Constant & - & - & 100 \\
\hline Jute/UP and EP & Polyesteramid Polyol & 10 & 10 & - & - \\
\hline Sisal/EP & Silane & 25 & - & 30 & - \\
\hline $\begin{array}{l}\text { Cellulose/UP } \\
\text { Thermoplastics }\end{array}$ & Dimethanolmelamine & Constant & - & - & 100 \\
\hline Cellulose/PS & Isocyanate & 30 & Constant & - & 50 \\
\hline \multirow[t]{2}{*}{ Cellulose/PP } & Stearinic acid & 30 & 15 & - & 50 \\
\hline & $\begin{array}{l}\text { Maleinanhydride- } \\
\text { PP-copolymer }\end{array}$ & 100 & Constant & - & - \\
\hline \multirow[t]{2}{*}{ Flax/PP } & Silane & Constant & 50 & - & - \\
\hline & Maleinanhydrid & 50 & 100 & - & - \\
\hline
\end{tabular}

Table 2-1 Influence of coupling agents on the mechanical properties of natural fiber reinforced plastics [6] 


\subsubsection{Graft copolymerization}

An effective way of chemical coupling of natural fibers to the polymer matrix is graft copolymerization; this reaction is initiated by free radicals of the cellulose molecule. For instance, the treatment of celluloses with hot polypropylene-maleic anhydride copolymer provides covalent bonds across the interface [7]. The mechanism of reaction can be divided into two steps: [4]

Activation of the copolymer by heating $\left(170^{\circ} \mathrm{C}\right)$<smiles>COC(=O)C(C=O)C(I)C(I)C=O</smiles>

$>$ Esterification of cellulose

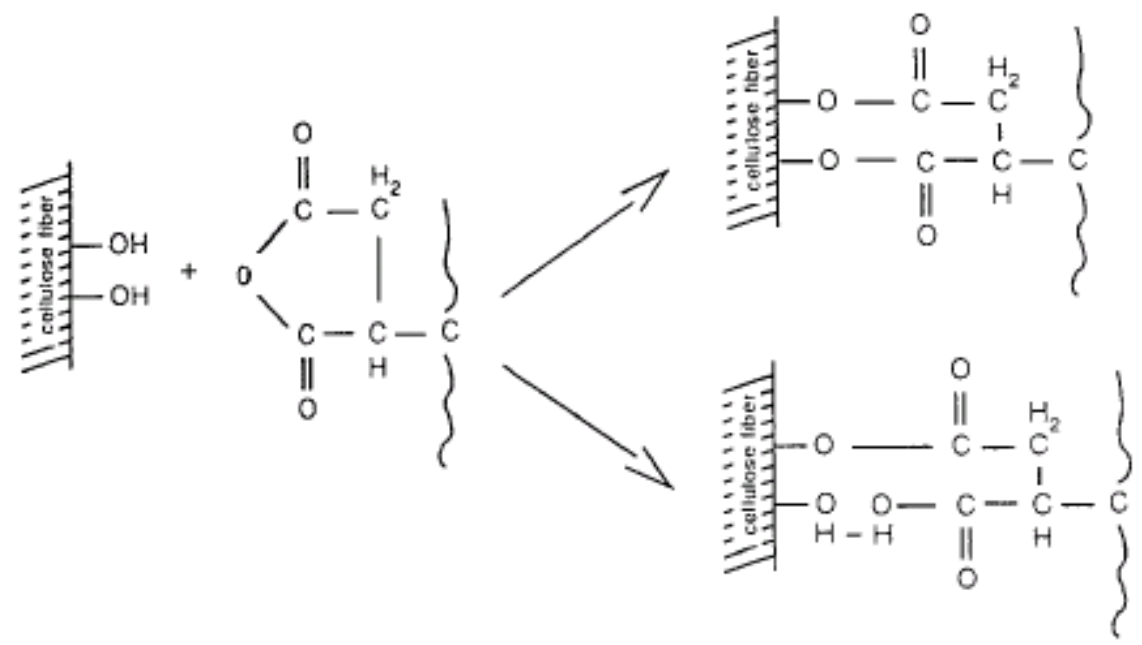

After the treatment the surface energy of the fiber is much closer to the matrix.

Thus, a higher interfacial adhesion is obtained. However, the graft copolymerization method is effective, but complex. 


\subsubsection{Compounds with methanol groups}

Cellulose can form stable, covalent bonds with chemical compounds which contain methanol groups $\left(-\mathrm{CH}_{2} \mathrm{OH}\right)$. Methanol containing compounds are well known and widely used in textile chemistry. Hydrogen bonds between these compounds and cellulose can be formed in this reaction as well.

The treatment of cellulose with methanol-melamine compounds, before forming cellulose/unsaturated-polyester composites, decreases the moisture pick up and increases the strength of the reinforced plastic [8].

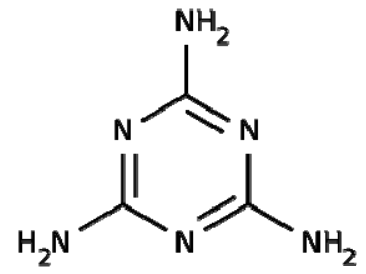

Figure 2-5 The structure of melamine, commonly used as coupling agent [8]

\subsubsection{Organosilanes}

Organosilanes are the most common coupling agents for glass-fiber reinforced polymers. Most of the silane coupling agents can be represented by $\mathrm{R}-\left(\mathrm{CH}_{2}\right)_{\mathrm{n}}-\mathrm{Si}\left(\mathrm{OR}^{\prime}\right)_{3}$, where $\mathrm{R}$ is the functional organic group and the $\mathrm{OR}$ ' is the hydrolysable alkoxy group (the alkoxyl group is an alkyl group linked to oxygen, such as $\mathrm{R}-\mathrm{O}$ ). The functional group $\mathrm{R}$ in the coupling agent is compatible with the polymer. Figure 2-6 shows the mechanism of how the alkoxy groups react with 
hydroxyl groups.
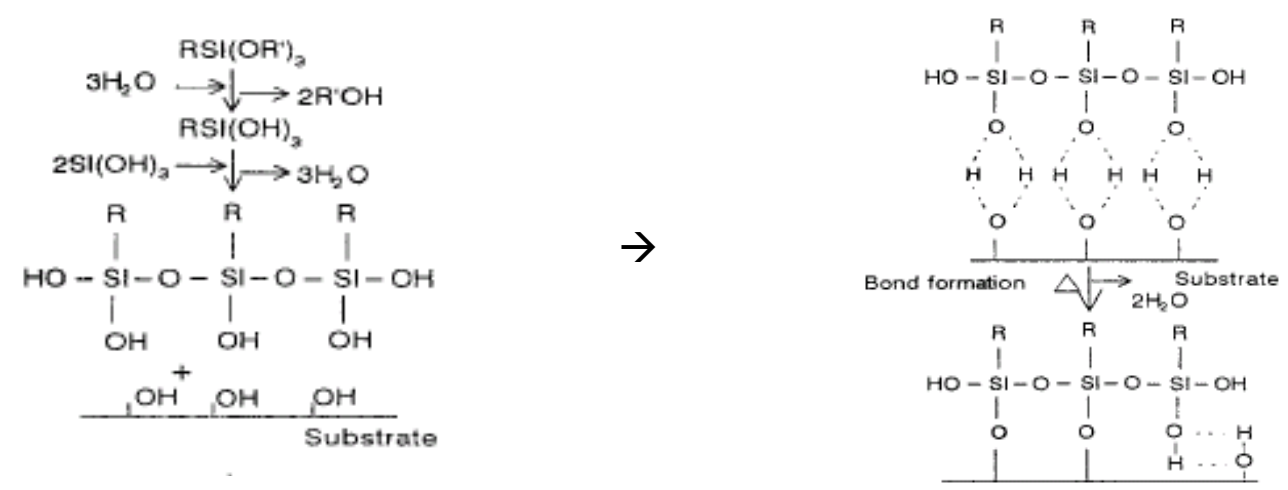

Figure 2-6 the mechanism of alkoxy groups react with hydroxyl groups [4]

\subsubsection{Isocyanates}

WPCs which use polyvinyl chloride (PVC) or polystyrene (PS) as the polymer matrix could enhance the mechanical properties by an isocyanate treatment of the cellulose fibers or of the polymer matrix [9]. Polymethylene-polyphenyl-isocyanate (PMPPIC) is chemically linked to the cellulose through strong covalent bonds as given below:

\section{$\mathrm{R}-\mathrm{N}=\mathrm{C}=\mathrm{O}+\mathrm{H}-\mathrm{O}-\mathrm{Cellulose}-\mathrm{R}-\mathrm{HN}-\mathrm{C}-\mathrm{O}-\mathrm{Cellulose}$}

The adhesion between PMPPIC and PS is due to them both containing benzene rings.

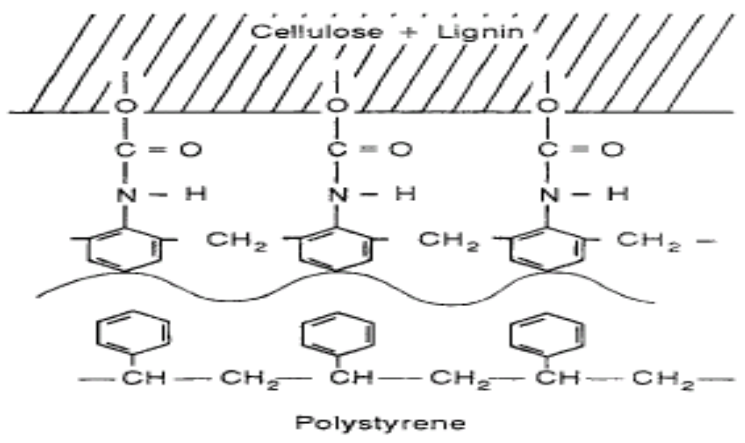


Figure 2-7 The mechanism of PMPPIC with polystyrene [4]

Comparing both methods, treatment with silane or isocyanates, it is obvious that the treatment by isocyanates is much better than by silane. The same result was obtained by Maldas et al. [9], when PMPPIC was used for the treatment of the polymer matrix or wood fibers.

\subsubsection{Triazine coupling agents}

Triazine derivatives can form covalent bonds with cellulose fibers. Figure 2-8 shows how the triazine is linked to cellulose fibers.

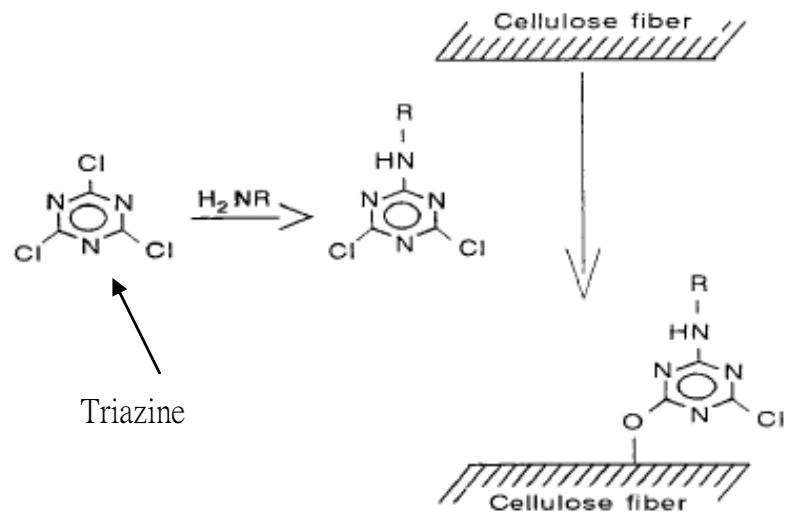

Figure 2-8 The link between triazine derivatives and cellulose fiber [4]

\subsubsection{Summary}

Among the various coupling agents, maleic anhydride grafted polymer is the most widely used coupling agent in the WPC industry today. This is because of its low cost and ready availability and its ability to enhance the strength of WPC. In PP-based WPC, using a coupling agent such as PP-g-MA not only increases the 
adhesion between interfaces, it also reduces the moisture absorption. The reduction of moisture absorption is due to the following reasons:

$>$ The coupling agent reduces the number of hydroxyl groups on the fiber surface which are available for moisture pick-up.

$>$ The coupling agent forms a cross-linked network by covalent bonding between the matrix and fibers. This restrains the swelling of the fiber. 


\subsection{The modification of wood fiber}

\subsubsection{Alkali treatment of wood fibers}

As mention earlier, cellulose constitutes the main structural component of wood fibers, although the non-cellulosic components such as hemicellulose and lignin also show their importance in the characteristic properties of the wood fibers. Hemicellulose has first been found to be sensitive to sodium hydroxide [3]. Later studies about the alkali treatment of natural fibers such as flax and jute fibers reported about the tensile characteristics of the fiber as affected by the removal of lignin and hemicellulose. After removing the hemicellulose, the region between fibrils seems to become less rigid and less dense. It makes the fiber become more available to rearranging itself along the direction of tensile deformation. Such a rearrangement among the fibers will lead to better load sharing and higher strength of WPC. As lignin is removed gradually, the middle lamella joining the ultimate cells is expected to be more plastic, as well as homogeneous, due to the gradual elimination of microvoids, whereas the ultimate cells themselves are only slightly affected, the modulus of wood fibers should increase [10].

On the other hand, softening the matrix will reduce the ability to transfer the stress between the fibers and matrix. Thus, the strength of WPC will decrease as the matrix softens. But generally speaking, the overall strength still increases after 
removing hemicellulose and lignin.

Further, a fair amount of randomness is introduced in the orientation of the crystallites due to the removal of non-cellulose matter by alkali treatment [11]. For example, the moduli of natural fibers are expected to increase with an increasing degree of molecular orientation. Comparing the moduli of flax and cotton, the well oriented fibers (flax) have a much higher Young's modulus than the medium oriented fiber (cotton). Besides the modification of orientation and the intensification of weak points, some other important factors that relate to the mechanical properties might be the crystallite length and degree of crystallinity. One easy way to increase the degree of crystallinity is removing the fractions of low polymerized celluloses.

Some authors [11] reported changes in crystallinity by alkaline treatment of coir and flax fibers. Due to removal of the cementing materials, the percentage of crystallinity of alkali treated fibers increased, which will lead to a better packing of cellulose chains.

In the last two decades, many organic solvents have been applied for using in organic-solvent delignification. But so far, only aqueous methanol and ethanol have shown the potential for practical application in the paper industry [12]. In solvent media containing water, the lignin solubility is valid only in a limited range of concentrations. For instance, to reach good lignin solubility, the volume fraction of 
methanol must exceed 0.6. At any solvent composition, the solubility will increase as the temperature is raised. The advantages of organic-solvent pulping include low investment costs, low contamination, and recovery of byproducts such as lignin as a solid material and hemicellulose as syrup. But due to the awareness of environmental consciousness in these days, organic-solvent process is going to be replaced by aqueous processes.

As early as 1935, Sarkar [13] treated jute fibers with a cold and dilute sodium hydroxide solution at a concentration of $1 \%$ and $8 \%$ for 48 hours, and then he found that the tensile strength of the treated fibers increased by $130 \%$. Samal et al. [16] chemically modified the jute fibers by alkali treatment, cross-linked them with formaldehyde, p-phenylenediamine and phthalic anhydride, and combined crosslink-cyanoethylation reactions to transform jute into a strong reinforcing candidate material [14]. After treating the jute fiber with $2 \% \mathrm{NaOH}$ solution for 1 hour at $35{ }^{\circ} \mathrm{C}$, a $13 \%$ and $8 \%$ increase in tensile strength and modulus respectively was observed. On the contrary, Ray [14] showed a steady decrease in the strength of the fiber with an increase in the alkali concentration when the fibers were treated with a $1-18 \% \mathrm{NaOH}$ solution for $2 \mathrm{hr}$ at room temperature. Fibers had only $44 \%$ of the original strength after treatment with $17.5 \% \mathrm{NaOH}$ solution. Coir fibers, when treated with $5 \%$ alkali solution for 72-96 hr showed improvement in tensile strength 
around $12 \%$ and in modulus of $40 \%$ [15]. Samal et al. [16] treated coir fiber with $\mathrm{NaOH}$ solution with a concentration of 2,8 , and $10 \%$, and this resulted in an increase in tensile strength by 24,19 , and $17 \%$. Again, a decrease in strength with increased concentration was observed.

Conflicting opinions have emerged regarding the effects of alkali treatment of coir and jute fibers. To clarify the effect of alkali treatment, Ray and Sarkar [14] investigated the changes occurring in jute fibers after a $5 \% \mathrm{NaOH}$ solution treatment for $0,2,4,6$, and $8 \mathrm{hr}$.

First of all, Ray and Sarkar [14] studied the weight loss of jute fiber during the alkali treatment. With respect to the maximum weight loss of $10.45 \%$, they found that there was a $9.63 \%$ loss in weight within $2 \mathrm{hr}$ of treatment (Figure 2-9). Chemical analysis (Table 2-1) showed that the weight losses are due to the dissolution of hemicellulose. The hemicellulose content of the jute fibers was reduced from $22 \%$ to $12.90 \%$ with the treatment time. But $\alpha$-Cellulose and lignin remained almost unchanged by the alkali treatment.

Table 2-1 Chemical Compositions of Raw Jute and Alkali-Treated Jute Fibers [14]

\begin{tabular}{ccccc}
\hline Sample Type & Weight Loss $(\mathrm{g})$ & Cellulose $(\mathrm{g})$ & $\begin{array}{c}\text { Hemicellulose } \\
(\mathrm{g})\end{array}$ & Lignin $(\mathrm{g})$ \\
\hline Untreated & 0.00 & 63.00 & 22.00 & 13.70 \\
2h alkali-treated & 9.63 & 62.70 & 12.90 & 13.48 \\
4h alkali-treated & 10.06 & 62.60 & 12.65 & 13.40 \\
6h alkali-treated & 10.43 & 62.52 & 12.40 & 13.35 \\
8h alkali-treated & 10.45 & 62.50 & 12.40 & 13.35 \\
\hline
\end{tabular}




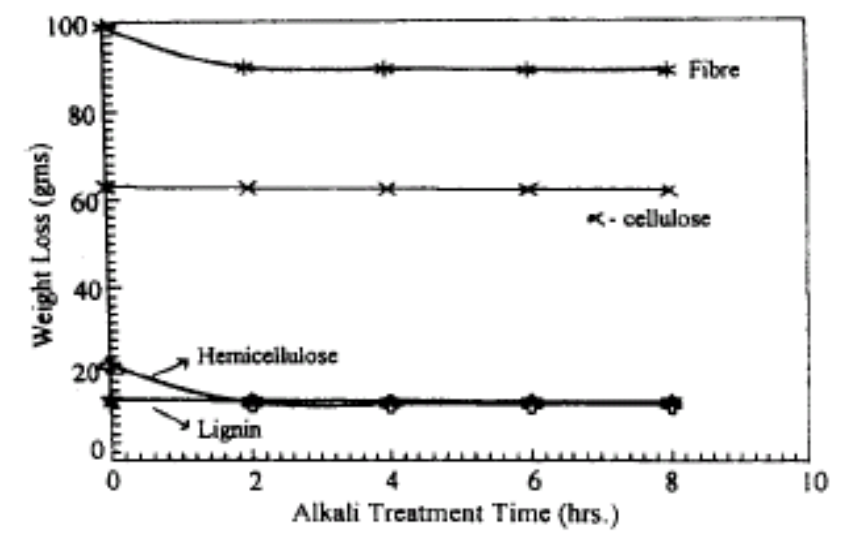

Figure 2-9 Loss of weight of the constituents during alkali treatment of jute fibers [14].

Further, from the result of linear density test (Figure 2-10), they found that the linear density showed no change during the $2 \mathrm{hr}$ treatment. After this, the linear density dropped about $56 \%$ (from 33.0 to 14.5 ) after $6 \mathrm{hr}$ of treatment. Splitting of fibers into finer filaments and progressive destruction of the mesh network occurred simultaneously during 2-6 hr treatment. The cellulosic component dissolved in the alkali solution creating voids in the fiber structure and swelling was observed. Then the fibers became well separated. The enlargement in volume with loss in weight led to a sharp decrease of the linear density.

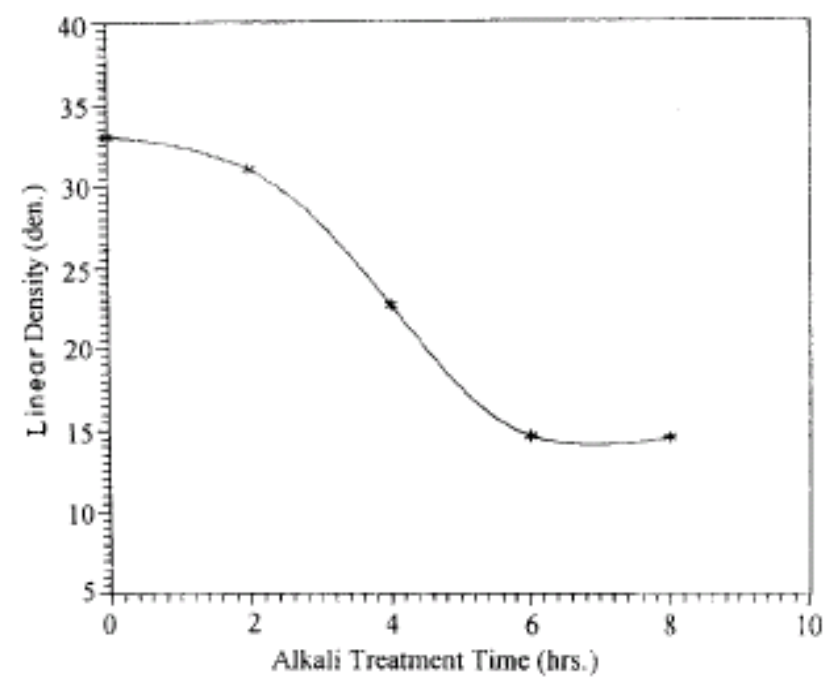

Figure 2-10 Change of linear density with alkali treatment times of jute fibers [14]. 
The effect of alkali treatment on the mechanical properties of the fibers is shown in Figure 2-11. The tensile strength of the fibers first showed a decrease after $2 \mathrm{hr}$ treatment, but an overall $45 \%$ improvement was observed after $8 \mathrm{hr}$ treatment. So did the fiber modulus, it had an increase of $79 \%$ (from 309.1 to 553.5 ) after $8 \mathrm{hr}$ treatment.

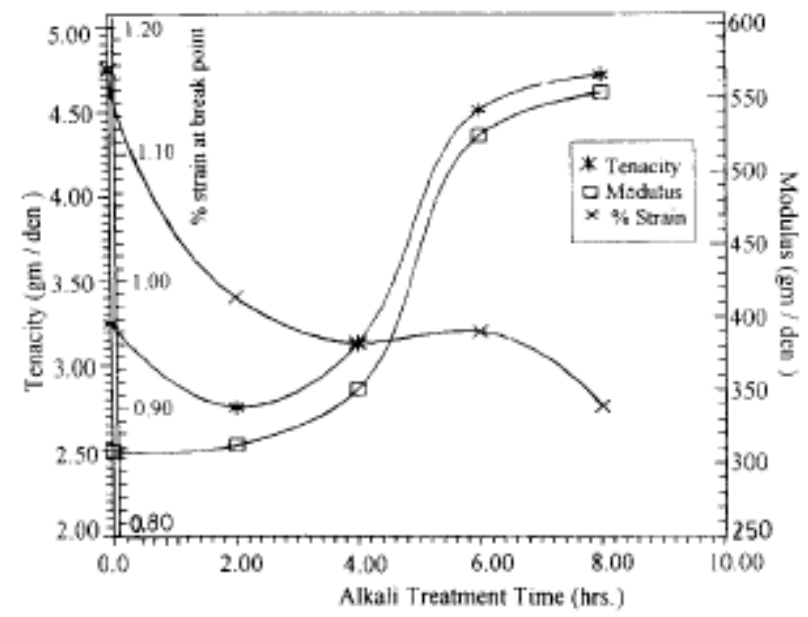

Figure 2-11 Effect of alkali treatment on the tensile strength, modulus, and percent breaking strain of jute fibers with varying treatment times [14].

According to the work of Ray and Sarkar [14], the dissolution of hemicellulose dominated till $4 \mathrm{hr}$ of treatment, followed by the development of crystallinity in cellulose between 4 and $8 \mathrm{hr}$ of treatment. The heavy loss of hemicellulose contributed to the closer packing of the cellulose chains. It gave the fibrils freedom to reorient along the direction of the tensile force. Beyond $4 \mathrm{hr}$ of treatment, crystallinity in cellulose was improved with a further closer packing of the cellulose chains and molecular reorientation happened. 
The reduction of linear density of the fiber could also contribute to the improvement in the mechanical properties. The large loss of hemicellulose made the fibers to separate from one another. The loss of cementing materials contributed to better separation of the individual cells, resulting in thinner fibers.

\subsubsection{Ultrasound treatment of wood fiber}

Ultrasound-assisted extraction is well established in the processing of plant raw materials, particularly for extraction of low molecular substances and depolymerizing macromolecules. Recently, ultrasound has been reported to improve pectin technology from apple pressings [17] and pharmaceutically active compounds from Salvia officinalis [18], and increase of the yield of xylans from corn hulls [19] and corn cobs [20] without significant changes in their structural and molecular properties [21.22].

Cavitation is induced in an aqueous suspension when the liquid is treated with ultrasound [23]. Then water decomposes into free radicals as shown below:

$$
\mathrm{H}_{2} \mathrm{O} \rightarrow \bullet \mathrm{OH}+\bullet \mathrm{H}
$$

Seino et al. [24] used electron spin resonance (ESR) methods to trap and characterize unstable radicals which were generated by ultrasound at $45 \mathrm{kHz}$ and $100 \mathrm{~W}$ in a lignin/Dimethylsulfoxide solution. They concluded that some specific linkages in lignin are homogeneously cleaved by the ultrasonic irradiation. 
Tan et al. [25], using a very high power ultrasound of $1200 \mathrm{~W}$ at $19 \mathrm{kHz}$, concluded that under the ultrasonic irradiation there is a formation of carbonyl groups $(\mathrm{C}=\mathrm{O})$ on the lignin surface. Pranovich et al. [26] studied the sonochemistry of lignin compounds under $20 \mathrm{kHz}$ frequency, and reported that the hydroxyl radical attacked the aromatic ring and then formed various products from lignin.

Sun and coworkers [21. 22] have applied ultrasound in the extraction of non-cellulose component (such as lignin and hemicellulose) from wheat straw to reach higher extraction yields. In this research, after an ultrasound assisted alkali treatment, nearly $50 \%$ of lignin and $70 \%$ of hemicellulose were extracted from wheat straw. Laine and Goring [27] using the pulp fiber as the matrix studied the influence on the physical and chemical properties after ultrasound irradiation. They reported the oxidation of carbohydrate hydroxyls on the fiber surface increased the carbonyl group content of the fiber, and the porosity of fiber wall increased after ultrasound treatment. The treatment of cellulosic fibers with ultrasound has also been used in various areas such as pulping, debarking, defibration, bleaching, stock preparation and grafting, beating, impregnation and penetration.

Although the high-frequency ultrasonic operation is quieter than low-frequency ultrasound, and high-frequency $(650 \mathrm{kHz})$ ultrasound is effective on oxidation reactions, but so far, only the low frequency $(20 \mathrm{kHz})$ ultrasound has been applied to 
wood fibers. The main reason is that the lower frequency ultrasound produces more violent cavitation, and this cavitation helps to split fiber into fibrils and destroy the links between cellulose and the non-cellulosic components. Further, compared to high-frequency ultrasound, low-frequency ultrasound has a better ability to penetrate. This makes low-frequency ultrasound break the fiber from the center and produce homogeneous fibrils.

Sun and coworkers [21. 22] compared the classic and ultrasound-assisted extraction process of wheat straw. In their conclusion, they indicated that the ultrasound-assisted procedures are superior to the traditional procedures. For the extraction of lignin, with $0.5 \mathrm{M} \mathrm{KOH}$ solution and 35 min sonication time, the ultrasonic irradiation promoted the extraction of lignin from wheat straw, and the yield and purity increased with sonication time (Table 2-2). The lignin fraction obtained by the ultrasound-assisted alkali extraction shows a higher molecular weight (Table 2-3). They also indicated that under ultrasonic alkali treatment there is no significant change in lignin composition and its structure. For the hemicellulose, under $0.5 \mathrm{M} \mathrm{NaOH}$ in $60 \%$ methanol at $60{ }^{\circ} \mathrm{C}$ for $2.5 \mathrm{~h}$, with a sonication time from 5-35 min resulted in an increasing yield from 2.9 to $9.2 \%$ (Table 2-4). And just as in the case of lignin and hemicellulose don't have significant change after ultrasound-assisted extraction. 
Table 2-2 The yield of lignin fraction (\% dry matter) from wheat straw [21]

\begin{tabular}{|c|c|c|c|c|c|c|c|c|}
\hline \multirow[t]{2}{*}{ Lignin fractions } & \multicolumn{8}{|c|}{ Ultrasonic time (min) } \\
\hline & 0 & 5 & 10 & 15 & 20 & 25 & 30 & 35 \\
\hline Total solubilized lignins & 7.5 & 7.5 & 7.5 & 7.6 & 7.6 & 7.8 & 8.0 & 8.4 \\
\hline Acid-insoluble lignins ${ }^{2}$ & 4.9 & 5.0 & 5.1 & 5.1 & 5.3 & 5.2 & 5.8 & 6.1 \\
\hline Acid-soluble lignins ${ }^{b}$ & 1.0 & 0.9 & 1.0 & 1.1 & 0.9 & 1.2 & 1.1 & 1.2 \\
\hline $\begin{array}{l}\text { Lignin associated in isolated } \\
\text { hemicelluloses }\end{array}$ & 1.6 & 1.4 & 1.4 & 1.4 & 1.4 & 1.4 & 1.1 & 1.1 \\
\hline
\end{tabular}

Table 2-3 The molecular weight of extracted lignin [21]

\begin{tabular}{lllllllll}
\hline & \multicolumn{1}{c}{ Ultrasonic time (min) } \\
\cline { 2 - 8 } & 0 & 5 & 10 & 15 & 20 & 25 & 30 & 35 \\
\hline $\bar{M}_{\mathrm{w}}$ & 2890 & 3010 & 3130 & 3470 & 3570 & 3300 & 3070 & 2760 \\
$\bar{M}_{\mathrm{n}}$ & 1490 & 1540 & 1550 & 1620 & 1620 & 1340 & 1150 & 1040 \\
$\bar{M}_{\mathrm{w}} / \bar{M}_{\mathrm{n}}$ & 1.94 & 1.95 & 2.02 & 2.14 & 2.20 & 2.46 & 2.66 & 2.65 \\
\hline
\end{tabular}

Table 2-4 The yield of hemicellulose from wheat straw [21]

\begin{tabular}{lllllllll}
\hline \multicolumn{7}{l}{ Ultrasonic time (min) } & \multicolumn{1}{l}{} \\
\cline { 2 - 8 } & 0 & 5 & 10 & 15 & 20 & 25 & 30 & 35 \\
\hline Hemicelluloses & 12.3 & 13.4 & 13.8 & 14.6 & 15.6 & 15.6 & 15.6 & 15.8 \\
Lignin & 10.5 & 11.6 & 11.8 & 12.8 & 13.3 & 13.3 & 13.4 & 13.5 \\
Residue & 75.0 & 72.8 & 72.2 & 70.4 & 68.9 & 68.9 & 68.8 & 68.5 \\
\hline
\end{tabular}

\subsection{Summary}

Previous researches have demonstrated that alkali and ultrasonic treatment are both of help in removing the non-cellulosic constituents from wood flour, but so far, the ultrasonic assisted alkali treatment is not fully studied. Further, most of the research about alkali treatment focuses on jute, maple and bamboo fibers, but only limited research focuses on pine wood. Due to the relatively low cost and easy availability, pine wood has great potential in WPC applications. In this work, polypropylene was chosen as the matrix due to its use in WPCs. It is not a stiff polymer. So it is easier to observe any increase of stiffness of WPC. By alkali treatment, the treated wood flour has a higher ratio of cellulose, and it is expected to 
provide better strength and stiffness to WPC. Also, by adding a coupling agent, not only will one increase the strength of WPC, but also reduce the water absorption of WPC by consuming the hydroxyl groups on the fiber surface. In summary, the object of this work is to study the effect of alkali and ultrasonic treatment on the mechanical properties and water absorption behavior of WPCs. 


\section{MATERIALS AND EXPERIMENTS}

In order to demonstrate the effect of alkali and ultrasonic treatment of wood, ASTM samples were required for measuring mechanical properties of WPCs. WPCs were formulated using polypropylene, a coupling agent, and pre-dried treated/untreated wood flour and were compounded using a twin screw extruder. After being fully dried, the pellets made by the twin screw extruder were processed by an injection molding machine to form ASTM samples. The other properties such as thermal degradation, the functional groups on fiber surface and so on were measured by TGA, FTIR, and SEM. Details are provided in this chapter.

\subsection{Chemicals and materials}

I. Wood fiber

Due to the higher aspect ratio of softwood cellulose, softwood is a better reinforcing material than hardwood. Pine wood is the most common softwood plant in North America. Due to the easy availability and the potential as a reinforcing material, pine wood fiber was chosen to be used in this work.

Pine wood flour (Pine 12020) of 120 mesh size (about $125 \mu \mathrm{m}$ ) was obtained from American Wood Fiber. The moisture content of the as-received wood flour was determined to be between 5 and $6 \mathrm{wt} \%$ by the ASTM D4442 method. Before use, the wood flour was pre-dried in an oven at $80^{\circ} \mathrm{C}$ for 8 
hours to reduce the moisture content to a value less than $1 \mathrm{wt} \%$. For purposes of comparison, highly pure cellulose fiber (CreaTech TC 180, $200 \mu \mathrm{m}$ average length and $20 \mu \mathrm{m}$ average width) was used to make WPC samples. This was obtained from CreaFill Fibers Corporation, and the raw material for the fibers is elemental chlorine free hardwood pulp.

II. Polypropylene

The flexural modulus of polypropylene is $1.07 \mathrm{GPa}$, and it is relatively low among plastics, By using PP as the matrix of WPC, the improvement in modulus is easy to observe. The polypropylene (PP1246) was provided by BP Amoco, and the melt flow index measured by ASTM D1238 was 20g/10min at $230^{\circ} \mathrm{C}$ and $2.16 \mathrm{~kg}$.

III. PP-g-MA Compatibilizer

Graft copolymer is the most common coupling agent used in the industry today. For the purpose of compatiblizing polypropylene and cellulose, PP-g-MA was chose to be the coupling agent in this work. The coupling agent PP-g-MA (PolyBond 3200) was provided by Chemtura. The molecular weight of this PP-g-MA is $120,000 \mathrm{~g} / \mathrm{mol}$ with $1 \mathrm{wt} \%$ MA content. The melt flow index of PolyBond 3200 is $115 \mathrm{~g} / 10 \mathrm{~min}$ at $190^{\circ} \mathrm{C}$ and $2.16 \mathrm{~kg}$ load. 
IV. Sodium hydroxide

The reagent grade $\left(97 \%^{+}\right)$sodium hydroxide employed in this work was purchased from Sigma-Aldrich; its particle size was between 20 and 40 mesh.

V. Potassium bromide $(\mathrm{KBr})$

Potassium bromide $\left(99 \%^{+}\right.$, FTIR grade) used for FTIR measurement was purchased from Sigma-Aldrich.

3.2. Surface modification of wood fiber

\subsubsection{Chemical modification.}

The procedure used is as follows:

I. Prepare $1700 \mathrm{~g} \mathrm{NaOH}$ solution $(1 \mathrm{wt} \%$ and $3 \mathrm{wt} \% \mathrm{NaOH})$.

II. Heat the $\mathrm{NaOH}$ solution to $60^{\circ} \mathrm{C}$ and maintain this temperature.

III. Introduce $170 \mathrm{~g}$ wood fiber in the $\mathrm{NaOH}$ solution and using high shear stress mixer stir for 30 minutes.

IV. Separate wood fiber by the help of a filter.

V. Put the wood fiber into a deionized water bath and stir by mixer for 10 $\min$.

VI. Remove wood fiber by filtration.

VII. Dry this wood fiber in an oven at $80^{\circ} \mathrm{C}$ for $12 \mathrm{hr}$. 


\subsubsection{Chemical modification with ultrasound assistance}

The procedure of ultrasound-assisted modification is the same as for chemical modification. The only difference is that when the wood fiber is mixed with the $\mathrm{NaOH}$ solution for 30 minutes (step III), a $20 \mathrm{kHz} 750 \mathrm{~W}$ ultrasound is applied by Cole-Parmer CP750 ultrasonic horn during this session. Beside this, all the processes are the same as above including the washing and drying steps.

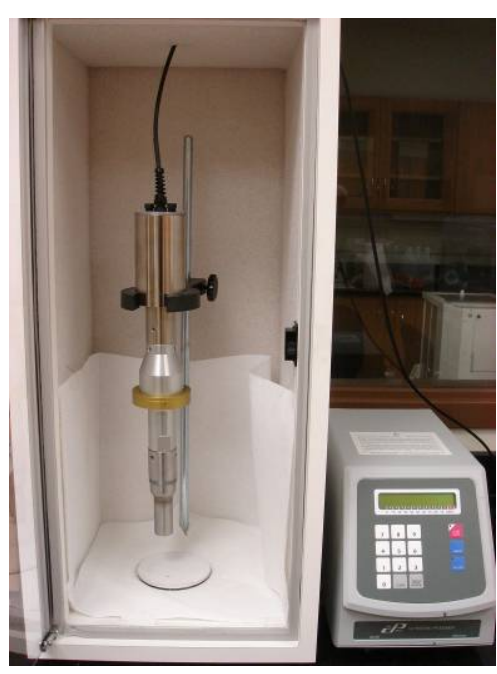

Figure 3-1 Cole-Parmer CP750

\subsection{Compounding}

Wood fiber and polymers were fed into a Leistritz Micro-27 co-rotating twin screw extruder (TSE) by K-Tron Soder K-CL-24-KT20 powder and K-CL-24-KQX4 pellet loss-in-weight feeders. Both of the feeders were controlled by a KSL Smart Line Control Display. The PP-g-MA pellets were well mixed with PP pellets before loading into the pellet feeder. The wood flour was pre-dried in an oven at $80{ }^{\circ} \mathrm{C}$ for $8 \mathrm{hr}$ to reduce the moisture content to less than $1 \mathrm{wt} \%$. Wood fiber 
and polymers were all added into the hopper of the twin-screw extruder at the same time. The barrel temperature of the TSE was fixed at $165-180{ }^{\circ} \mathrm{C}$ from hopper to die. The total feeding rate was $2.4 \mathrm{~kg} / \mathrm{hr}$ (both $1.2 \mathrm{~kg} / \mathrm{hr}$ of powder and pellet feeder), and the screw rotation speed was $85 \mathrm{rpm}$. These conditions are based on previous work done with WPCs at WVU [28].

\subsection{Injection molding}

The compounded WPC pellets were dried in an oven at $80{ }^{\circ} \mathrm{C}$ for 7 hours before injection molding. Samples were injection molded by a Battenfeld BA 1000-CDC injection molding machine to produce standard ASTM samples. The barrel temperature was controlled between $165-175^{\circ} \mathrm{C}$. The injection and holding pressures were fixed at 10,000 PSI and 4000 PSI respectively.

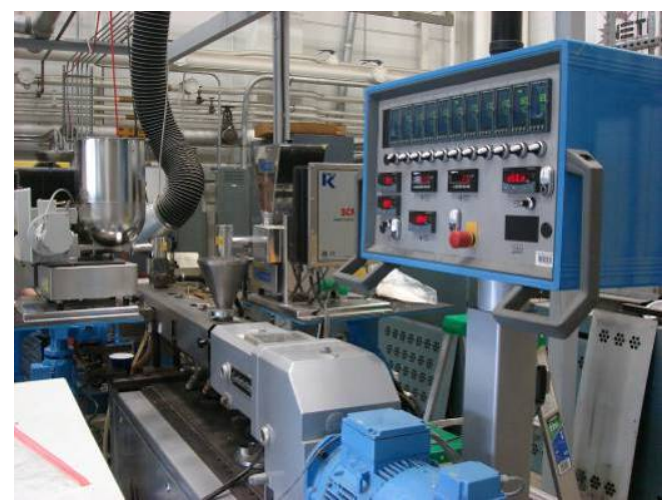

Figure 3-2a Twin Screw Extruder

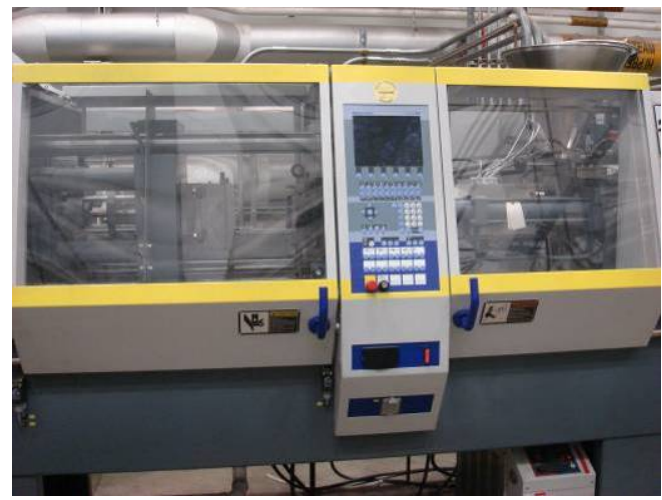

Figure 3-2b Injection Molding Machine

\subsection{Mechanical property tests}

The tensile and flexural strength and stiffness values of the WPC samples were measured using an Instron 5869 universal testing machine (Figure 3-3). The samples were conditioned in a controlled humidity atmosphere for at least $40 \mathrm{hr}$. All the data 
were analyzed according to ASTM D638 (Type I) and D790, respectively. Each value reported is an average of six samples. An Instron-SATEC impact tester model BL1 was used to measure the reverse notch impact strength of the WPC samples according to ASTM D256.

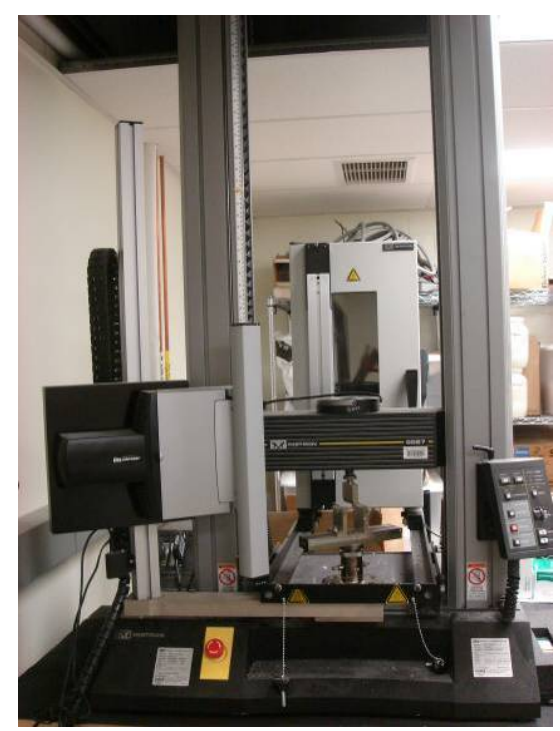

Figure 3-3 Instron 5869 Universal Testing Machine

3.6. Fourier transfer infrared spectroscopy (FTIR)

FTIR spectra of the wood flour were recorded on a PerkinElmer spectrophotometer (Figure 3-4) using $\mathrm{KBr}$ pellets that contained $1 \mathrm{wt} \%$ of a well-ground fiber sample. A minimum of 32 scans were averaged with a signal resolution of $2 \mathrm{~cm}^{-1}$ within the $400-4000 \mathrm{~cm}^{-1}$ range. 


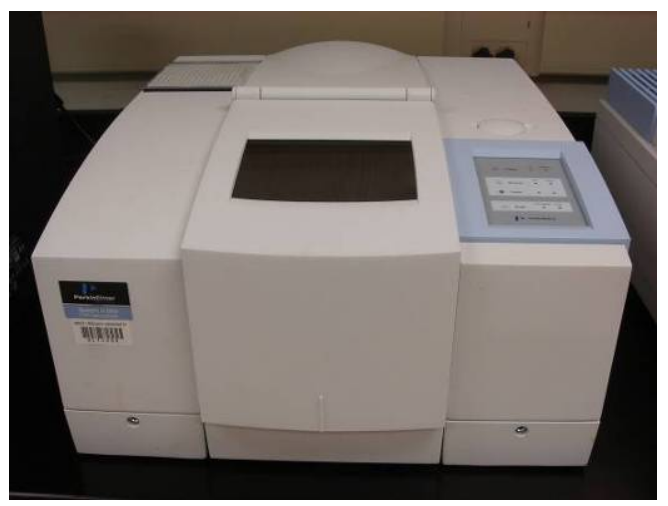

Figure 3-4 PerkinEImer Spectrophotometer

3.7. Thermal degradation analysis

Thermal degradation properties of the treated wood flour were measured with the help of a Thermo Gravimetric Analyzer (TGA), model Q500 from TA Instruments (Figure 3-5) and operated from room temperature to $600{ }^{\circ} \mathrm{C}$, with a heating rate of 10 ${ }^{\circ} \mathrm{C} /$ min and purged with air. The measurements were conducted using a sample weight of 6-10 mg; weight retention/temperature curves were recorded. From these scans, the transition temperature that represents the onset of degradation can be computed.

\subsection{Scanning Electron Microscope (SEM)}

In order to examine the shape, size, size distribution and the surface of the wood reinforcement before and after alkali treatment, a Hitachi S-4700 Field Emission Scanning Electron Microscope (Figure 3-6) was used; samples were pre-coated with gold. 


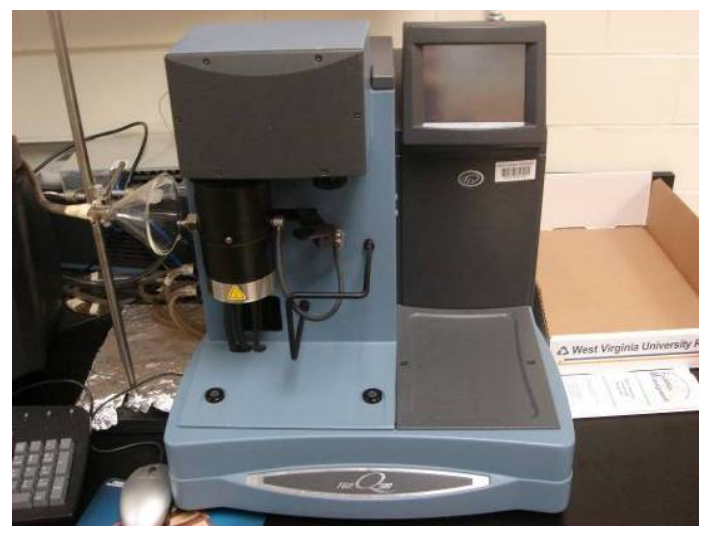

Figure 3-5 Thermal degradation analysis Q500

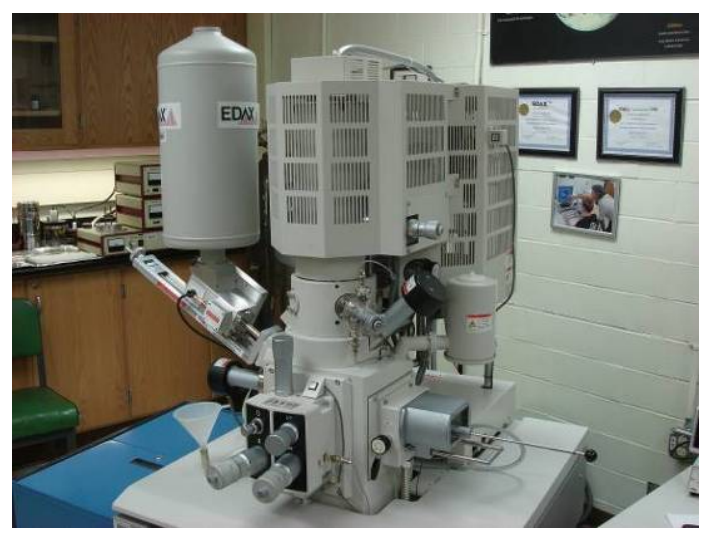

Figure 3-6 Hitachi S-4700 Field Emission Scanning Electron Microscope

\subsection{Polarized optical microscope (POM)}

An INSTEC polarized optical microscope (Leitz Laborlux 12 Pol) with HCS302 hot and cold stage attached to a STC200 controller was used to examine the crystallization behavior of the polymer in the WPC adjacent to the wood surface. All the samples were heated to $230{ }^{\circ} \mathrm{C}$ at a rate of $30{ }^{\circ} \mathrm{C} / \mathrm{min}$ to melt any pre-existing crystals. Once all the crystals had melted (about $1 \mathrm{~min}$ ), the sample was cooled to 180 ${ }^{\circ} \mathrm{C}$ at a rate of $30{ }^{\circ} \mathrm{C} / \mathrm{min}$ and initial pictures were taken through the microscope. The sample was further cooled to $170{ }^{\circ} \mathrm{C}$ at $2{ }^{\circ} \mathrm{C} / \mathrm{min}$, and additional pictures were taken. Finally the sample temperature was maintained at $170{ }^{\circ} \mathrm{C}$ for 2 minutes, and the last 
set of pictures was taken. Note that the crystallization temperature of polypropylene is around $174{ }^{\circ} \mathrm{C}$.

3.10. Water absorption behavior

The rate of water absorption of the WPCs was determined using a "blot and weigh" method. Three weighed samples were taken from each batch to conduct this test. The typical injection-molded impact test sample of $12.5 \mathrm{~mm}$ x $64 \mathrm{~mm} \times 3.175$ mm was soaked in a sealed container of distilled water at room temperature and was periodically removed and weighed. The results were plotted as percentage weight gained versus time of immersion. 


\section{RESULTS AND DISSCUSSION}

4.1. Characterization of modified wood fibers

\subsubsection{Fourier transfer infrared spectroscopy (FTIR)}

Figure 4-1 shows the spectra of: (a) Pristine (untreated) wood flour (b) Wood flour treated with $1 \% \mathrm{NaOH}$ (c) Wood flour treated with $1 \% \mathrm{NaOH}$ and ultrasound assistance (d) Wood flour treated with 3\% NaOH and (e) Wood flour treated with 3\% $\mathrm{NaOH}$ and ultrasound assistance. These spectra can be used to compare the effectiveness of the various treatment procedures for removing lignin and hemicellulose from wood particulates.

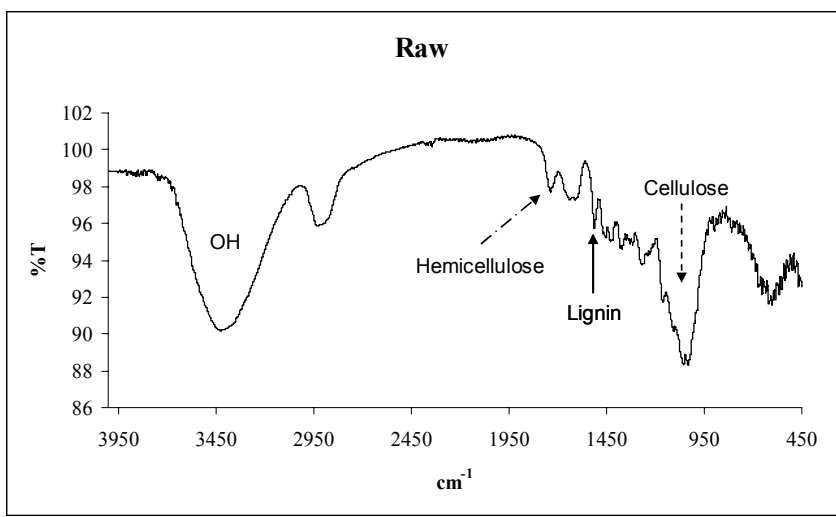

(a)Pristine wood fiber

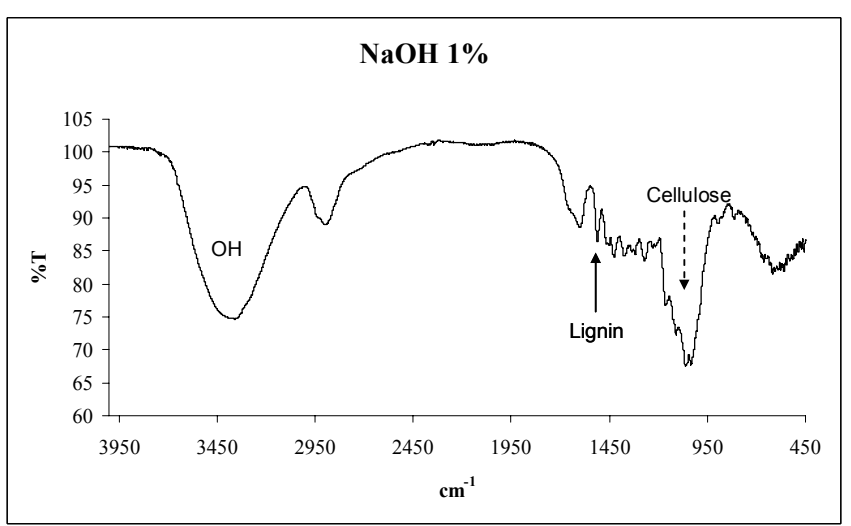

(b)Wood fiber treated with $1 \% \mathrm{NaOH}$ 


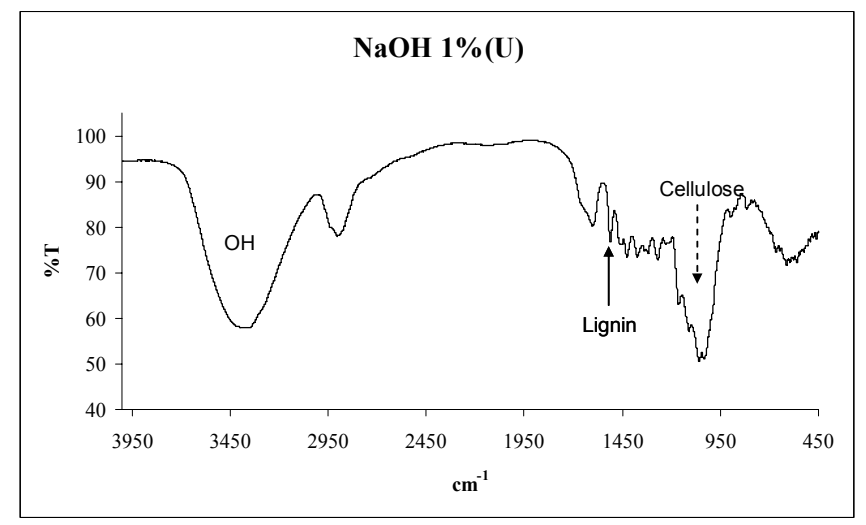

(c)Wood fiber treated with $1 \% \mathrm{NaOH}$ and ultrasound assistance

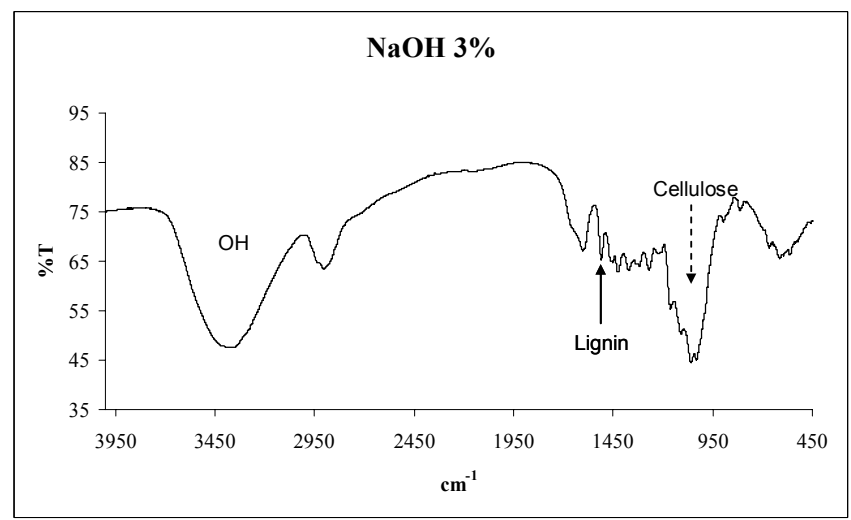

(d)Wood fiber treated with $3 \% \mathrm{NaOH}$

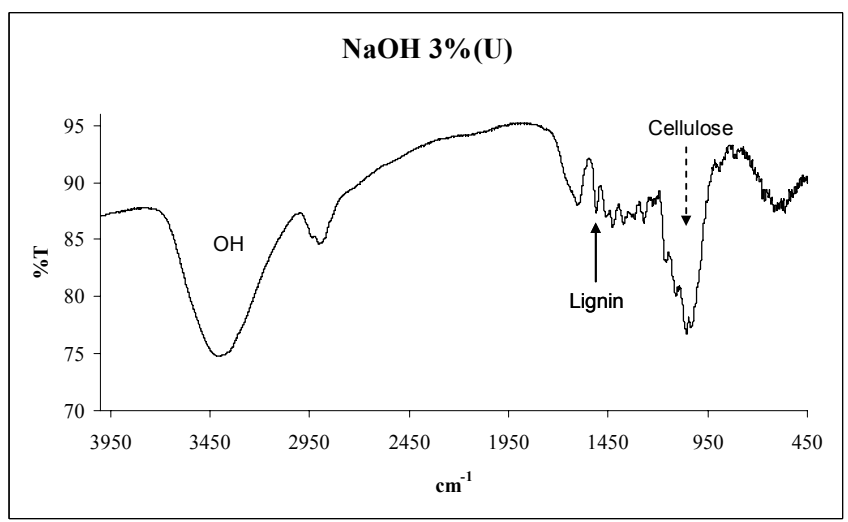

(e)Wood fiber treated with $3 \% \mathrm{NaOH}$ and ultrasound assistance

Figure 4-1 The FT-IR spectra of modified wood fiber with or without ultrasound assistance

In the spectrum of the pristine wood flour, several peaks are observed against the background. From the literature [29] and the result of FTIR (Fig 4-2), these peaks at $900,1020,1060$ and $1160 \mathrm{~cm}^{-1}$ represent the cellulose in the wood. The peaks at 1510 
and $1600 \mathrm{~cm}^{-1}$ are the bonds of the aromatic ring of lignin. However, the peak at 1600 $\mathrm{cm}^{-1}$ is also representative of the structure of $\mathrm{C}=\mathrm{O}$. Thus, only the peak at $1510 \mathrm{~cm}^{-1}$ can be used to estimate the degree of lignin fiber removal from the wood [29]. Also, the most significant absorption peak of the carbonyl group of the hemicellulose in the FTIR spectrum of wood is at $1740 \mathrm{~cm}^{-1}[30]$.

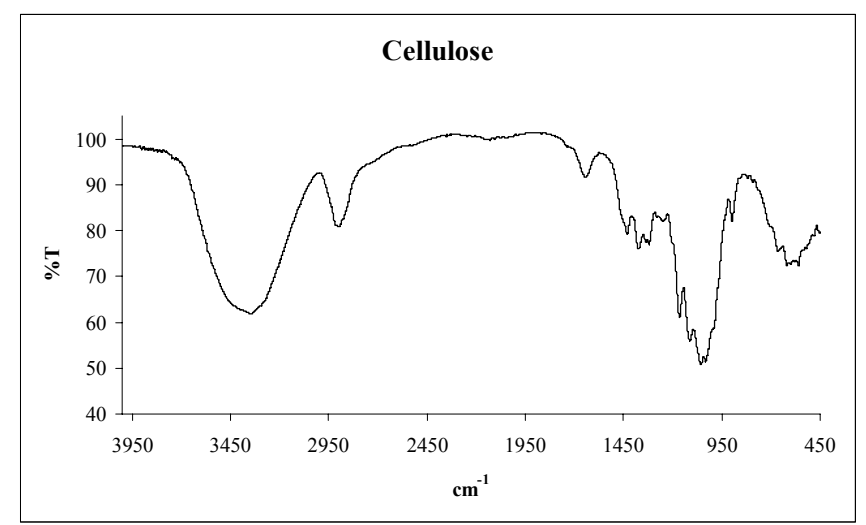

Figure 4-2 The FTIR spectrum of cellulose fiber

Besides removing lignin from the wood flour, another purpose of alkali treatment is to increase the concentration of hydroxyl groups on the cellulose surface. These hydroxyl groups can react with the maleic anhydride (MA) present in the polymer in the form of PP-g-MA which is the coupling agent, and the result is covalent bonding with the wood. Since PP-g-MA is compatible with polypropylene, increasing the amount of hydroxyl groups will lead to better adhesion between the polymer matrix and the reinforcement leading to improvements in WPC strength. Note that the peak that is representative of the hydroxyl groups in the IR spectrum of wood is usually broad and lies between $3000 \mathrm{~cm}^{-1}$ and $3700 \mathrm{~cm}^{-1}[30]$. 
From Figure 4-1, it is observed that the peak at $1740 \mathrm{~cm}^{-1}$ disappears after alkali treatment. Since this peak is associated with the presence of hemicellulose, one can conclude that most of hemicellulose is removed after alkali treatment. With the absence of hemicellulose, the fibers split into thinner fibrils which have more freedom in reorientation during compounding with polymers. This ability to reorient should result in an increase in strength of WPCs.

Unlike the removal of hemicellulose upon alkali treatment, changes in the amount of lignin or of the number of hydroxyl groups are not obvious in the FTIR spectrum. These can be quantified by integrating the area below the peaks of cellulose, lignin, and hydroxyl groups [30]. This is done in Figure 4-3.

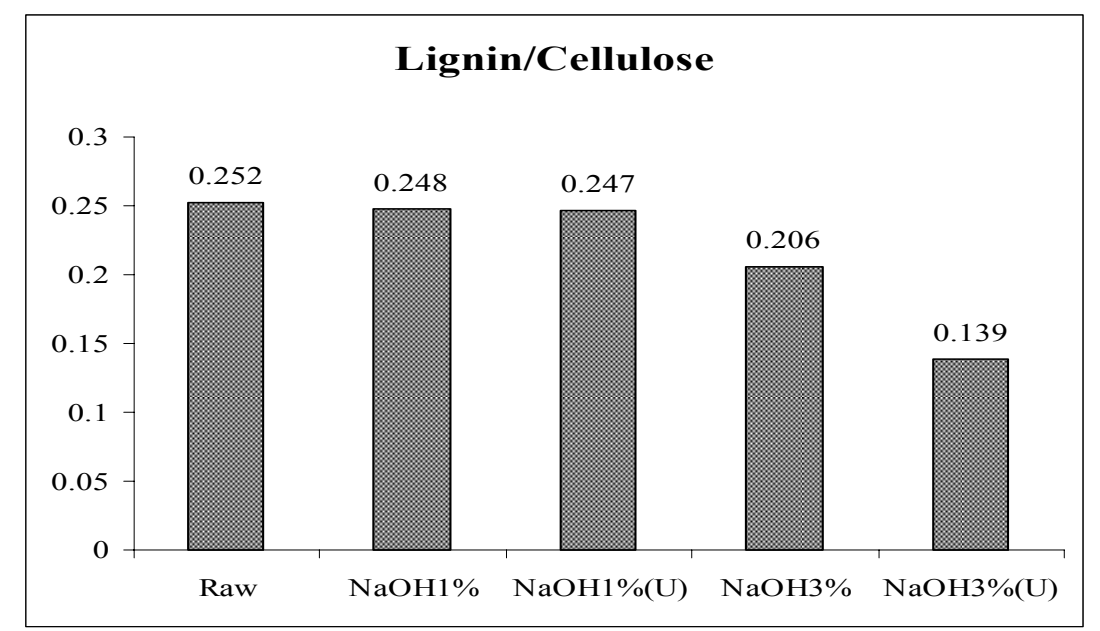

(a) The FTIR integration area calculation for the changes of lignin/cellulose 


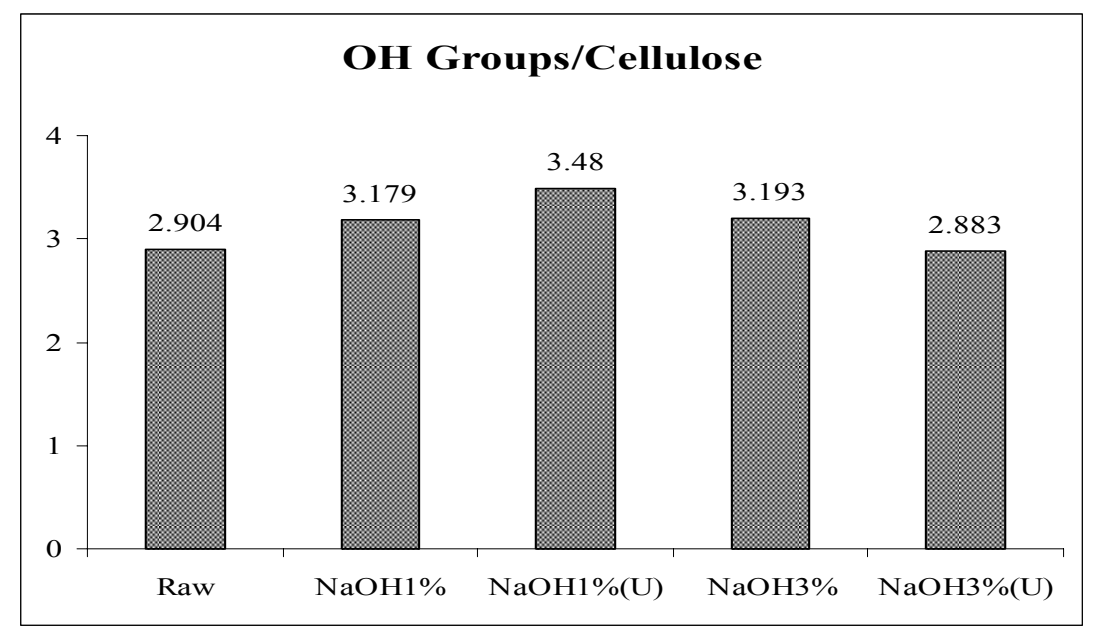

(b) The FTIR integration area calculation for the changes of hydroxyl groups/cellulose

Figure 4-3 The result of integration area calculation of FTIR

It is seen that wood fiber treated with $1 \% \mathrm{NaOH}$ solution does not remove lignin very effectively; only $1.6 \%$ of lignin have been removed. Even with the assistance of ultrasound, only $2 \%$ lignin is removed from the wood flour. However, $1 \% \mathrm{NaOH}$ treatment does increase the concentration of hydroxyl groups on the fiber surface by 9.4\%. The application of ultrasound results in a further increase in the $\mathrm{OH}$ groups to a total increase of $19.8 \%$ over the value for raw wood. When wood flour was treated with $3 \% \mathrm{NaOH}$ solution, nearly $18.3 \%$ of lignin was eliminated, and ultrasound assistance continued this process so that a total of $44.8 \%$ of lignin was removed. Concerning the increase in $\mathrm{OH}$ groups, alkali treatment was now just as effective as before, and $\mathrm{OH}$ groups increased by $10.0 \%$. Ultrasound, however, did not help, and the $\mathrm{OH}$ groups even reduced slightly by $0.7 \%$. This unexpected result is probably due to the reduction in the content of lignin. Lignin, by itself, has $\mathrm{OH}$ groups in its 
structure and, therefore, when the content of lignin is reduced, the total amount of $\mathrm{OH}$ groups on the wood flour surface is also reduced.

\subsubsection{Scanning Electron Microscope (SEM)}

Figure 4-4 shows SEM pictures of alkali treated and untreated wood fibers at magnifications of 300 and 1,000 . It is seen that the pristine wood fibers are much thicker than the others, and what appear to be small branches are everywhere on the wood surface. These small branches are most likely the non-cellulosic components, such as lignin and hemicellulose. Treatment with $1 \% \mathrm{NaOH}$ solution seems to result in a reduction in particle size, and the cellulose surface becomes smoother. By comparing Figures 4-4(a) and 4-4(b), one notices that the fibers, after alkali treatment, split into thinner fibrils due of the removal of hemicellulose. This observation is consistent with conclusions drawn from an examination of the FTIR spectrum.
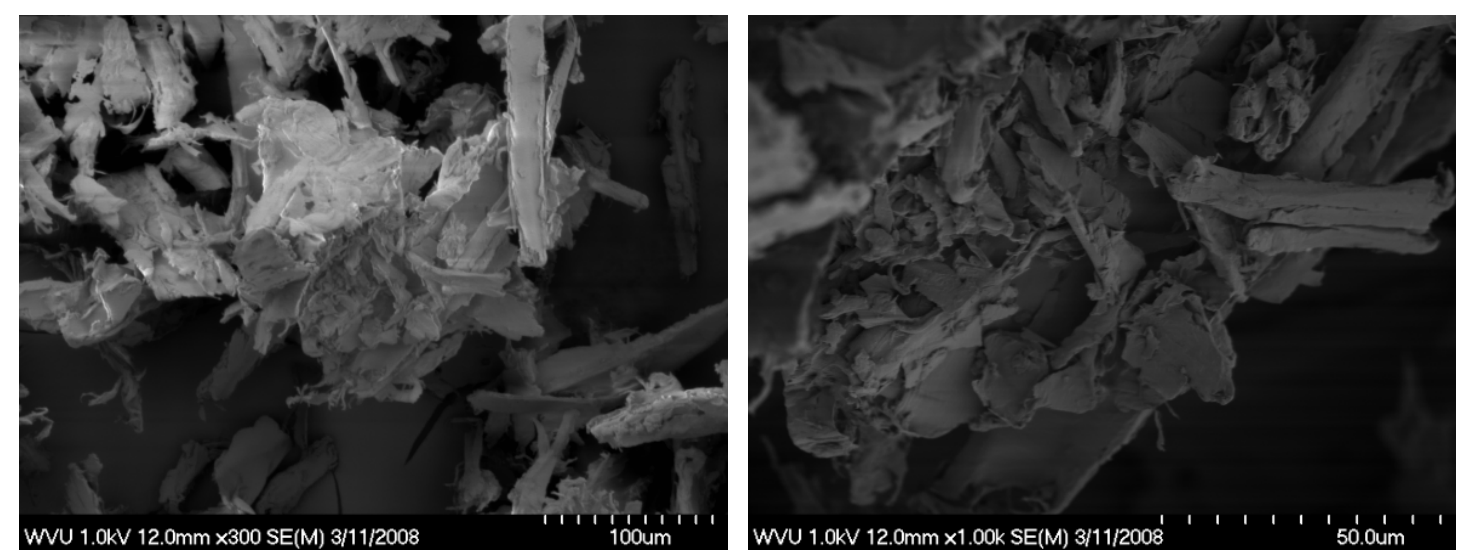

Figure 4-4 (a) the SEM picture of pristine wood fibers 

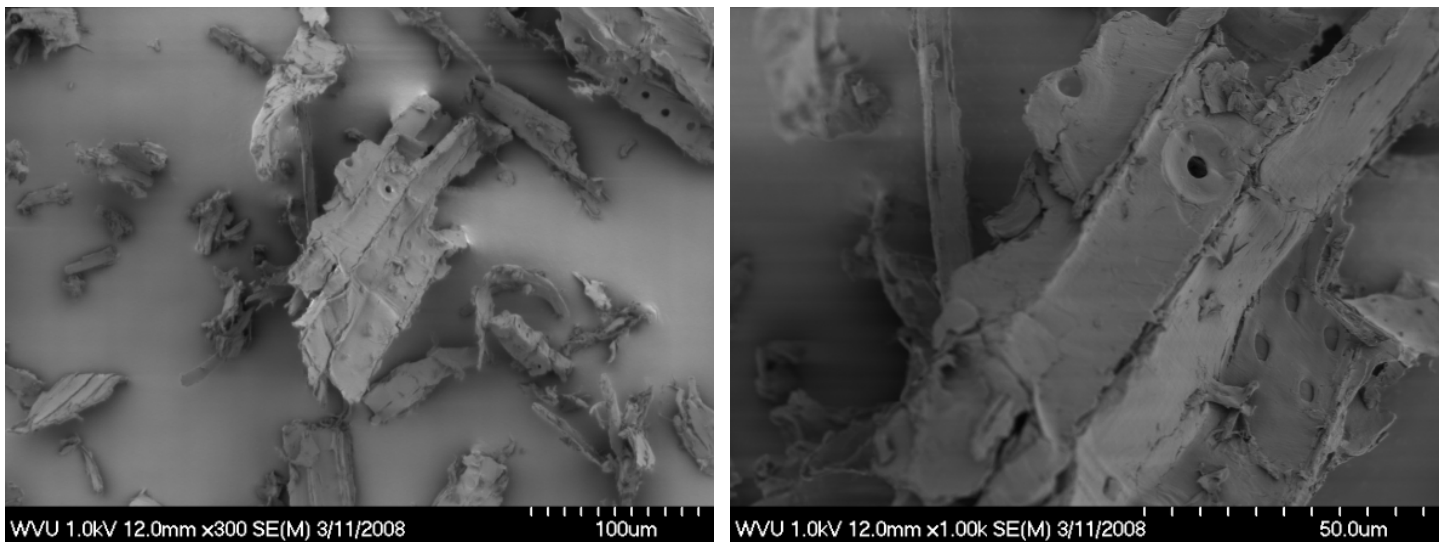

Figure 4-4 (b) the SEM picture of wood fibers treated with $1 \% \mathrm{NaOH}$
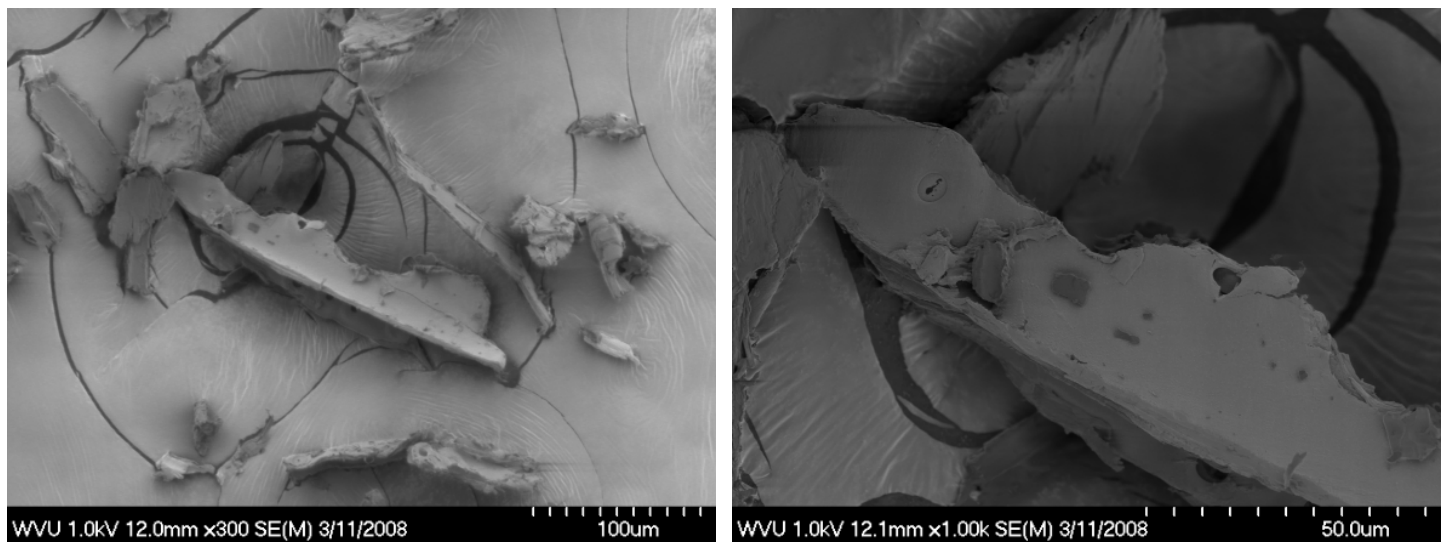

Figure 4-4 (c) the SEM picture of wood fibers treated with $1 \% \mathrm{NaOH}$ and ultrasound

Figure 4-4 (c) shows that ultrasound seems to promote the effect of the $1 \%$

alkali treatment and further splits the fibers into thinner pieces.
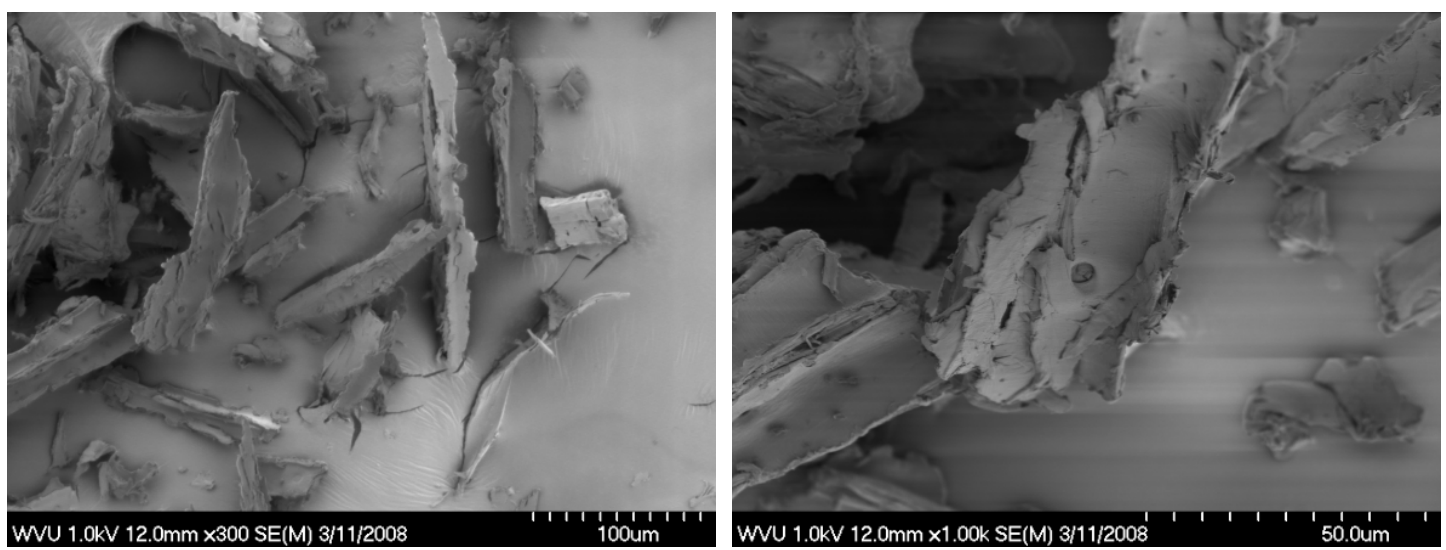

Figure 4-4 (d) the SEM picture of wood fibers treated with 3\% NaOH 

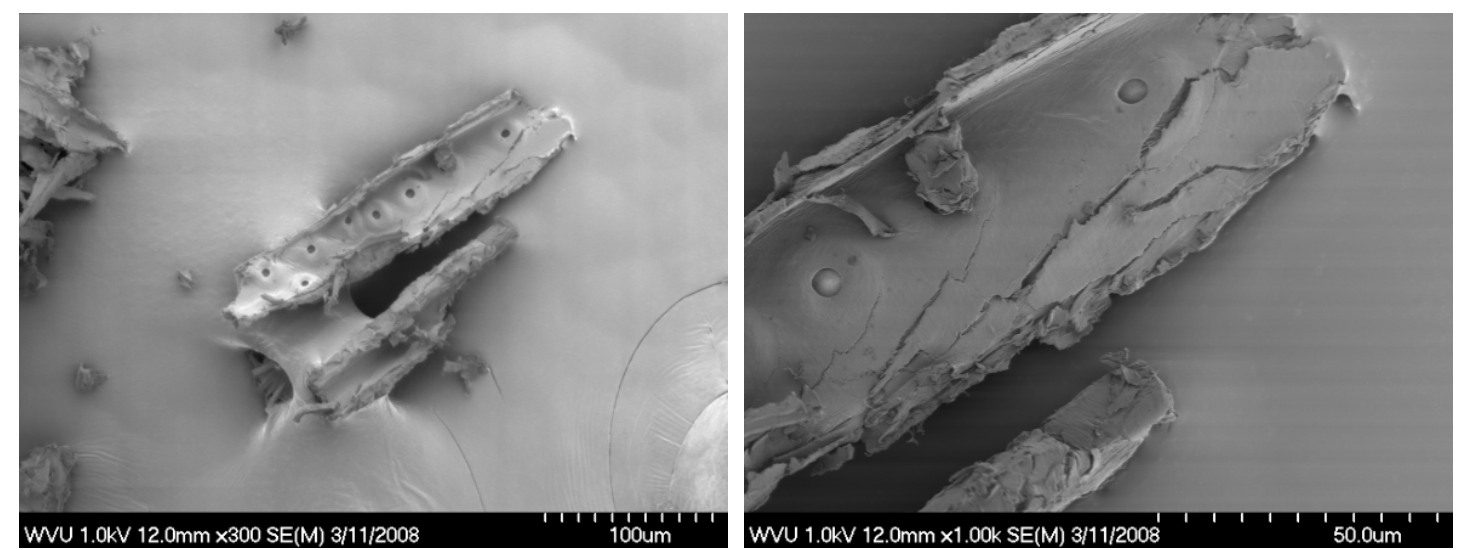

Figure 4-4 (e) the SEM picture of wood fibers treated with $3 \% \mathrm{NaOH}$ and ultrasound

According to the literature, alkali treatment can not only remove lignin and hemicellulose from wood, it can also decompose the cellulose [2, 10, 20, and 21]. This is seen in Figures 4-4 (d) and 4-4 (e), which show the effect of 3\% $\mathrm{NaOH}$ and the combined effect of alkali and ultrasound respectively. It is evident that there are cracks on the fiber surface. Thus, while $3 \%$ alkali treatment can remove much more lignin than $1 \%$ alkali treatment does, it also damages the cellulose. One expects that the removal of lignin will result in an increase in the modulus of WPCs, but the decomposition of cellulose will reduce the strength. Figure 4-4 (f) shows pure cellulose fibers, and these have a much larger aspect ratio as compared to the wood particulates. 

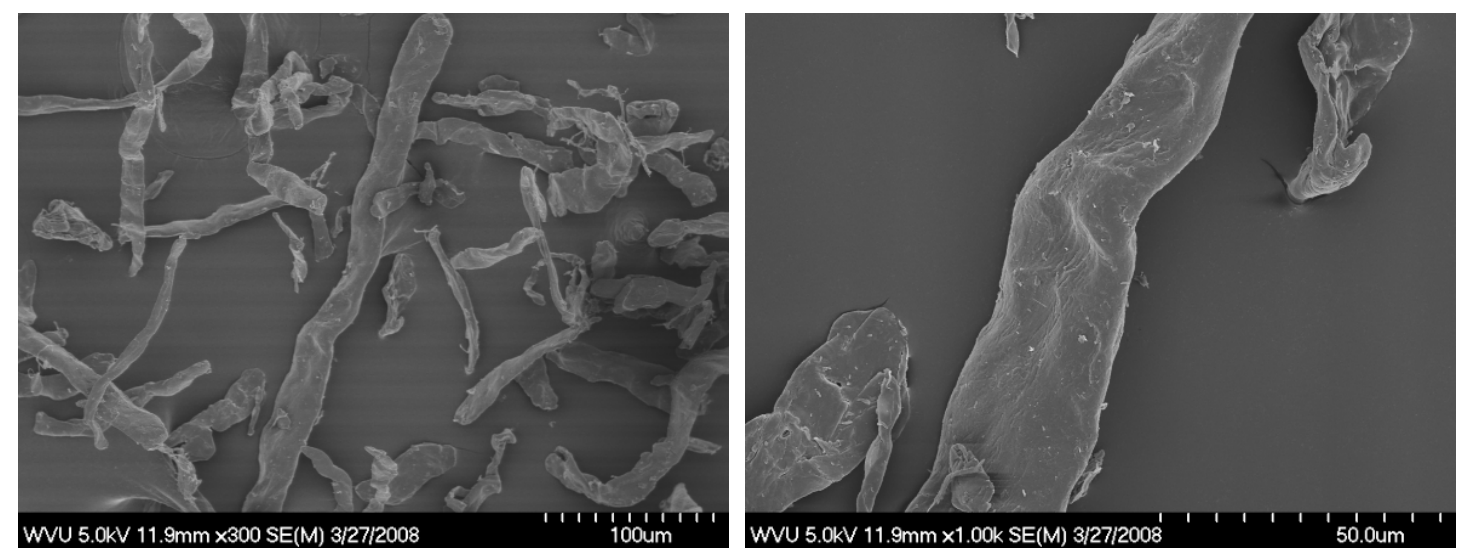

Figure 4-4 (f) artificial cellulose fibers

\subsubsection{Particle Size Analysis}

The SEM observations are complemented by particle size analysis using a set of sieves, and the results are displayed in Figure 4-5. It is found that while $87.48 \%$ of the pristine wood fibers are larger than 80 mesh, only $9.72 \%$ are between 80 and 100 mesh. After treatment with $0.5 \% \mathrm{NaOH}$, the particle size increases slightly, and $90.18 \%$ of particles are larger than 80 mesh while $7.23 \%$ are between 80 and 100 mesh. Although an appearance enhancement in particle size is observed, this does not mean that alkali treatment enlarges particles. It is most likely that the dilute alkali causes the disintegration of the smallest particles, resulting in the observation of a larger average size. With increasing $\mathrm{NaOH}$ concentration, all the particles are affected, and the particle size becomes progressively smaller. Thus, for the $3 \% \mathrm{NaOH}$ treated fibers, only $80.82 \%$ of particles are larger than 80 mesh, and $14.60 \%$ of particles are between 80 and 100 mesh. 


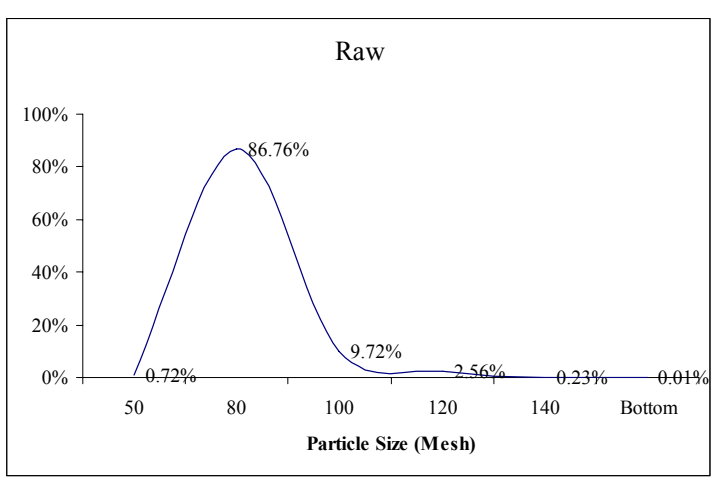

(a) Pristine wood fiber

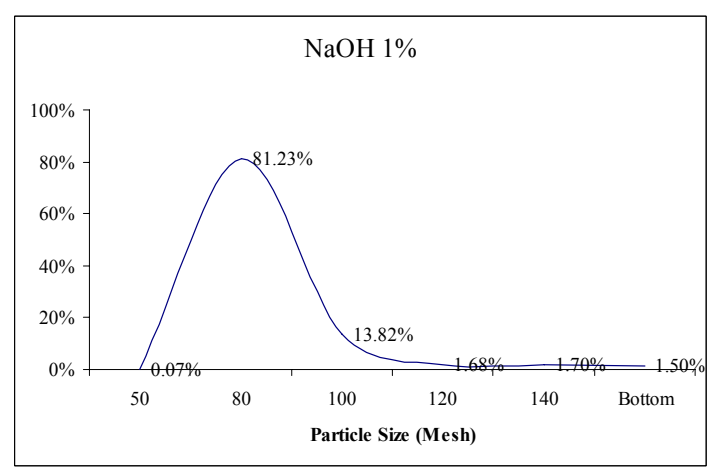

(c) $1 \% \mathrm{NaOH}$ treated wood fiber

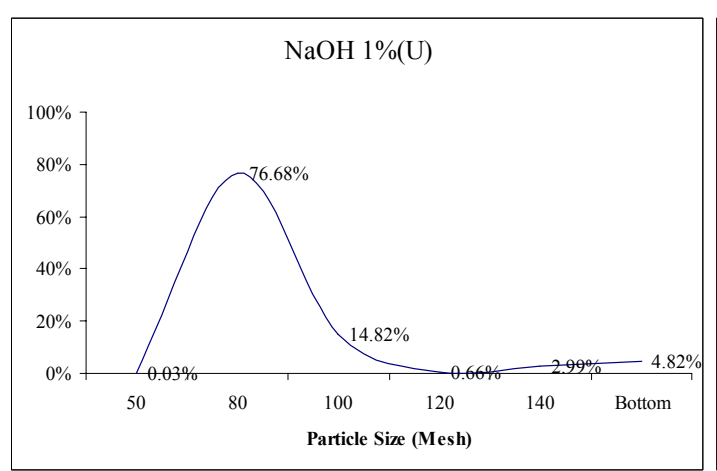

(e) $1 \% \mathrm{NaOH}(\mathrm{U})$ treated wood fiber

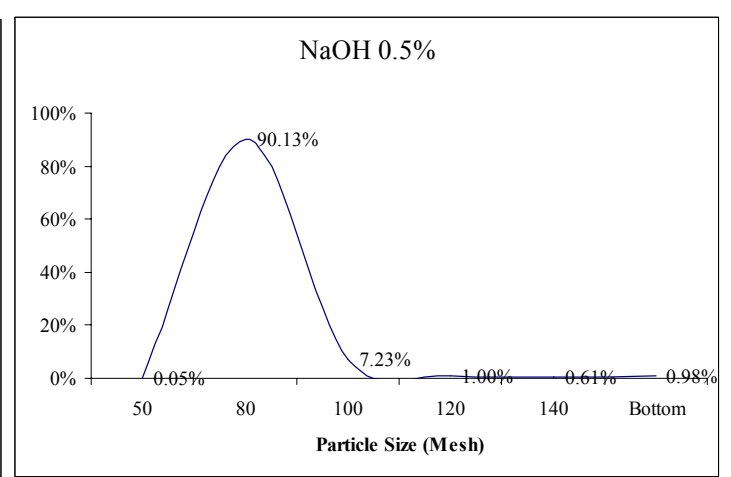

(b) $0.5 \% \mathrm{NaOH}$ treated wood fiber

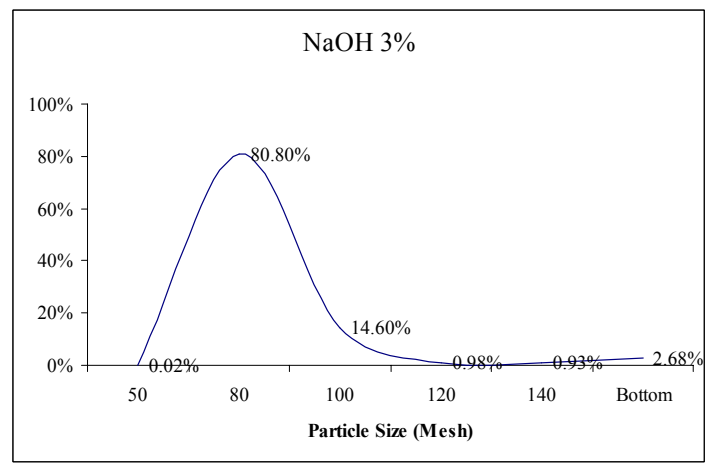

(d) $3 \% \mathrm{NaOH}$ treated wood fiber

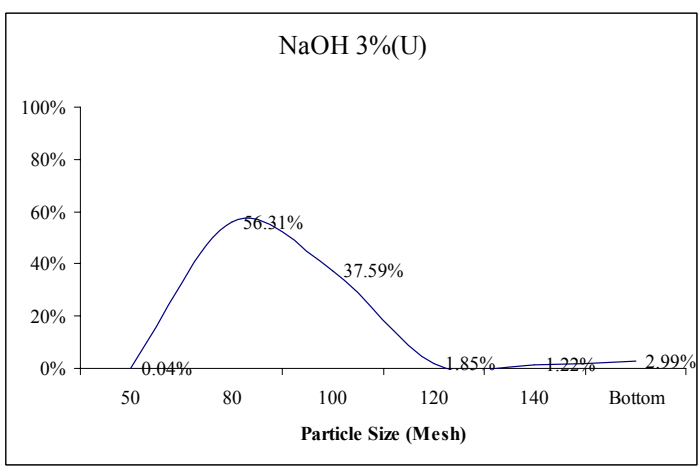

(f) $3 \% \mathrm{NaOH}(\mathrm{U})$ treated wood fiber

Figure 4-5 The result of particle size analysis

High energy ultrasound not only accelerates the effect of alkali treatment, it also reduces the particle size by itself. By combining ultrasonic and alkali treatment together, the particle size reduces further. Thus, for wood particulates treated with $3 \%$ 
$\mathrm{NaOH}$ with ultrasound assistance, only $56.35 \%$ of the particulates are large than 80 mesh, and there are $37.59 \%$ particulates that are between 80 and 100 mesh.

4.1.4. Thermal Degradation Analysis (TGA) of wood fibers

The characterization of the alkali-treated wood is completed using thermo gravimetric analysis, and a typical TGA curve is shown in Figure 4-6 for the untreated wood. This figure also defines the transition temperature which represents the temperature at the onset of thermal degradation; for pristine wood, this value is 272.49 ${ }^{\circ} \mathrm{C}$.

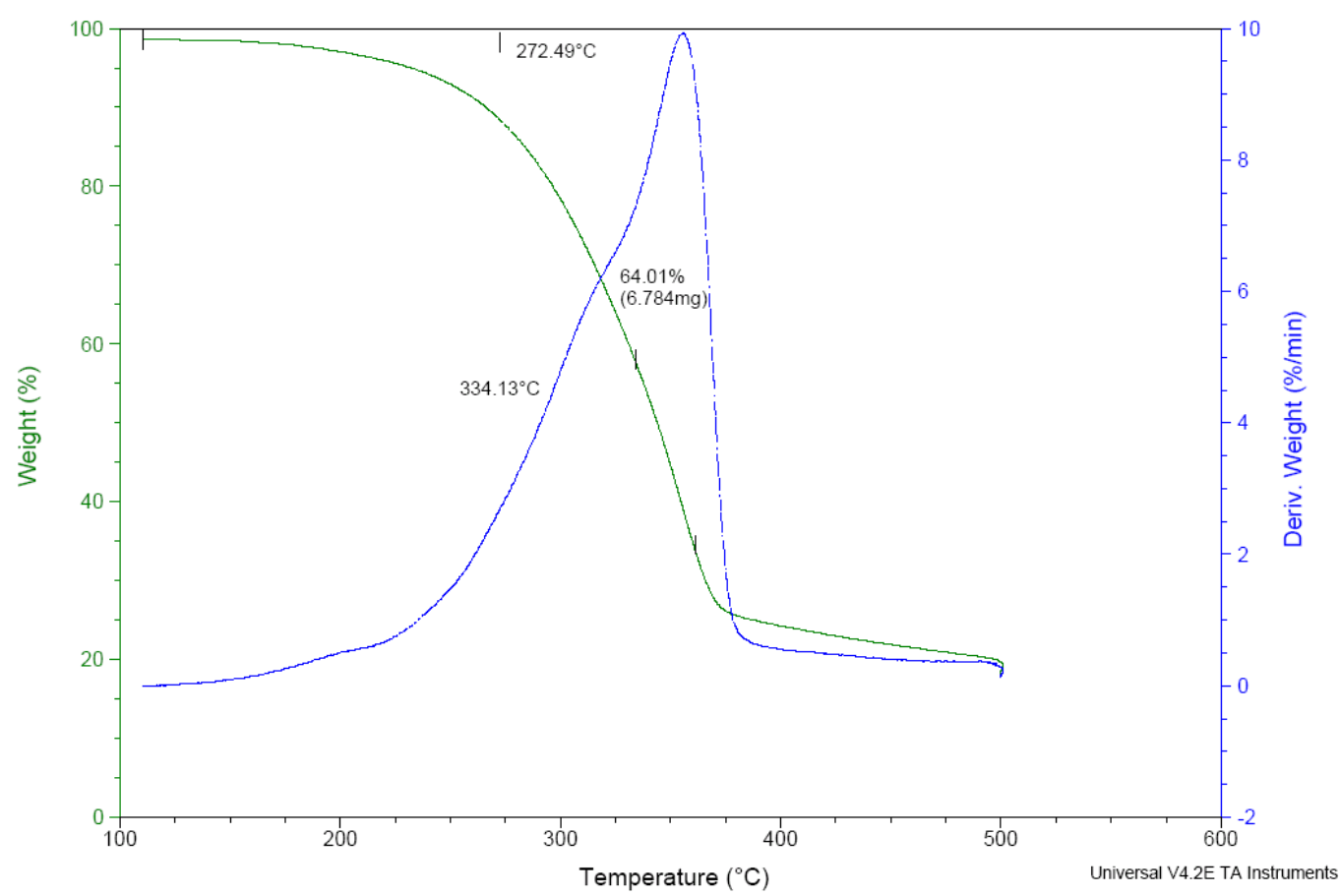

Figure 4-6 Thermal degradation analysis of pristine wood fiber 


\begin{tabular}{|c|c|}
\hline Fiber Type & $\begin{array}{c}\text { Transition Temperature } \\
\left({ }^{\mathbf{o}} \mathbf{C}\right)\end{array}$ \\
\hline Pristine wood & 272.49 \\
\hline $\mathrm{NaOH} \mathrm{1 \%}$ & 248.96 \\
\hline $\mathrm{NaOH} \mathrm{1 \% (U)}$ & 247.12 \\
\hline $\mathrm{NaOH} \mathrm{3 \%}$ & 240.23 \\
\hline $\mathrm{NaOH} \mathrm{3 \%}(\mathrm{U})$ & 237.03 \\
\hline
\end{tabular}

Table 4-1 Transition temperatures of wood fibers

Table 4-1 shows the transition temperatures of all the treated and untreated wood particulates. It is seen that thermal stability reduces with alkali treatment, and the situation becomes slightly worse with ultrasound. These observations can be understood by noting that wood contains components besides cellulose, lignin and hemicellulose. In particular, wood contains minerals, and these minerals help wood fibers remain stable at high temperatures. However, these minerals can be eliminated by alkali treatment, and this causes a reduction of thermal resistance of wood fibers. Also, while the thermal stability of cellulose is superior when compared to the other constituents of wood, cellulose is degraded by alkali treatment. Thus, the degradation of cellulose is also partly responsible for the loss of thermal stability of alkali-treated wood. 


\subsection{Characterization of wood plastic composites}

\subsubsection{Thermal degradation analysis of WPC}

Figure 4-7 present the result of thermal degradation analysis of WPC which use pristine wood fiber and without adding any coupling agent. From this figure, there are two transition temperature is observed: $271.15^{\circ} \mathrm{C}$ and $432.81{ }^{\circ} \mathrm{C}$. The first and second transition temperatures are caused by the degradation of wood fibers and polymer matrix respectively. Because the polymer matrix of the WPC is polypropylene, the second transition temperature shows very little difference among different WPCs.

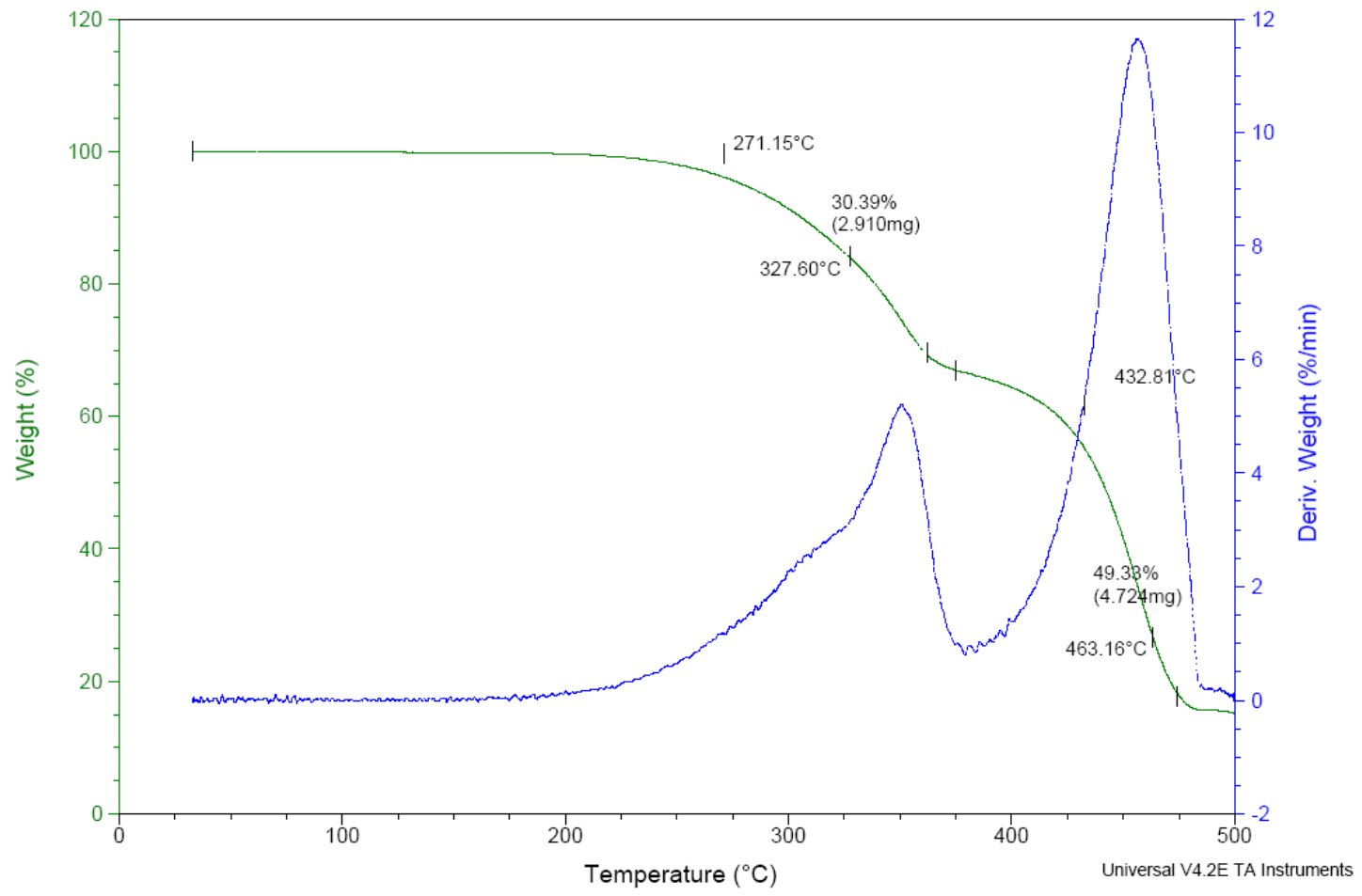

Figure 4-7 Thermal degradation analysis of WPC

Figure 4-8 shows the first transition temperature of various WPCs. From the results, the first transition temperature doesn't have much change with different ratio of coupling agent. But the first transition temperature drops about $22{ }^{\circ} \mathrm{C}$ in average 
after $1 \%$ alkali treatment, and drops $26^{\circ} \mathrm{C}$ in average after $3 \%$ alkali treatment. Since the first degradation is caused by the degradation of wood fibers, the thermal properties of wood fibers are responsible for the recession of thermal stability of WPC. As mentioned earlier, alkali treatment decreases the thermal resistance of wood fibers. That explains why the WPC which use alkali treated fibers have lower thermal resistivity.

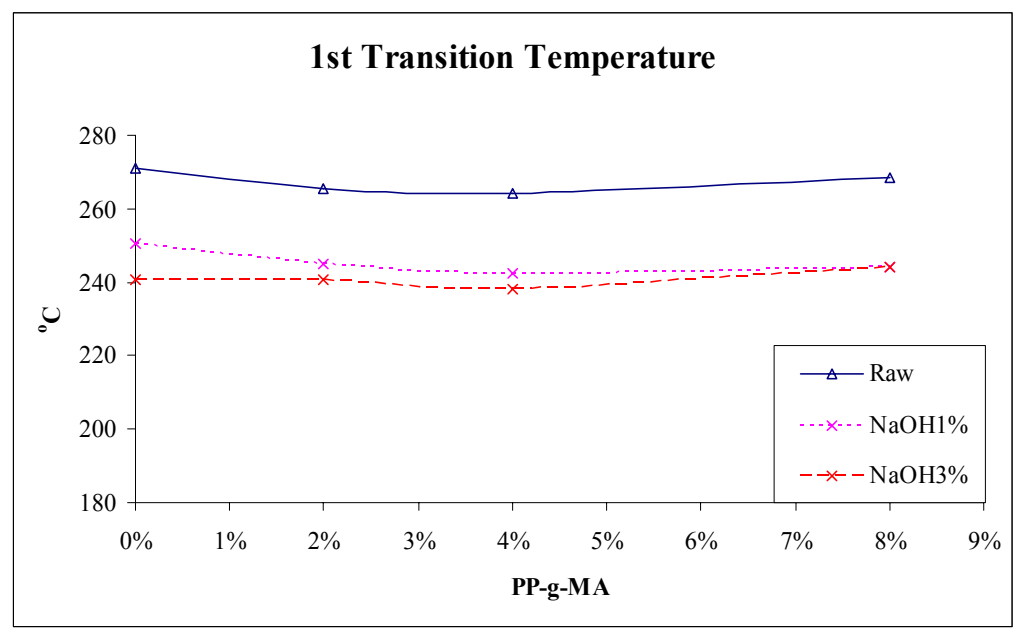

Figure 4-8 First transition temperature of WPCs

As mention in chapter 4.1.4, ultrasound treatment does not make significant changes on the thermal stability of wood fibers, and thus the WPC which use ultrasound-assisted treated fibers don't show significant changes in thermal stability. Fig 4-9 (a) and (b) show the result of first transition temperature of the WPC which use $1 \%$ and $3 \%$ alkali treated fibers. 


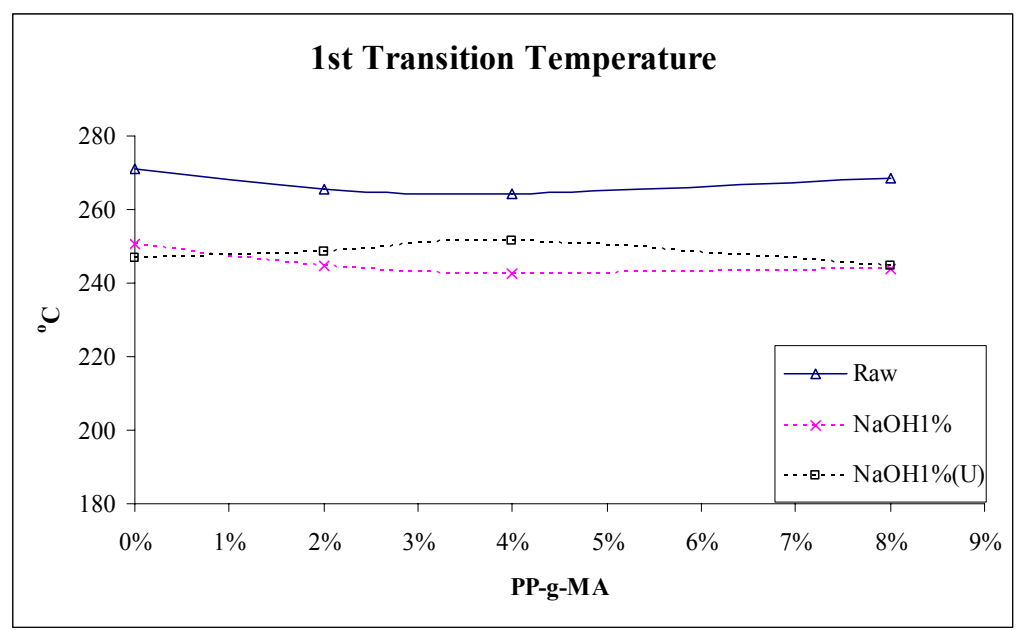

(a) The thermal stability of WPC with $1 \%$ alkali treated fibers

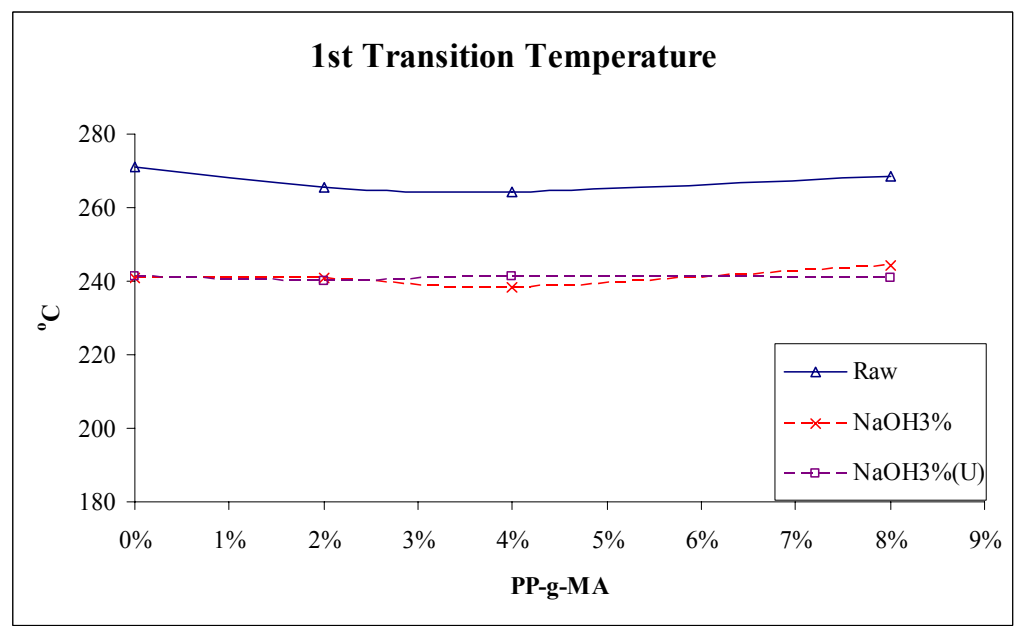

(b) The thermal stability of WPC with $3 \%$ alkali treated fibers

Figure 4-9 First transition temperature of WPCs

\subsubsection{Mechanical properties test}

In this research, three types of mechanical properties were measured: tensile properties, flexural properties, and impact properties.

\subsubsection{Tensile properties test}

A tensile test, also known as a tension test, is probably the most fundamental type of mechanical test. Tensile tests are simple, relatively inexpensive, and fully 
standardized. As one extends the material until it breaks, a complete tensile stress/strain profile is obtained. A curve results which shows how the sample reacted to the forces being applied. The point of failure is of much interest and is typically called the "Ultimate Strength" on the chart.

According to Figure 4-10, alkali treatment improves tensile strength, and the improvement is very significant in the presence of the PP-g-MA coupling agent. Furthermore, this improvement is maintained as the level of coupling agent is increased. In the absence of the coupling agent, the improvement in tensile strength is mainly due to the removal of the relatively weaker non-cellulosic components from the wood flour and only slightly due to the increase in the number of hydroxyl groups on the cellulose surface. In the presence of the coupling agent, though, it is the effect of the increase in hydroxyl groups that dominates since these groups help to improve the bonding between the cellulose and the coupling agent.

The data presented in Figure 4-10 are somewhat anomalous in that the WPC made with $1 \% \mathrm{NaOH}$ treated wood has a higher tensile strength as compared to that made with $3 \% \mathrm{NaOH}$ treated wood. This can, however, be explained. As mentioned earlier, FTIR analysis revealed that treatment with $3 \% \mathrm{NaOH}$ removes much more lignin than with the use of $1 \% \mathrm{NaOH}$. Therefore, a higher tensile strength should be obtained in the former case. However, SEM pictures revealed that $3 \% \mathrm{NaOH}$ not only 
removes hemicellulose and lignin from the wood, it also cleaves and weakens the cellulose. This explains why strength data for $1 \% \mathrm{NaOH}$ lie above similar data for $3 \%$ $\mathrm{NaOH}$. It is noted that WPCs made with pure cellulose exhibited the best tensile strength. This is despite the fact that the pure cellulose employed here is more like hardwood cellulose than softwood cellulose. In general, softwood cellulose is a better reinforcing material due to its higher aspect ratio, and by optimization, treated pine fibers could perform even better than the pure cellulose used here.

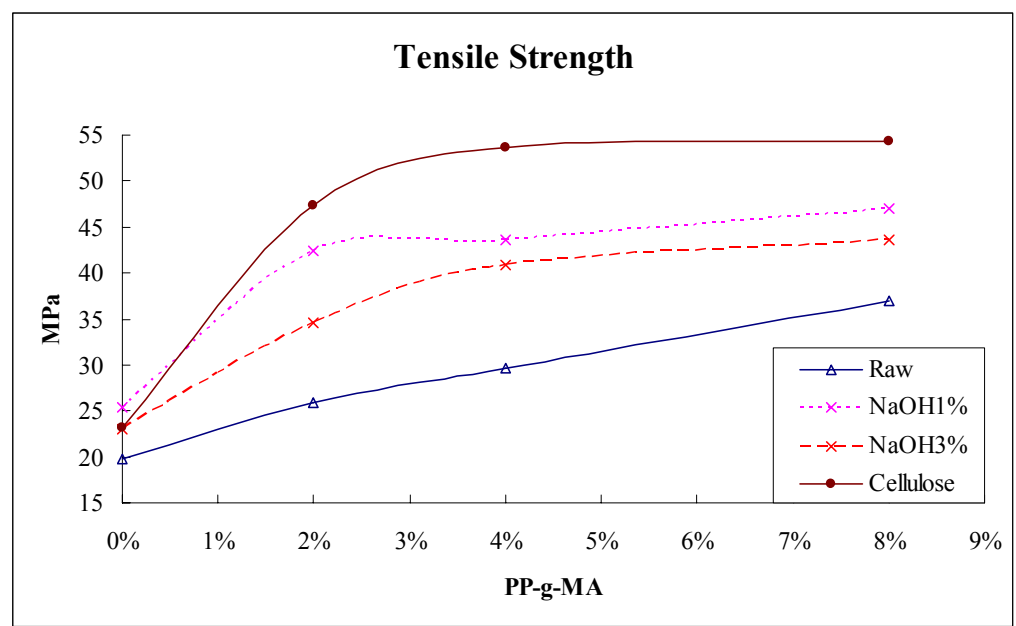

Figure 4-10 Tensile Strength of WPC

The corresponding results for the tensile modulus of WPCs are shown in Fig 4-11. The best tensile modulus is again obtained with the use of pure cellulose, but now there is no anomaly. Fibers treated with $3 \% \mathrm{NaOH}$ perform better than fibers treated with $1 \% \mathrm{NaOH}$. However, the use of a coupling agent is no longer beneficial. This is because modulus, unlike strength, is a small-strain property that does not depend much on fiber-matrix adhesion. The improvement in modulus with alkali 
treatment is undoubtedly due to the removal of the non-cellulosic components from wood fibers, leaving the stiffest component to reinforce the plastic. Thus, compared to the tensile modulus of WPCs made with pristine wood, WPCs containing $1 \%$ and $3 \%$ $\mathrm{NaOH}$-treated wood fibers exhibit a $13 \%$ (from 4.27 to $4.83 \mathrm{GPa}$ ) and $20 \%$ (from 4.27 to $5.13 \mathrm{GPa}$ ) improvement in average tensile modulus respectively.

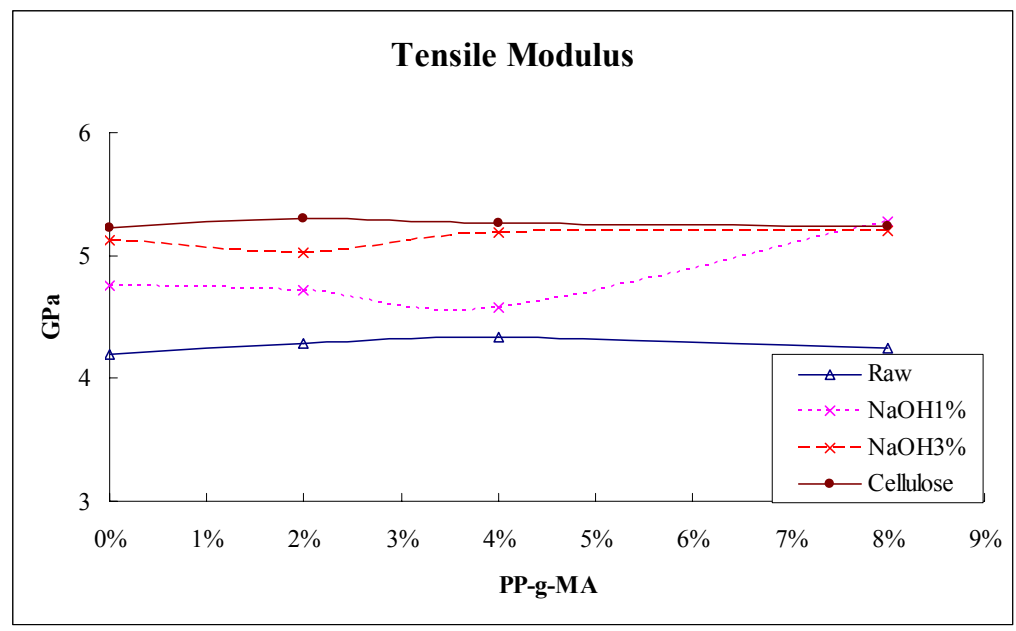

Figure 4-11 Tensile Modulus of WPC

Ultrasound helps the alkali solution to penetrate into the wood flour and provides homogeneous vibrations to each particulate. It, therefore, accelerates the removal of lignin from wood, and it increases the number of hydroxyl groups on the cellulose surface by combining with alkali treatment. Ultrasound also helps to reduce the particle size of the wood. All these effects influence the strength and stiffness of WPCs made from alkali-treated wood.

The results of tensile strength test on WPCs which use ultrasound-assisted alkali-treated fibers are shown in Figure 4-12. A comparison with Figure 4-10 shows 
that use of ultrasound treatment in combination with alkali treatment results in a higher tensile strength for the composites that with the use of alkali treatment alone, and this is true for both alkali treatments. Compared with WPCs made using pristine wood fibers, ultrasound assistance provides an extra $6 \%$ and an extra $8 \%$ improvement in average tensile strength, as compared to composites made with fiber treated with $1 \%$ and $3 \%$ alkali solution alone.

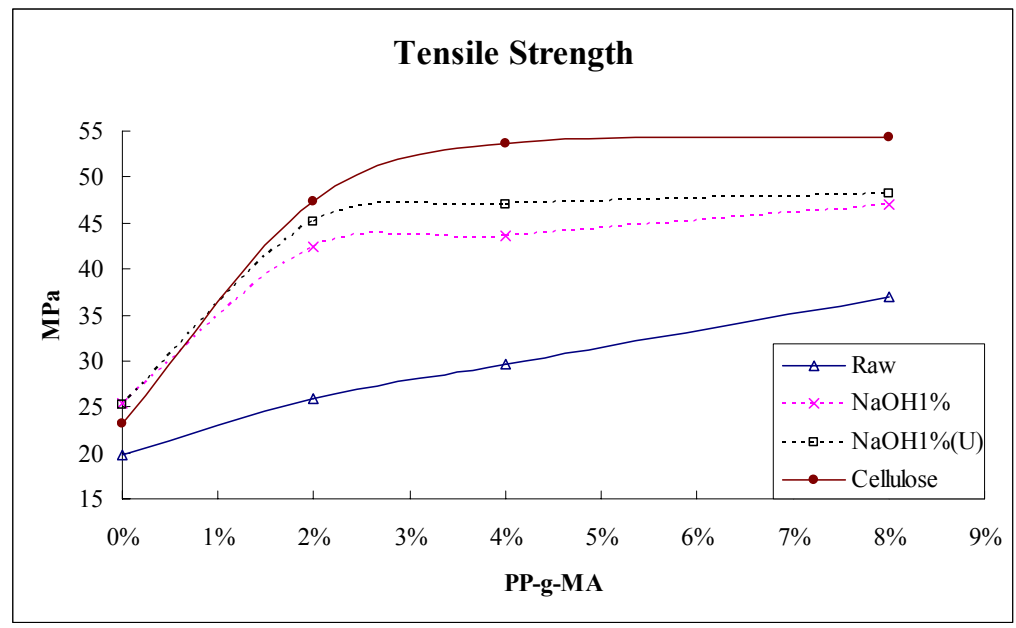

(a) The effect of ultrasound for $1 \%$ alkali treatment

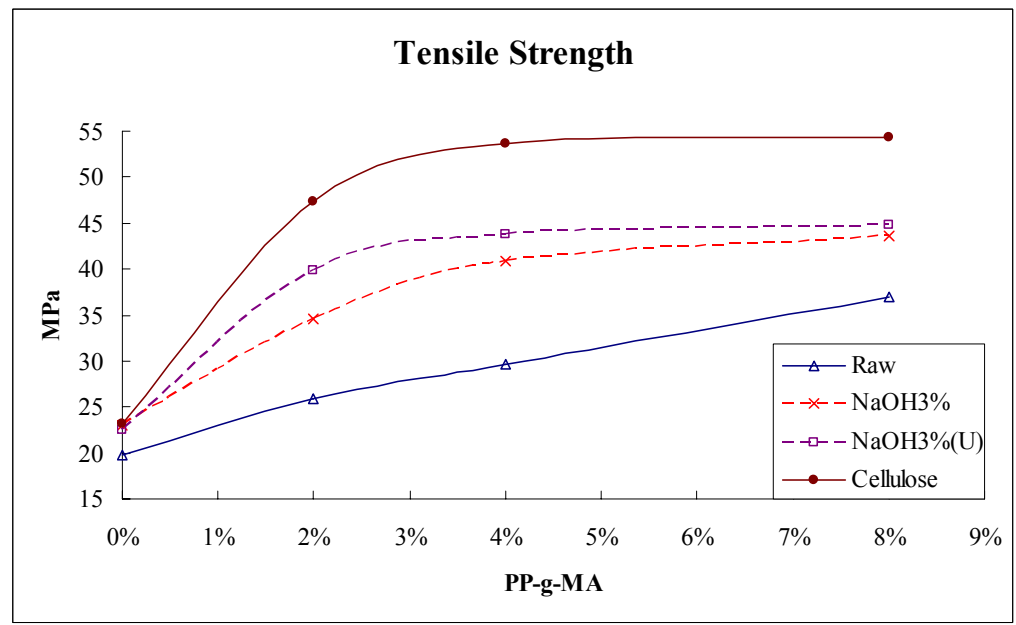

(b) The effect of ultrasound for $3 \%$ alkali treatment

Figure 4-12 Tensile Strength of WPC 
The results of tensile modulus test of WPCs which use ultrasound-assisted alkali-treated fibers are shown in Figure 4-13. In combination with 1\% alkali solution, ultrasound assistance gives an extra $10 \%$ (from $4.83 \mathrm{GPa}$ to $5.26 \mathrm{GPa}$ ) improvement in tensile modulus on average, and this makes the tensile modulus of the WPC almost as high as that of the WPC made with pure cellulose (5.26 GPa). When wood is treated with $3 \%$ alkali solution in combination with ultrasound, the results are even better. The gain in modulus is $13 \%$ (from $5.13 \mathrm{GPa}$ to $5.69 \mathrm{GPa}$ ) on average, and this makes the WPC modulus $10 \%$ higher than the modulus of the WPC made with pure cellulose.

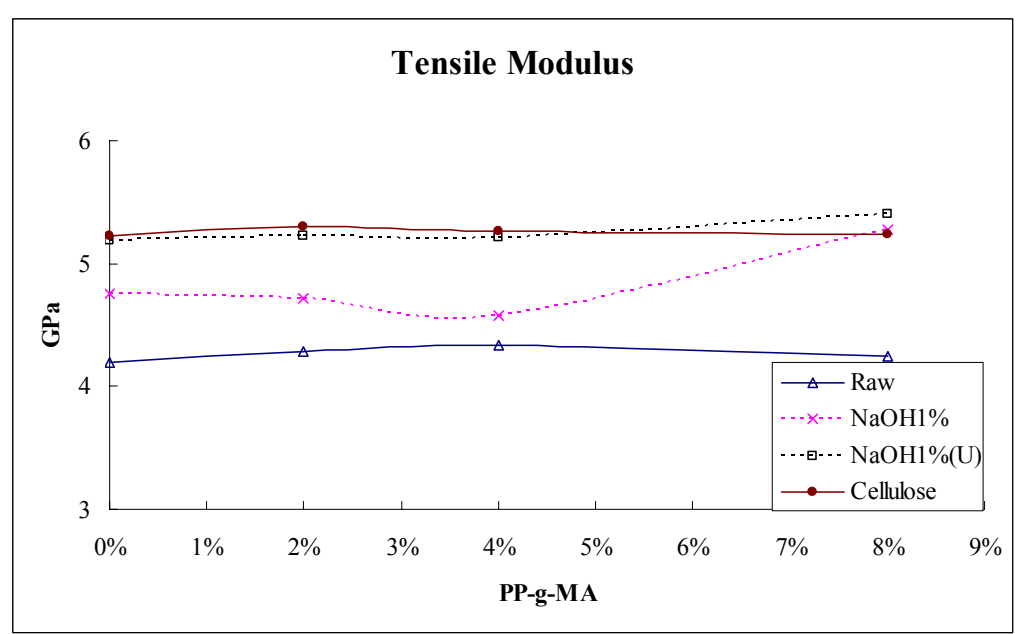

(a) The effect of ultrasound for $1 \%$ alkali treatment 


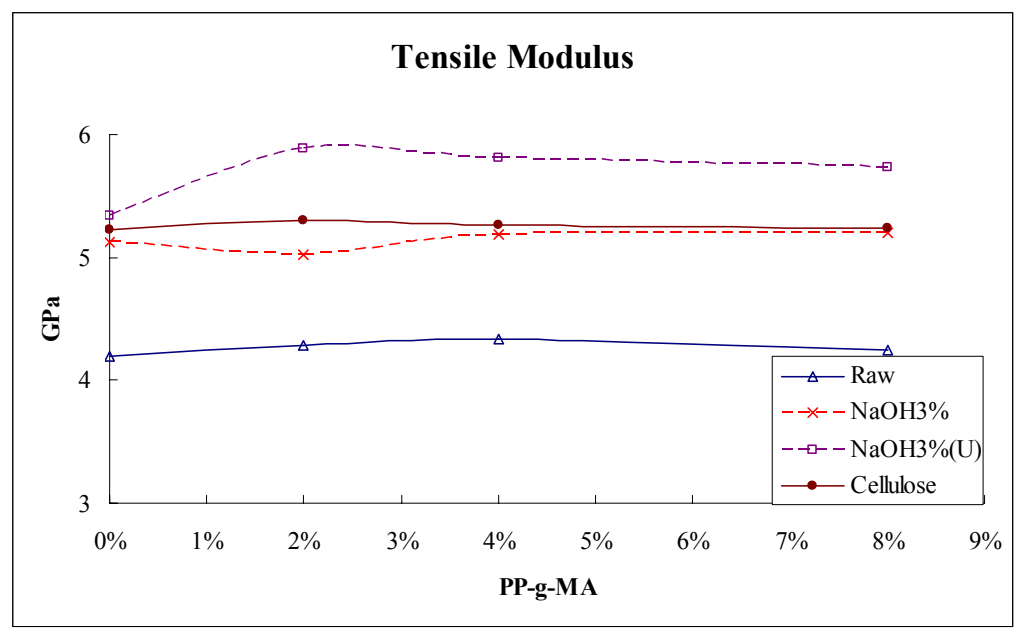

(b) The effect of ultrasound for $3 \%$ alkali treatment

Figure 4-13 Tensile Modulus of WPC

Table 4-2 The results of tensile strength test

\begin{tabular}{|l|c|c|c|c|}
\hline \multicolumn{5}{|c|}{ Tensile Strength Test } \\
\hline & PPGMA0\% & PPGMA2\% & PPGMA4\% & PPGMA8\% \\
\hline RAW & $19.73( \pm 0.08)$ & $25.86( \pm 0.24)$ & $29.62( \pm 0.22)$ & $36.96( \pm 0.13)$ \\
\hline $\mathrm{NaOH} 1 \%$ & $25.40( \pm 0.28)$ & $42.43( \pm 0.04)$ & $43.58( \pm 0.15)$ & $47.08( \pm 0.21)$ \\
\hline $\mathrm{NaOH} 1 \%(\mathrm{U})$ & $25.19( \pm 0.65)$ & $45.11( \pm 0.31)$ & $47.04( \pm 0.29)$ & $48.24( \pm 0.20)$ \\
\hline $\mathrm{NaOH} 3 \%$ & $23.04( \pm 0.33)$ & $34.55( \pm 0.45)$ & $40.81( \pm 0.16)$ & $43.68( \pm 0.58)$ \\
\hline $\mathrm{NaOH} \%(\mathrm{U})$ & $22.51( \pm 0.35)$ & $39.88( \pm 0.21)$ & $43.80( \pm 0.29)$ & $44.76( \pm 0.23)$ \\
\hline Cellulose & $23.19( \pm 0.30)$ & $47.33( \pm 0.32)$ & $53.57( \pm 0.32)$ & $54.38( \pm 0.42)$ \\
\hline
\end{tabular}

Units: MPa

Table 4-3 The results of tensile modulus test

\begin{tabular}{|l|c|c|c|c|}
\hline \multicolumn{5}{|c|}{ Tensile Modulus Test } \\
\hline & PPGMA0\% & PPGMA2\% & PPGMA4\% & PPGMA8\% \\
\hline $\mathrm{RAW}$ & $4.19( \pm 0.08)$ & $4.29( \pm 0.13)$ & $4.34( \pm 0.10)$ & $4.25( \pm 0.10)$ \\
\hline $\mathrm{NaOH} 1 \%$ & $4.75( \pm 0.07)$ & $4.72( \pm 0.07)$ & $4.57( \pm 0.11)$ & $5.27( \pm 0.19)$ \\
\hline $\mathrm{NaOH} 1 \%(\mathrm{U})$ & $5.19( \pm 0.21)$ & $5.22( \pm 0.07)$ & $5.21( \pm 0.03)$ & $5.40( \pm 0.11)$ \\
\hline $\mathrm{NaOH} \% \%$ & $5.12( \pm 0.13)$ & $5.02( \pm 0.07)$ & $5.19( \pm 0.13)$ & $5.20( \pm 0.11)$ \\
\hline $\mathrm{NaOH} \%(\mathrm{U})$ & $5.34( \pm 0.11)$ & $5.88( \pm 0.08)$ & $5.81( \pm 0.10)$ & $5.73( \pm 0.11)$ \\
\hline Cellulose & $5.23( \pm 0.14)$ & $5.30( \pm 0.10)$ & $5.26( \pm 0.08)$ & $5.24( \pm 0.12)$ \\
\hline
\end{tabular}

Units: GPa 


\subsubsection{Flexural properties test}

The flexural test measures behavior of materials subjected to simple beam loading. It is also called a transverse beam test with some materials. Flexural testing is often done on relatively flexible materials such as polymers, wood and composites. There are two test types; 3-point flex and 4-point flex. In a 3-point test, the area of uniform stress is quite small and concentrated under the center loading point. In a 4-point test, the area of uniform stress exists between the inner span loading points. The flexural properties of WPCs were measured by a 3-point test in this work.

The flexural strength results of the different WPCs mirror the tensile strength results and are shown in Figure 4-14. The composite flexural strength decreases in the order: pure cellulose, $1 \%$ alkali treated fibers, 3\% alkali treated fibers, and pristine fibers. In the absence of the coupling agent, $1 \%$ and $3 \%$ alkali-treated fibers give $27.6 \%$ (from $34.16 \mathrm{MPa}$ to $43.58 \mathrm{MPa}$ ) and $17.2 \%$ (from $34.16 \mathrm{MPa}$ to 40.02 $\mathrm{MPa}$ ) improvement in WPC flexural strength respectively. With 2\% coupling agent added, wood flour treated with $1 \%$ alkali solution results in an increase of $59.2 \%$ (from $43.27 \mathrm{MPa}$ to $68.88 \mathrm{MPa}$ ) in the flexural strength of the WPC. The corresponding increase with the use of $3 \%$ alkali is $29.2 \%$ (from $43.27 \mathrm{MPa}$ to 55.89 $\mathrm{MPa}$ ). The reasons for this behavior are the same as those mentioned earlier in the case of tensile strength. 


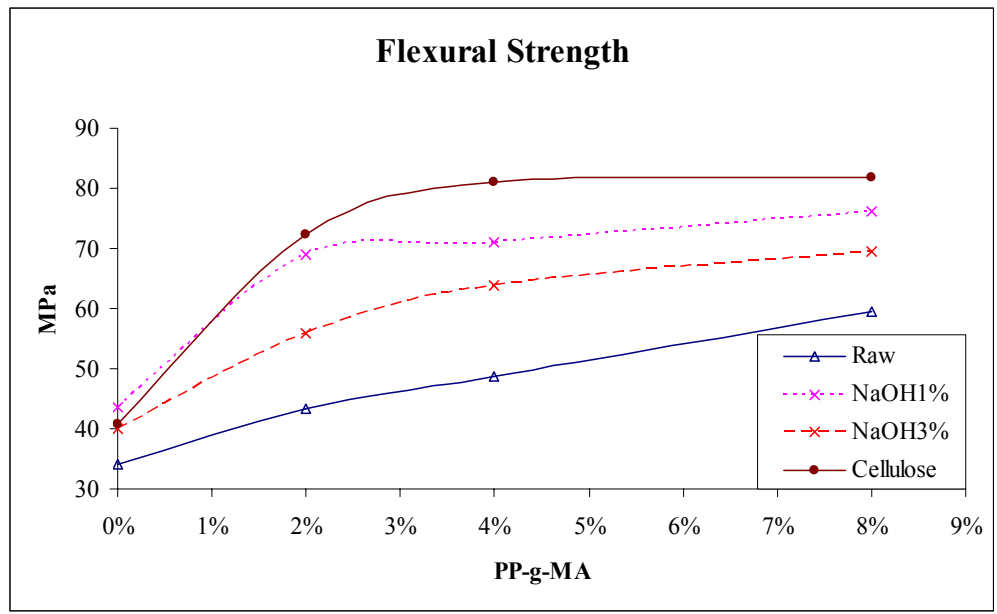

Figure 4-14 Flexural Strength of WPC

The results of flexural modulus testing of the different WPCs are shown in Figure 4-15. As in the case of the tensile modulus, the presence of the coupling agent does not affect WPC flexural modulus. The modulus, however, does change with changes in alkali treatment. As compared to the flexural modulus of WPCs made with pristine fibers, $1 \%$ alkali treatment of wood increases the modulus by $13.9 \%$ (from $3.23 \mathrm{GPa}$ to $3.68 \mathrm{GPa}$ ) to on average, and $3 \%$ alkali treatment increases the modulus by $22.3 \%$ (from $3.23 \mathrm{GPa}$ to $3.95 \mathrm{GPa}$ ). In the latter situation, the flexural modulus is just as high as that obtained with the use of pure cellulose. 


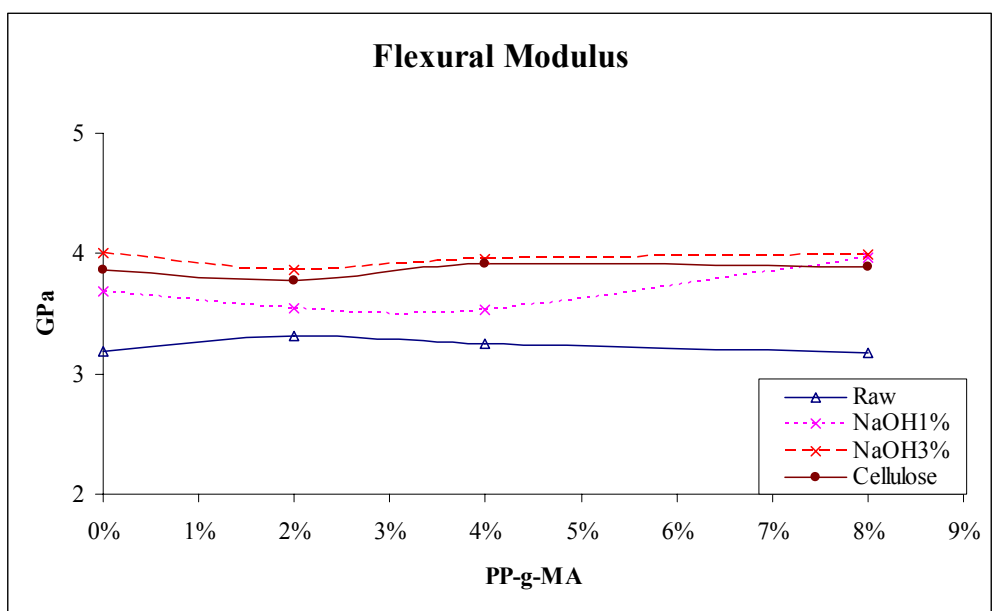

Figure 4-15 The effect of alkali treatment on flexural modulus of WPC

The results of flexural testing of WPC made with wood subjected to both alkali treatment and ultrasound are shown in Figures 4-16 and 4-17. The use of ultrasound improves the flexural strength when combined with either $1 \%$ or $3 \%$ alkali treatment. When compared with the WPC made with pristine fibers, the use of ultrasound treatment gained an extra 3\% improvement in flexural strength when combined with $1 \%$ alkali treatment, and gained an extra $9 \%$ improvement when combined with $3 \%$ alkali treatment.

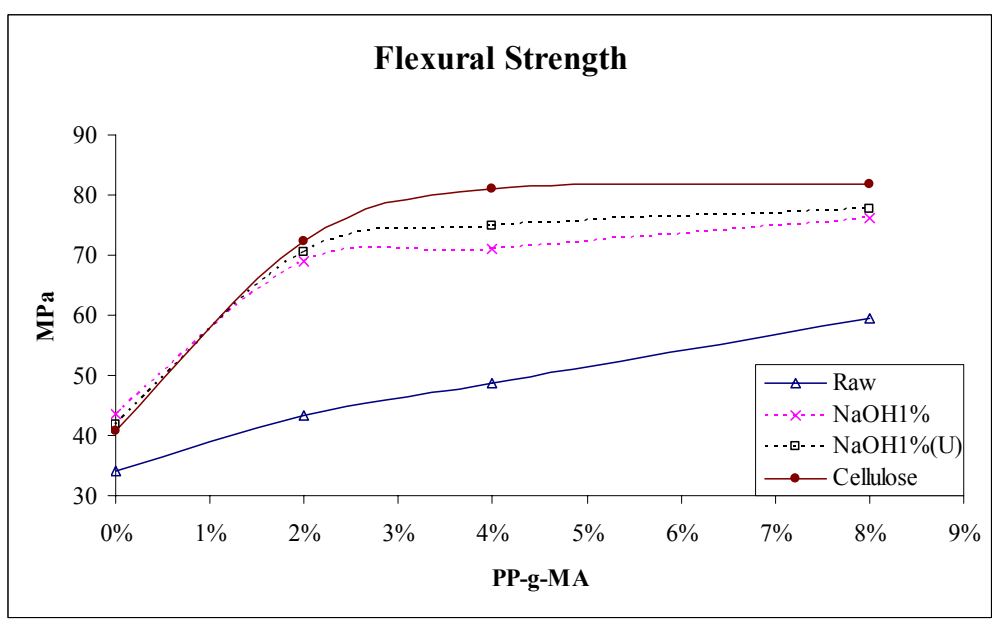

(a) The effect of ultrasound for $1 \%$ alkali treatment on flexural strength 


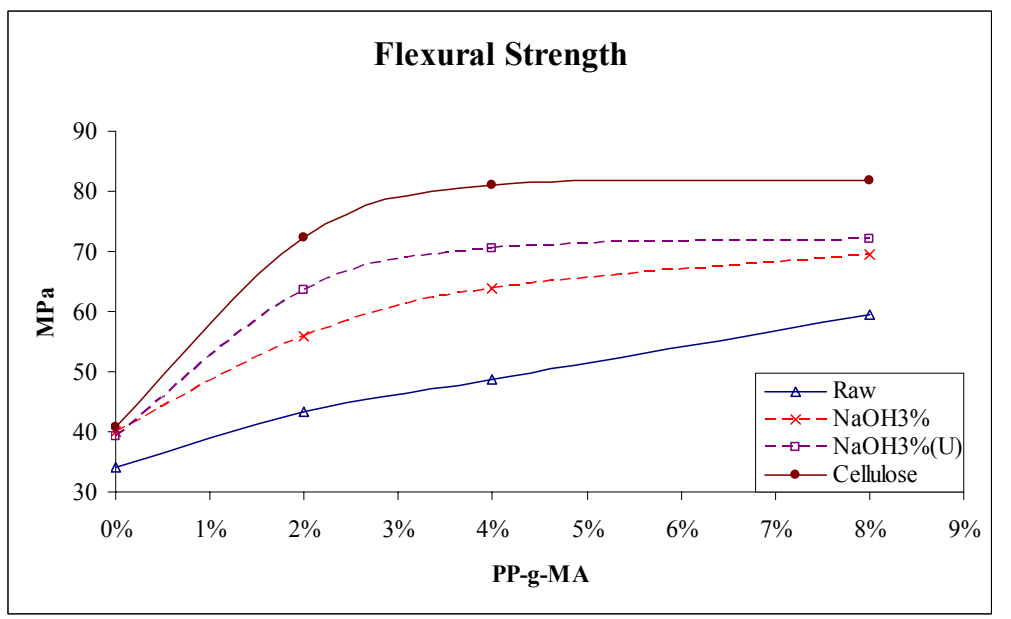

(b) The effect of ultrasound for $3 \%$ alkali treatment on flexural strength

Figure 4-16 Flexural Strength of WPC

Similarly, with $1 \%$ alkali treatment, ultrasound assistance increased the flexural modulus from $13.9 \%$ (from $3.23 \mathrm{GPa}$ to $3.68 \mathrm{GPa}$ ) to $28.1 \%$ (from $3.23 \mathrm{GPa}$ to 4.14 GPa) on average. When the wood was treated with $3 \%$ alkali solution along with ultrasound, the flexural modulus was enhanced from $22.3 \%$ (from $3.23 \mathrm{GPa}$ to 3.95 $\mathrm{GPa}$ ) to $34.7 \%$ (from $3.23 \mathrm{GPa}$ to $4.36 \mathrm{GPa}$ ) on average.

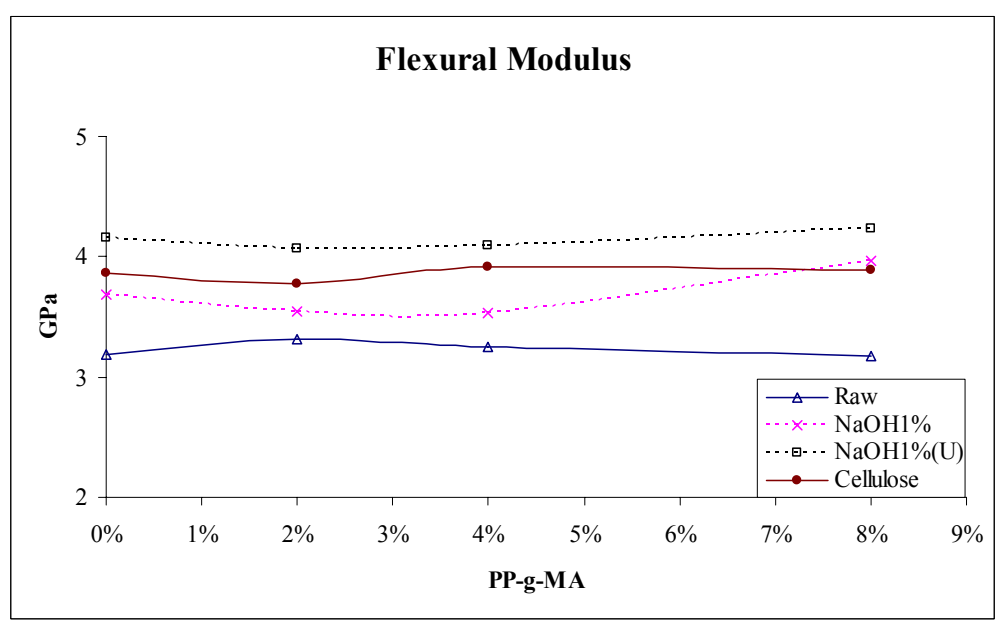

(a) The effect of ultrasound for $1 \%$ alkali treatment 


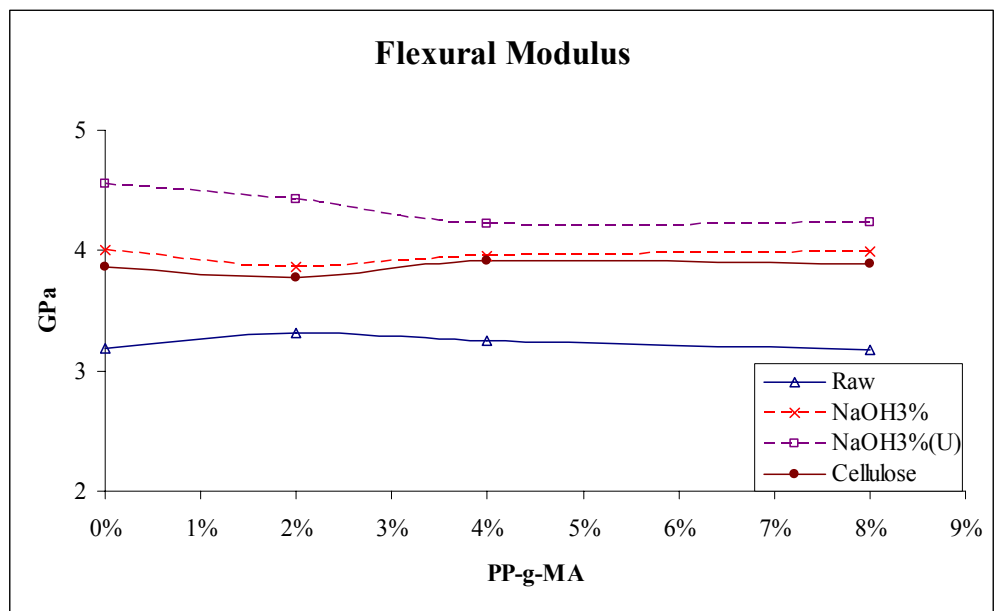

(b) The effect of ultrasound for $3 \%$ alkali treatment

Figure 4-17 Flexural Modulus of WPC

Table 4-4 The results of flexural strength test

\begin{tabular}{|l|c|c|c|c|}
\hline \multicolumn{5}{|c|}{ Flexural Strength Test } \\
\hline & PPGMA0\% & PPGMA2\% & PPGMA4\% & PPGMA8\% \\
\hline $\mathrm{RAW}$ & $34.16( \pm 0.42)$ & $43.27( \pm 0.29)$ & $48.73( \pm 0.10)$ & $59.49( \pm 0.32)$ \\
\hline $\mathrm{NaOH} 1 \%$ & $43.58( \pm 0.31)$ & $68.88( \pm 0.50)$ & $71.04( \pm 0.25)$ & $76.22( \pm 0.73)$ \\
\hline $\mathrm{NaOH} 1 \%(\mathrm{U})$ & $41.86( \pm 1.22)$ & $70.58( \pm 1.38)$ & $74.89( \pm 1.26)$ & $77.79( \pm 0.42)$ \\
\hline $\mathrm{NaOH} 3 \%$ & $40.02( \pm 0.30)$ & $55.89( \pm 0.81)$ & $63.80( \pm 0.55)$ & $69.49( \pm 0.89)$ \\
\hline $\mathrm{NaOH} 3 \%(\mathrm{U})$ & $39.24( \pm 0.13)$ & $63.64( \pm 0.85)$ & $70.54( \pm 0.80)$ & $72.08( \pm 0.63)$ \\
\hline Cellulose & $40.82( \pm 0.58)$ & $72.31( \pm 0.71)$ & $81.01( \pm 0.30)$ & $81.87( \pm 0.33)$ \\
\hline
\end{tabular}

Units: MPa

Table 4-5 The results of flexural modulus test

\begin{tabular}{|l|c|c|c|c|}
\hline \multicolumn{5}{|c|}{ Flexural Modulus Test } \\
\hline & PPGMA0\% & PPGMA2\% & PPGMA4\% & PPGMA8\% \\
\hline $\mathrm{RAW}$ & $3.19( \pm 0.05)$ & $3.31( \pm 0.00)$ & $3.25( \pm 0.03)$ & $3.18( \pm 0.01)$ \\
\hline $\mathrm{NaOH} 1 \%$ & $3.69( \pm 0.03)$ & $3.55( \pm 0.04)$ & $3.53( \pm 0.03)$ & $3.96( \pm 0.06)$ \\
\hline $\mathrm{NaOH} 1 \%(\mathrm{U})$ & $4.16( \pm 0.03)$ & $4.07( \pm 0.05)$ & $4.09( \pm 0.05)$ & $4.24( \pm 0.02)$ \\
\hline $\mathrm{NaOH} 3 \%$ & $4.00( \pm 0.03)$ & $3.87( \pm 0.04)$ & $3.95( \pm 0.04)$ & $3.99( \pm 0.02)$ \\
\hline $\mathrm{NaOH} \%(\mathrm{U})$ & $4.55( \pm 0.07)$ & $4.42( \pm 0.00)$ & $4.22( \pm 0.04)$ & $4.23( \pm 0.04)$ \\
\hline Cellulose & $3.87( \pm 0.03)$ & $3.78( \pm 0.11)$ & $3.91( \pm 0.05)$ & $3.89( \pm 0.07)$ \\
\hline
\end{tabular}

Units: GPa 


\subsubsection{Impact properties test}

An impact test examing an object's ability to resist high-rate loading. It is a test for determining the energy absorbed in fracturing a test piece at high velocity. Impact resistance is one of the most important properties for a part designer to consider, and without question, it is the most difficult to quantify. The impact resistance of a part is, in many applications, a critical measure of service life. More importantly these days, it involves the perplexing problem of product safety and liability. The IZOD impact test was used in this work, and the specimens were prepared as reversed notched specimens.

The results of impact testing of the different WPCs are shown in Figure 4-18. The impact strength is highest of the WPC made with pure cellulose, and then it decreases in the order: $1 \%$ alkali treated fibers, $3 \%$ alkali treated fibers, and pristine fibers. These results are consistent with those of tensile and flexural strength tests. Without the use of the coupling agent, the difference in impact strength values among the various WPCs is not significant. This, though, changes with the addition of the coupling agent. While $2 \%$ PP-g-MA is present in the WPC, the fibers treated with $1 \%$ alkali solution increase the impact strength of the composite by $82.1 \%$ (from $75.47 \mathrm{~J} / \mathrm{m}$ to $137.42 \mathrm{~J} / \mathrm{m}$ ), but treatment with $3 \%$ alkali solution only increases the impact strength by $16.0 \%$ (from $75.47 \mathrm{~J} / \mathrm{m}$ to $87.58 \mathrm{~J} / \mathrm{m}$ ). It seems that 
the degradation of cellulose caused by the $3 \%$ alkali treatment results in a more severe reduction in impact strength than is the case with tensile and flexural strength.

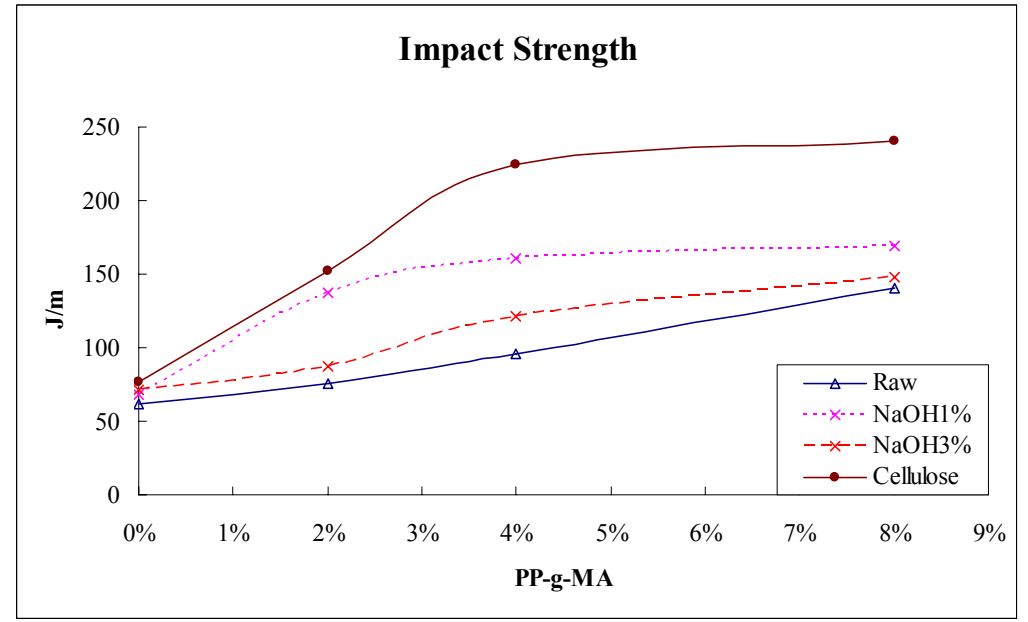

Figure 4-18 Impact Strength of WPC

Impact strength results for WPCs which use alkali treated fibers along with ultrasound are shown in Figure 4-19. For the 1\% alkali solution, the impact strength of WPCs shows an extra $31.0 \%$ improvement on average due to ultrasound assistance. Even for wood treated with $3 \%$ alkali solution, the assistance of ultrasound provides an extra $7.6 \%$ improvement on average.

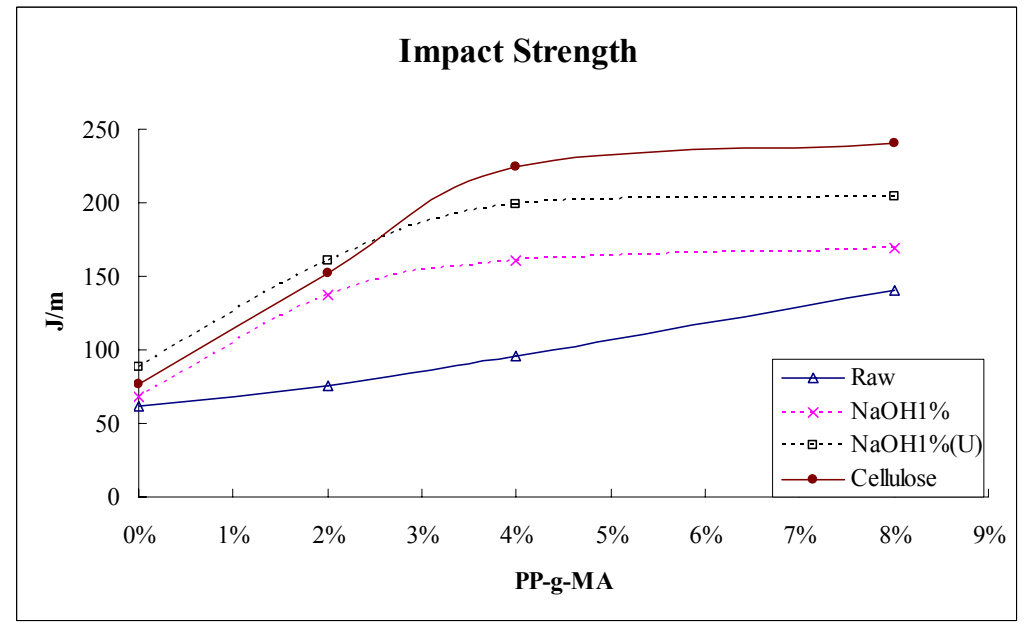


(a) The effect of ultrasound for $1 \%$ alkali treatment

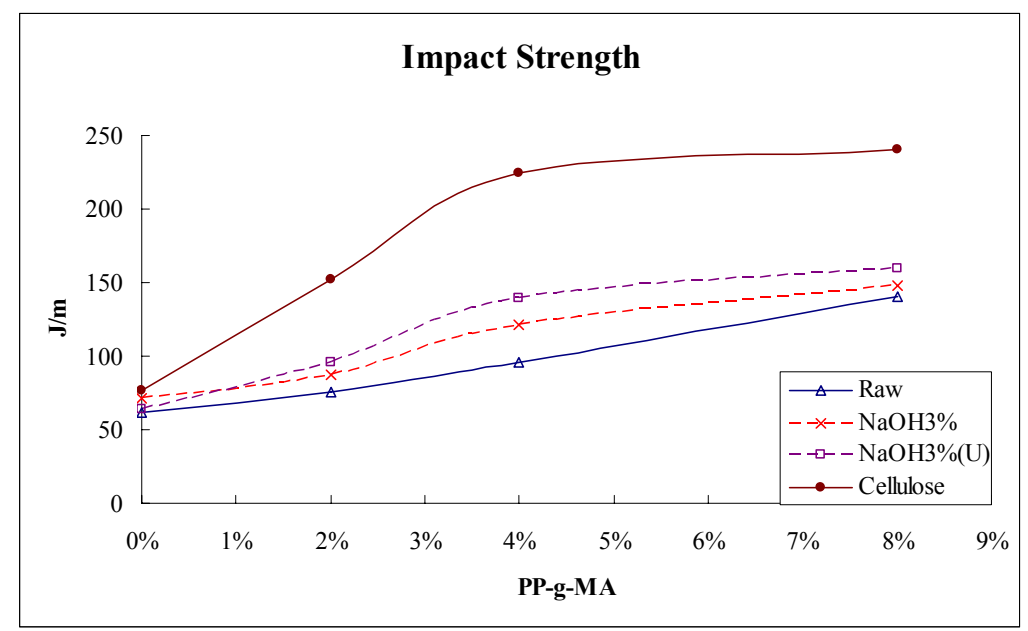

(b) The effect of ultrasound for $3 \%$ alkali treatment

Figure 4-19 Impact Strength of WPC

Table 4-6 The results of impact strength test

\begin{tabular}{|l|c|c|c|c|}
\hline \multicolumn{5}{|c|}{ Impact Strength Test } \\
\hline & PPGMA0\% & PPGMA2\% & PPGMA4\% & PPGMA8\% \\
\hline $\mathrm{RAW}$ & $61.94( \pm 5.89)$ & $75.47( \pm 11.03)$ & $96.12( \pm 3.57)$ & $140.26( \pm 4.20)$ \\
\hline $\mathrm{NaOH} 1 \%$ & $68.35( \pm 3.82)$ & $137.42( \pm 13.62)$ & $160.20( \pm 9.65)$ & $169.46( \pm 17.44)$ \\
\hline $\mathrm{NaOH} 1 \%(\mathrm{U})$ & $88.29( \pm 5.84)$ & $160.20( \pm 7.02)$ & $198.65( \pm 20.17)$ & $204.34( \pm 16.96)$ \\
\hline $\mathrm{NaOH} 3 \%$ & $71.20( \pm 4.41)$ & $87.58( \pm 13.71)$ & $121.75( \pm 7.52)$ & $148.10( \pm 16.58)$ \\
\hline $\mathrm{NaOH} \%(\mathrm{U})$ & $63.37( \pm 4.99)$ & $95.41( \pm 6.43)$ & $138.84( \pm 10.38)$ & $159.49( \pm 9.23)$ \\
\hline Cellulose & $76.18( \pm 9.90)$ & $151.66( \pm 22.07)$ & $224.99( \pm 22.71)$ & $239.94( \pm 12.21)$ \\
\hline
\end{tabular}

Units: $\mathbf{J} / \mathbf{m}$

4.2.2.4. Summary of mechanical properties tests

WPCs which use alkali treated fibers have a higher strength and a higher modulus. $1 \%$ alkali treatment is found to be better in improving the strength of WPC, especially in impact strength. However, the modulus of WPCs is better improved by treatment with $3 \%$ alkali solution. The strength and modulus of WPCs both benefit 
from the ultrasound assistance, no matter treated with $1 \%$ or $3 \%$ alkali solution. Due to poor compatibility between wood fibers and polymer matrix, the effects of alkali treatment are not so significant in the absence of a coupling agent. The artificial pure cellulose fibers are made from hardwood cellulose. Due to the higher aspect ratio, softwood cellulose should be better in reinforcing polymer and in improving the mechanical properties of composites. This explains why the modified fiber WPCs sometimes have better mechanical properties than pure cellulose fiber WPCs.

\subsubsection{Polarized optical microscope}

Since polypropylene is a crystallizable polymer, composite mechanical properties depend on the extent and nature of crystallinity as well. In particular, if the polymer matrix forms crystals on the reinforcement surface, it usually means that there is good compatibility between the polymer and the reinforcement. This aspect is investigated in Figures 4-20, 21, 22 and 23.

Figure 4-20 is the result of sample 1 (Pristine wood fiber without coupling agent), and it was found that the pristine wood fiber has only has a small number of spherulites generated around the fiber when the temperature reaches $170{ }^{\circ} \mathrm{C}$. Even upon holding the temperature constant for 2 minutes, only a very thin layer of spherulites forms on the fiber surface. Figure 4-21 displays the results for sample 2 (Pristine wood fiber with 2\% PP-g-MA). Now a thin layer of spherulites is formed 
when the temperature reaches $170{ }^{\circ} \mathrm{C}$. Upon holding the temperature at $170{ }^{\circ} \mathrm{C}$ for two minutes, a thick spherulite layer appears around the fiber surface. Comparing these two samples, the WPC with the coupling agent has better crystallizability, and this ability contributes to higher strength of this WPC. In the mechanical properties tests discussed earlier, the flexural and tensile strengths of similar samples were $27 \%$ (from 34.16 to $43.27 \mathrm{MPa}$ ) and $31 \%$ (from 19.73 to $25.86 \mathrm{MPa}$ ) higher than the corresponding values for sample 1 .

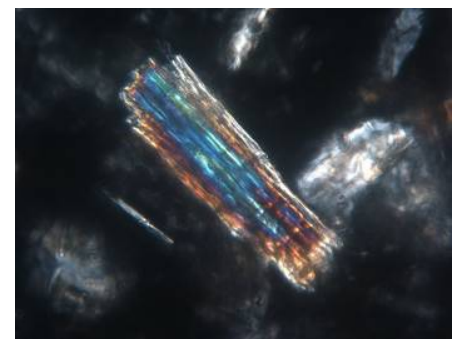

Pic1

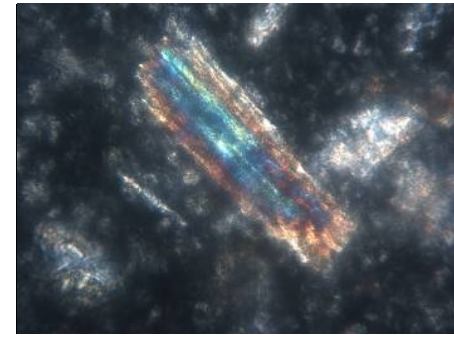

Pic2

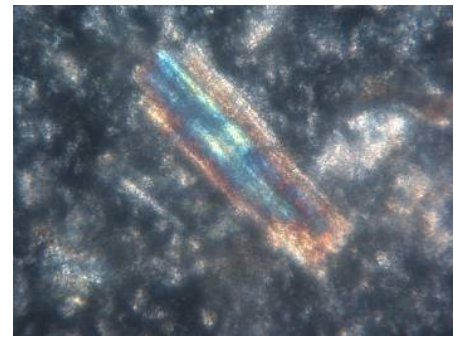

Pic3

Figure 4-20 Pristine wood fiber without coupling agent (Sample 1)

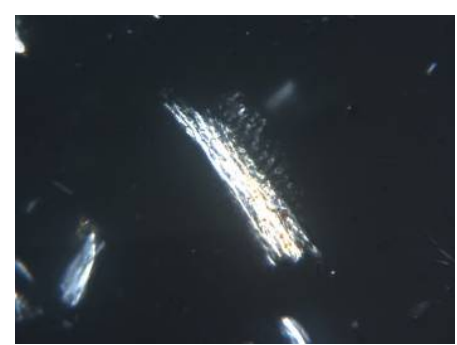

Pic1

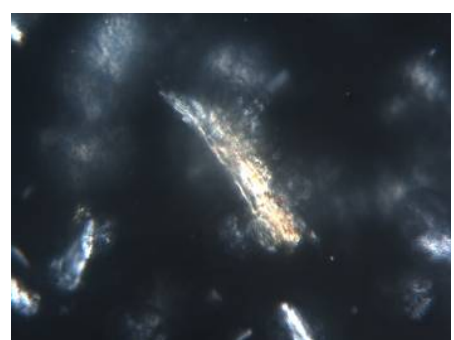

Pic2

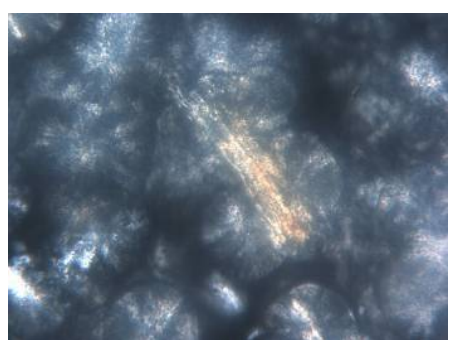

Pic3

Figure 4-21 Pristine wood fiber with 2\% PP-g-MA (Sample 2)

Figure 4-22 shows the crystallization behavior for sample $3(\mathrm{NaOH} 1 \%$ treated wood fiber with 2\% PP-g-MA), and figure 4-23 contains results for sample $4(\mathrm{NaOH}$ $1 \%$ and ultrasound treated wood fiber with $2 \%$ PP-g-MA). From these two sets of 
pictures, one can observe that the wood treated with alkali increases polymer crystallizability on the filler surface. The spherulites around the alkali-treated wood are very uniform and they form a very thick layer. It is obvious that the crystallizability of polypropylene on the alkali-treated fiber is far superior to that on the pristine fiber, but ultrasound effects on polymer crystallizability may not be significant. The results of mechanical property testing appear consistent with these conclusions drawn from the results of polarized optical microscopy. Indeed, in flexural and tensile strength, sample 3 is $59 \%$ (from 43.27 to $68.88 \mathrm{MPa}$ ) and $64 \%$ (from 25.86 to $42.43 \mathrm{MPa}$ ) superior to sample 2, but sample 4 is just $2 \%$ (from 68.88 to $70.58 \mathrm{MPa}$ ) and $6 \%$ (from 42.43 to $45.11 \mathrm{MPa}$ ) better than sample 3 .

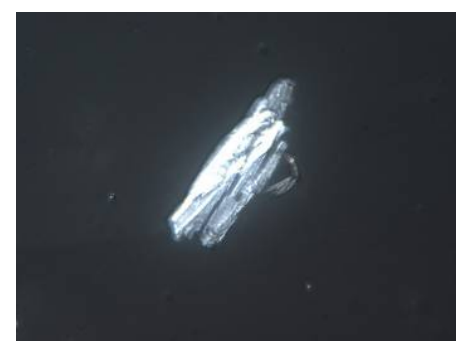

Pic1

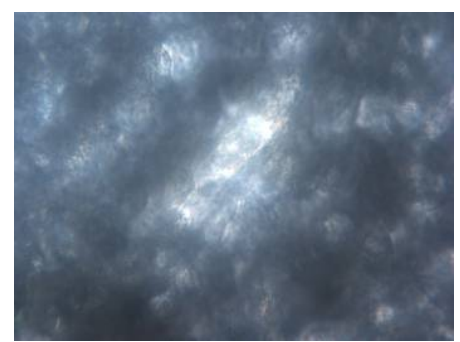

Pic2

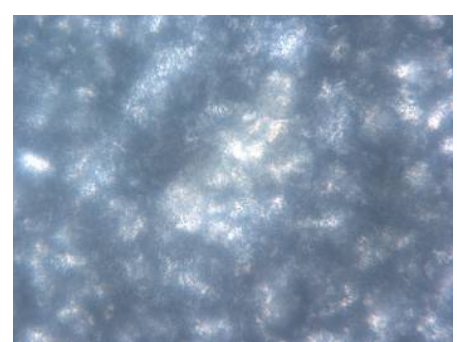

Pic3

Figure 4-22 NaOH 1\% treated wood fiber with 2\% PP-g-MA (Sample 3)

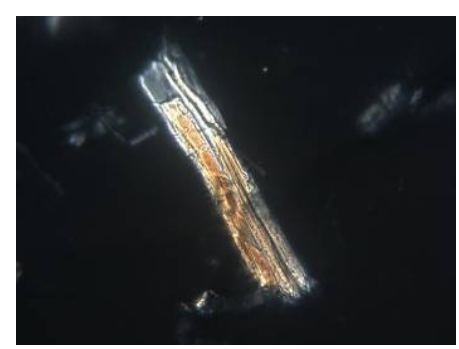

Pic1

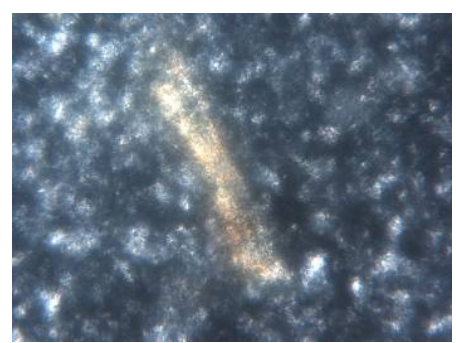

Pic2

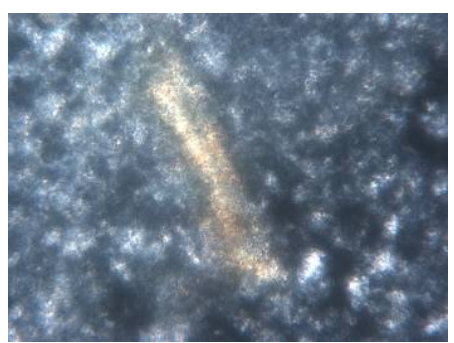

Pic3

Figure 4-23 NaOH 1\% and ultrasound treated wood fiber with 2\% PP-g-MA (Sample 4) 


\subsubsection{Water absorption behavior}

Since the majority of WPCs are used outdoors, their water absorption behavior can be of concern. Among the three main components of wood, cellulose and hemicellulose are more hydrophilic than lignin. Thus, removing hemicellulose should reduce moisture absorption, but removing lignin should increase moisture absorption by WPCs. Actual results of moisture absorption are shown in Figure 4-24. It is seen that, in comparison with the untreated wood, $1 \%$ alkali treatment reduces the maximum moisture absorption from $13.86 \%$ to $12.26 \%$ of the composite when PP-g-MA is not used. The 3\% alkali treatment does not do as well since it not only removes hemicellulose from the wood fiber, it also removes lignin. None the less, wood treated with $3 \%$ alkali still reduces the maximum absorption from $13.86 \%$ to $12.91 \%$ when compared to no treatment.

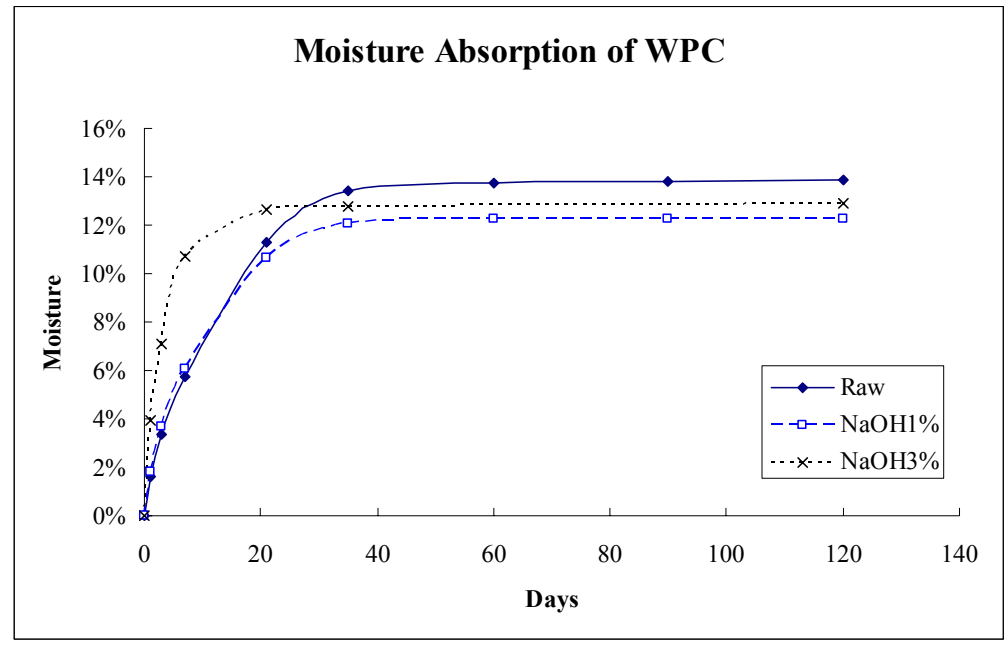

Figure 4-24 Moisture absorption of WPC (no coupling agent) 
As seen earlier, combining ultrasonic and alkali treatment is more effective in reducing the particle size of wood particulates. For the same amount of material, therefore, the surface area that is exposed increases as the particle size is reduced. In wood plastic composites, the smaller wood particulates, which have a higher specific surface area, should allow for more water absorption. Further, ultrasonic treatment promotes the elimination of lignin, and since lignin is the relatively hydrophobic component of wood, the use of alkali treatment in combination with ultrasound is likely to make the wood more hydrophilic. This is exactly what is observed. Data plotted in Figures 4-25(a) and 4-25(b) show that ultrasonic treatment increases both the rate of moisture absorption and the maximum amount of moisture absorbed. When treated with $1 \%$ alkali solution, the WPC which used ultrasound-treated fibers absorbed $45 \%$ more moisture in one week, and the maximum amount absorbed was $16 \%$ higher than for the samples without ultrasound treatment. When treated with $3 \%$ alkali solution, the use of ultrasound increased by $19 \%$ the moisture absorbed during the first week and increased the maximum amount of water absorbed by $8 \%$. 


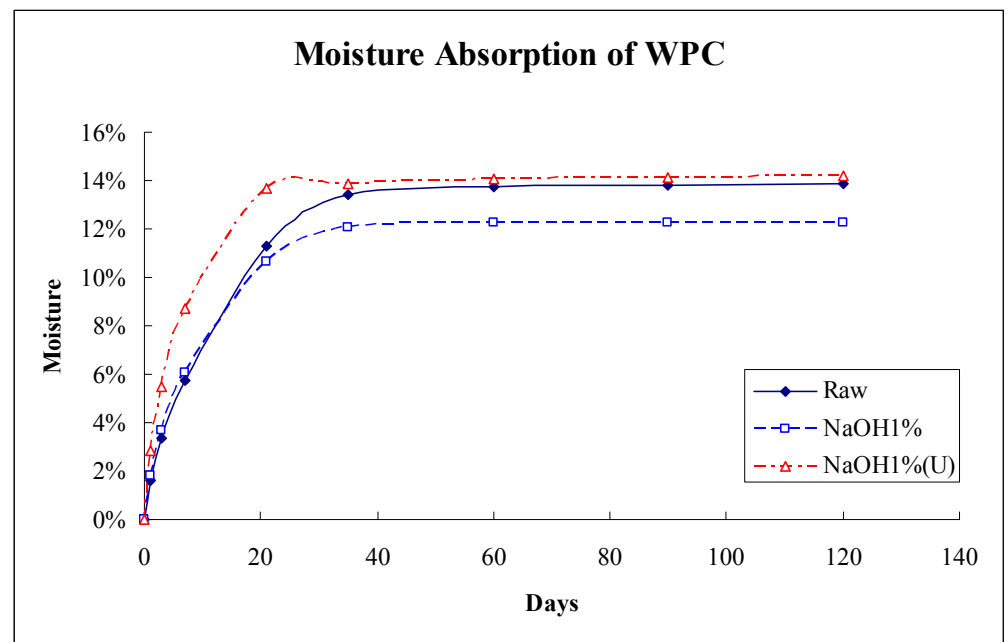

(a) $1 \%$ alkali treatment with ultrasound assistance

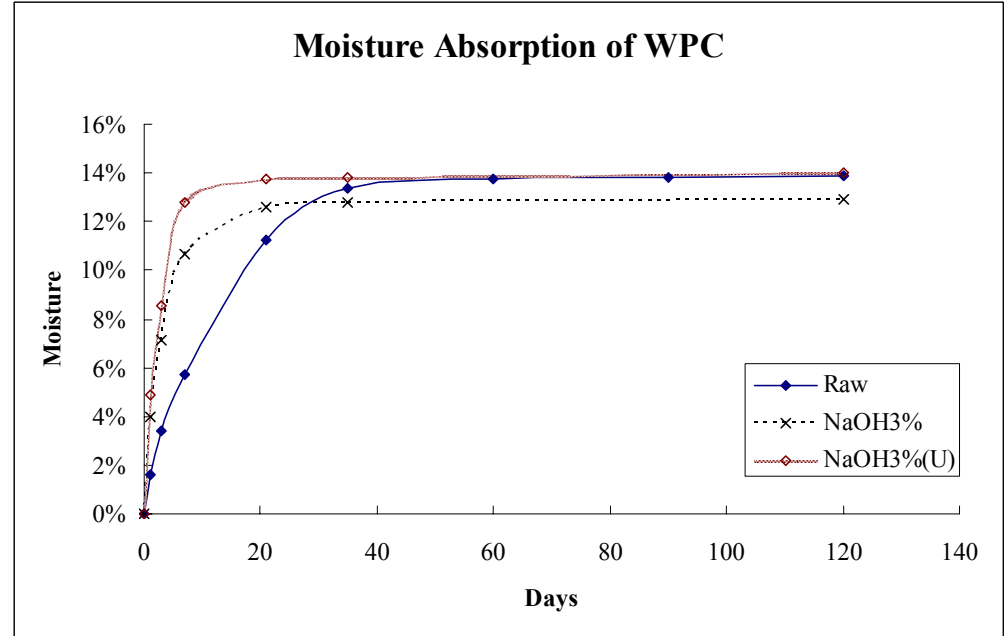

(b) $3 \%$ alkali treatment with ultrasound assistance

Figure 4-25 Moisture absorption of WPC (no coupling agent)

Finally, Figure 4-26 shows the influence of the coupling agent in the WPC. Recall that PP-g-MA forms covalent bonds with the wood surface and is itself compatible with the polymer matrix. Its presence, therefore, acts to limit the swelling of WPC. The ability or inability of the WPC to swell controls the rate of moisture absorption. This is made clear by the moisture absorption data displayed in Figure 4-26. Thus, in the case of WPC made using pristine fibers (Fig 4-26(a)) the composite absorbed 5.72 
$\mathrm{wt} \%$ moisture in 1 week when no coupling agent was used. With a coupling agent content of $8 \%$, however, the composite absorbed only $2.20 \mathrm{wt} \%$ moisture in 1 week. The rate of moisture absorption was, therefore, reduced by almost $60 \%$ by the presence of the coupling agent. The WPC which used 3\% alkali-treated fibers (Fig 4-26(d)) absorbed $10.68 \mathrm{wt} \%$ moisture in 1 week when there was no coupling agent in WPC, but only $7.46 \mathrm{wt} \%$ moisture could be absorbed in the same time period when there was $8 \%$ coupling agent present.

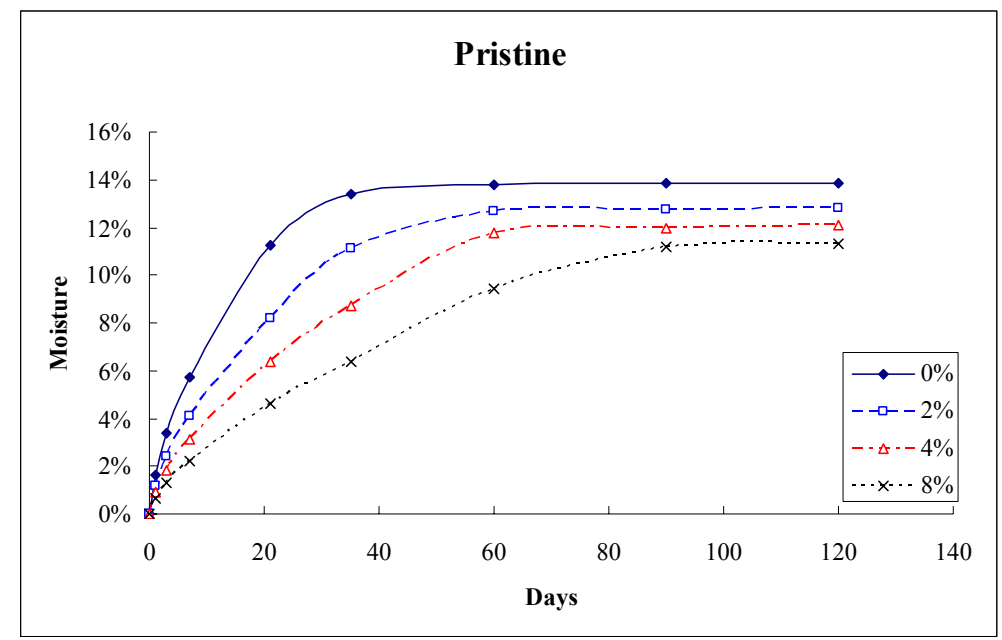

(a) Pristine fiber WPC

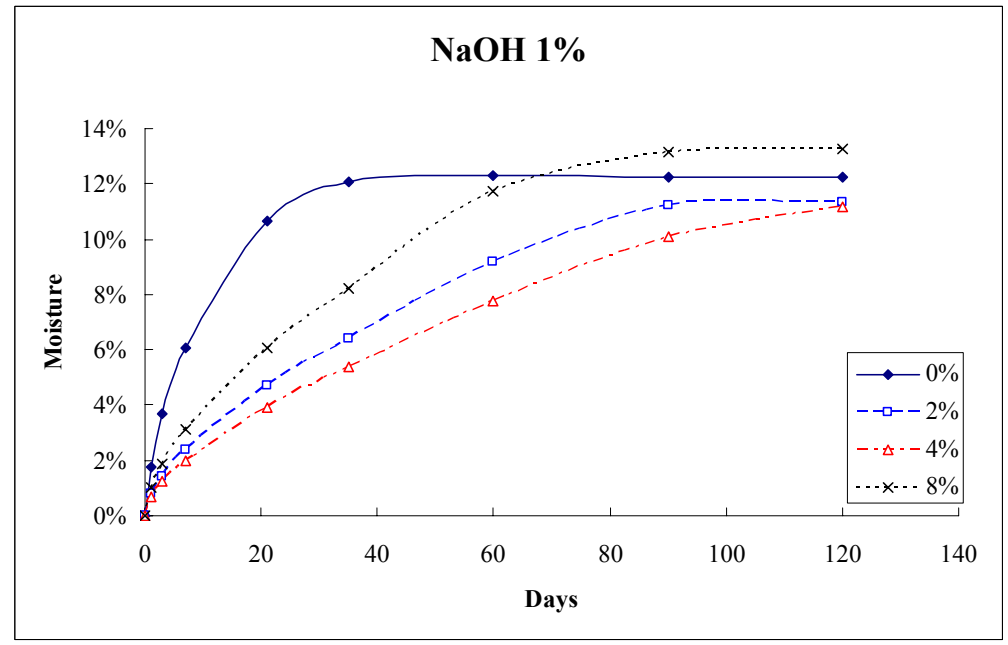

(b) $1 \%$ alkali treated fiber WPC 


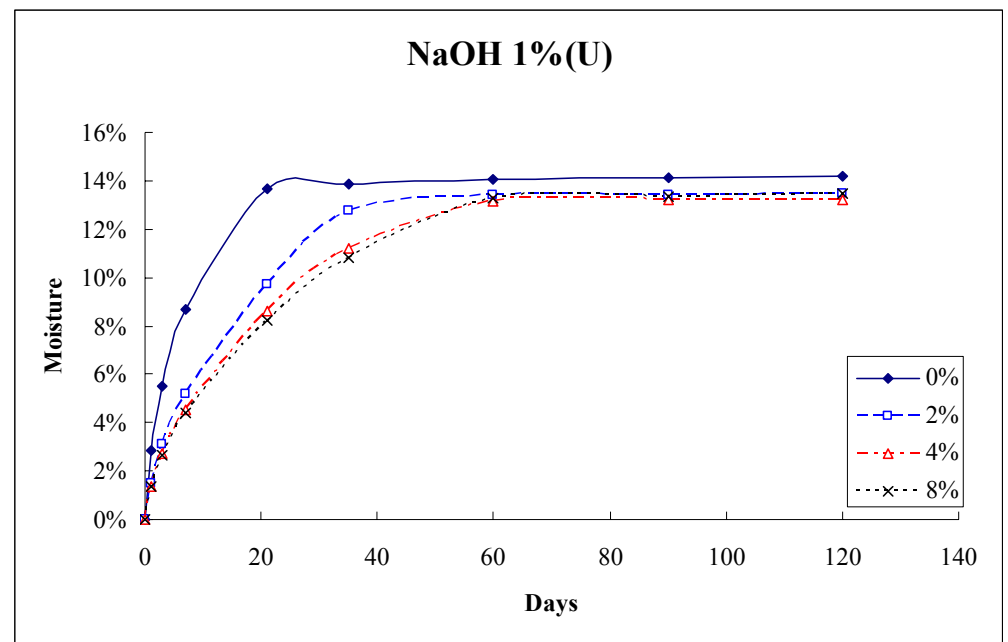

(c) $1 \%$ alkali and ultrasonic treated fiber WPC

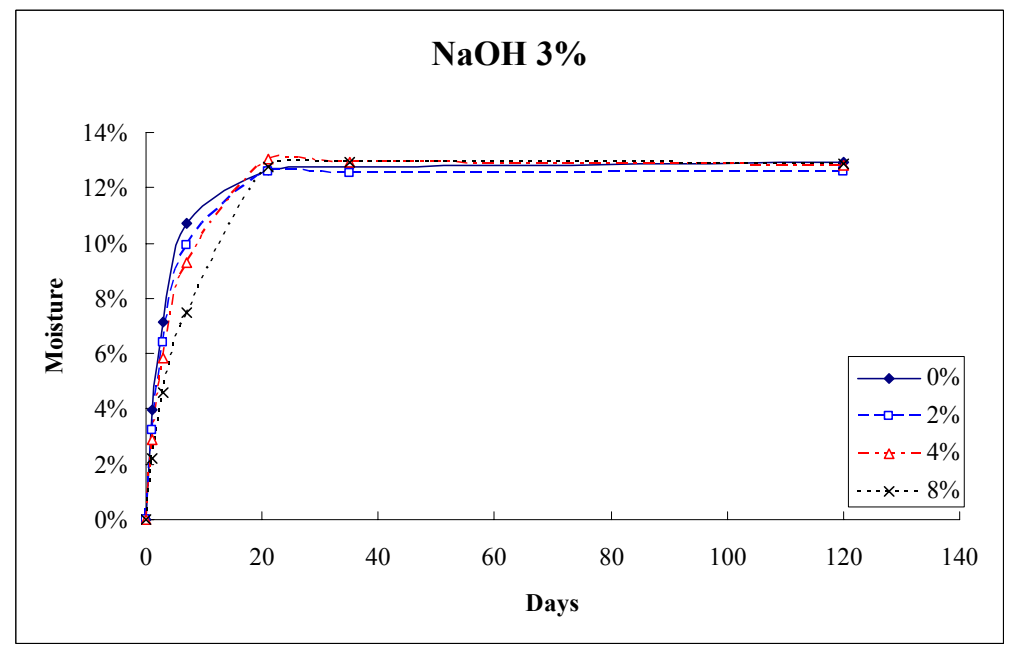

(d) $3 \%$ alkali treated fiber WPC

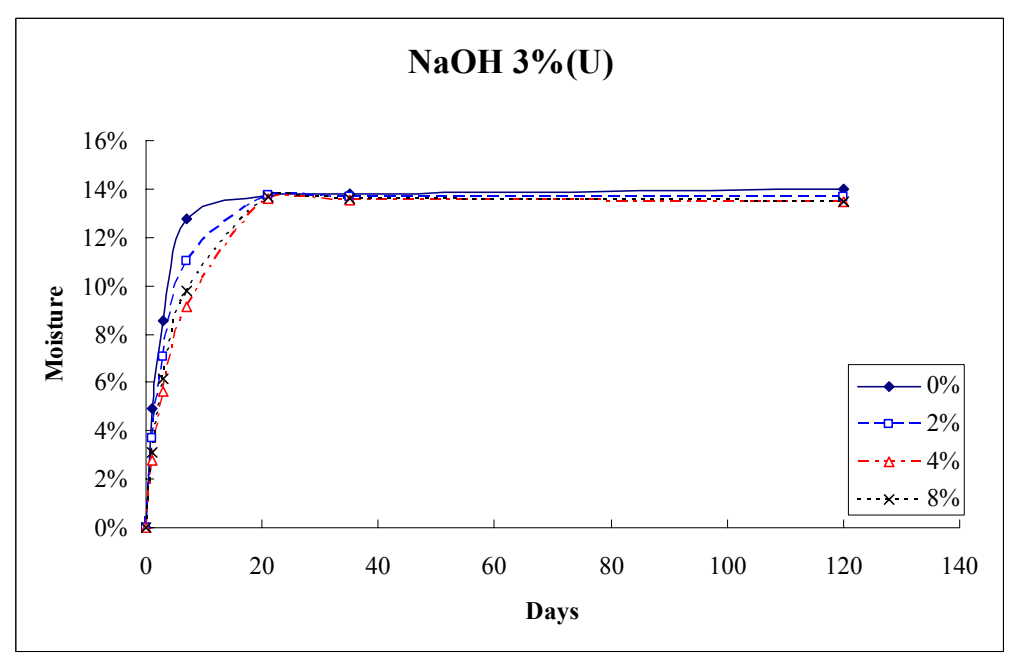

(e) $3 \%$ alkali and ultrasonic treated fiber WPC

Figure 4-26 Moisture absorption of WPCs 
Figures 4-26(a) - 4-26(e) reveal that the coupling agent helps to reduce the maximum amount of moisture absorption when pristine fibers are used. After treating the fibers with the alkali solution, however, the coupling agent seems to lose its effectiveness as far as its ability to control the equilibrium moisture content is concerned. The most likely reason for this behavior is the possible change in the nature of bonding between the coupling agent and wood fibers. As mentioned earlier, the coupling agent can bond with wood in two possible ways: covalent bonding and hydrogen bonding (see Figure 4-27). Since covalent bonding is much stronger than hydrogen bonding, the mechanical properties of the WPC will be excellent if the bonding between wood fibers and the coupling agent is entirely covalent in nature. The benefits of hydrogen bonding are that the hydrogen bonding is easier to form and one hydroxyl group can form multiple hydrogen bonds. Therefore, when the reaction time is short or the numbers of maleic anhydride groups on the coupling agent and the hydroxyl groups on the fiber surface are not equal, there will be more hydrogen bond formation as compared to covalent bond formation. 


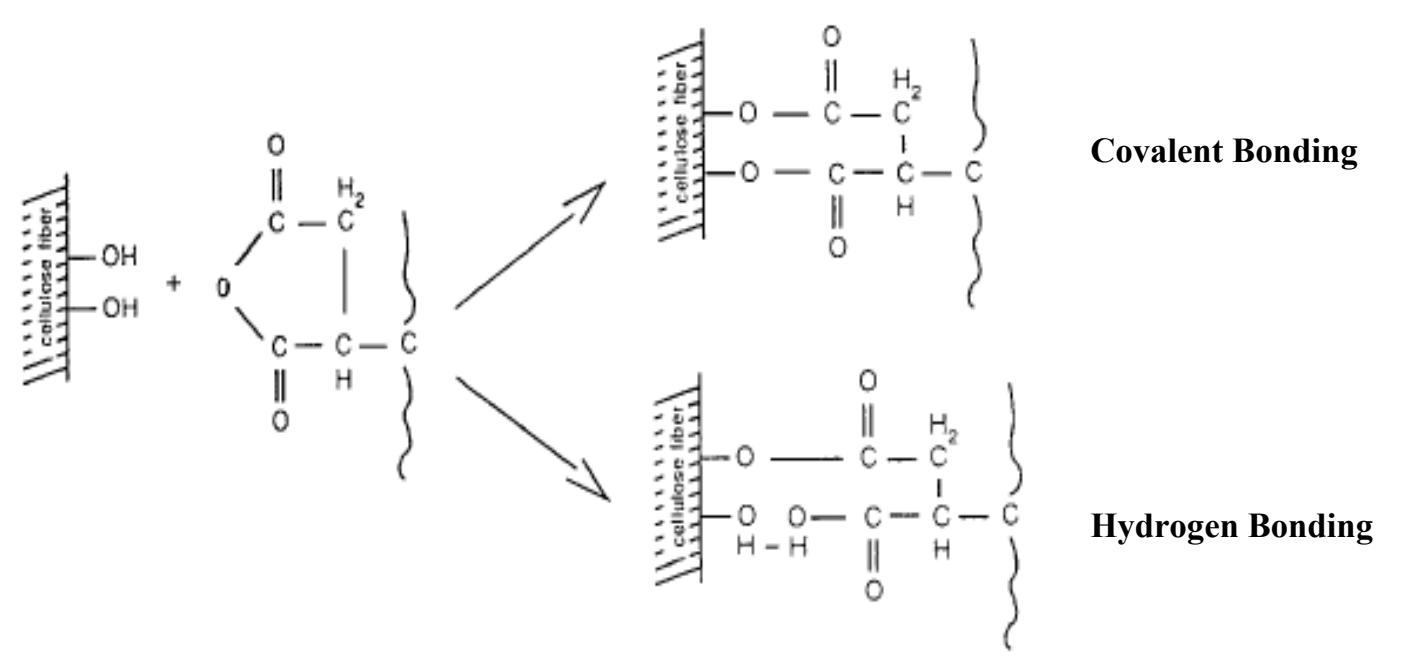

Figure 4-27 The bonding between coupling agent and wood fibers [4]

From the result of tensile and flexural testing (Figures 4-12 and Figures 4-14), the effect of coupling agent for the pristine fibers was almost linear. Thus, it could be assumed that the bonding was covalent. After alkali treatment, the effect of the coupling agent was non-linear. For example, when $2 \%$ coupling agent was added to the 3\% alkali-treated WPC, the tensile strength increased by $50 \%$. But when $4 \%$ coupling agent was added, the strength increased by another $27 \%$. This most likely happened because of the formation of hydrogen bonds between the coupling agent and the wood fibers. These hydrogen bonds help to increase the mechanical properties, but apparently do not help to reduce the amount of moisture absorbed.

The covalent bonding consumed the hydroxyl groups on the fiber surface, and this result in the reduction of the moisture absorption. The water molecule is more polar than the hydroxyl groups on the fiber surface, when moisture diffuses into the WPC, it can break the hydrogen bonding between the coupling agent and wood fibers 
and form new moisture/coupling agent and moisture/wood fibers hydrogen bonds. In this situation, the coupling agent can reduce the moisture absorption only in the first few days. While all this appears to be reasonable, it needs to be confirmed by additional experimentation in the future. 
Table 4-7(a) The results of moisture absorption test of WPC (Units: wt \%)

\begin{tabular}{|c|c|c|c|c|c|c|c|c|}
\hline \multicolumn{10}{|c|}{ Pristine } \\
\hline Days & $\mathbf{1}$ & $\mathbf{3}$ & $\mathbf{7}$ & $\mathbf{2 1}$ & $\mathbf{3 5}$ & $\mathbf{6 0}$ & $\mathbf{9 0}$ & $\mathbf{1 2 0}$ \\
\hline PP-g-MA 0\% & 1.61 & 3.38 & 5.72 & 11.27 & 13.39 & 13.77 & 13.48 & 13.86 \\
\hline PP-g-MA 2\% & 1.18 & 2.41 & 4.12 & 8.18 & 11.14 & 12.71 & 12.75 & 12.82 \\
\hline PP-g-MA 4\% & 0.88 & 1.80 & 3.12 & 6.35 & 8.70 & 11.75 & 12.00 & 12.08 \\
\hline PP-g-MA 8\% & 0.64 & 1.28 & 2.20 & 4.62 & 6.39 & 9.46 & 11.20 & 11.34 \\
\hline
\end{tabular}

Table 4-7(b) The results of moisture absorption test of WPC (Units: wt \%)

\begin{tabular}{|c|c|c|c|c|c|c|c|c|}
\hline \multicolumn{10}{|c|}{ NaOH 1\% } \\
\hline Days & $\mathbf{1}$ & $\mathbf{3}$ & $\mathbf{7}$ & $\mathbf{2 1}$ & $\mathbf{3 5}$ & $\mathbf{6 0}$ & $\mathbf{9 0}$ & $\mathbf{1 2 0}$ \\
\hline PP-g-MA 0\% & 1.78 & 3.66 & 6.04 & 10.64 & 12.05 & 12.28 & 12.25 & 12.26 \\
\hline PP-g-MA 2\% & 0.77 & 1.42 & 2.38 & 4.70 & 6.39 & 9.17 & 11.20 & 11.33 \\
\hline PP-g-MA 4\% & 0.70 & 1.23 & 2.00 & 3.91 & 5.38 & 7.78 & 10.09 & 11.18 \\
\hline PP-g-MA 8\% & 1.02 & 1.88 & 3.13 & 6.05 & 8.21 & 11.72 & 13.15 & 13.28 \\
\hline
\end{tabular}

Table 4-7(c) The results of moisture absorption test of WPC (Units: wt \%)

\begin{tabular}{|c|c|c|c|c|c|c|c|c|}
\hline \multicolumn{10}{|c|}{ NaOH 1\%(U) } \\
\hline Days & $\mathbf{1}$ & $\mathbf{3}$ & $\mathbf{7}$ & $\mathbf{2 1}$ & $\mathbf{3 5}$ & $\mathbf{6 0}$ & $\mathbf{9 0}$ & $\mathbf{1 2 0}$ \\
\hline PP-g-MA 0\% & 2.83 & 5.49 & 8.70 & 13.66 & 13.87 & 14.09 & 14.13 & 14.17 \\
\hline PP-g-MA 2\% & 1.52 & 3.11 & 5.20 & 9.73 & 12.74 & 13.43 & 13.43 & 13.47 \\
\hline PP-g-MA 4\% & 1.35 & 2.73 & 4.52 & 8.59 & 11.23 & 13.18 & 13.23 & 13.19 \\
\hline PP-g-MA 8\% & 1.36 & 2.67 & 4.41 & 8.24 & 10.84 & 13.28 & 13.34 & 13.45 \\
\hline
\end{tabular}

Table 4-7(d) The results of moisture absorption test of WPC (Units: wt \%)

\begin{tabular}{|c|c|c|c|c|c|c|c|c|}
\hline \multicolumn{10}{|c|}{ NaOH 3\% } \\
\hline Days & $\mathbf{1}$ & $\mathbf{3}$ & $\mathbf{7}$ & $\mathbf{2 1}$ & $\mathbf{3 5}$ & $\mathbf{1 2 0}$ & & \\
\hline PP-g-MA 0\% & 3.96 & 7.12 & 10.68 & 12.63 & 12.76 & 12.91 & & \\
\hline PP-g-MA 2\% & 3.23 & 6.41 & 9.95 & 12.61 & 12.53 & 12.60 & & \\
\hline PP-g-MA 4\% & 2.88 & 5.85 & 9.30 & 13.02 & 12.92 & 12.83 & & \\
\hline PP-g-MA 8\% & 2.22 & 4.57 & 7.46 & 12.76 & 12.91 & 12.84 & & \\
\hline
\end{tabular}

Table 4-7(d) The results of moisture absorption test of WPC (Units: wt \%)

\begin{tabular}{|c|c|c|c|c|c|c|c|c|}
\hline \multicolumn{10}{|c|}{ NaOH 3\%(U) } \\
\hline Days & $\mathbf{1}$ & $\mathbf{3}$ & $\mathbf{7}$ & $\mathbf{2 1}$ & $\mathbf{3 5}$ & $\mathbf{1 2 0}$ & & \\
\hline PP-g-MA 0\% & 4.90 & 8.56 & 12.79 & 13.75 & 13.80 & 13.98 & & \\
\hline PP-g-MA 2\% & 3.66 & 7.07 & 11.04 & 13.70 & 13.69 & 13.66 & & \\
\hline PP-g-MA 4\% & 2.75 & 5.64 & 9.13 & 13.59 & 13.55 & 13.46 & & \\
\hline PP-g-MA 8\% & 3.10 & 6.15 & 9.77 & 13.66 & 13.57 & 13.46 & & \\
\hline
\end{tabular}




\subsection{Summary}

The mechanical properties of wood particulates are very good, and this makes them a good reinforcing material for plastic composites. The tensile strength and modulus of softwood cellulose fibers may be as high as $1000 \mathrm{MPa}$ and $40 \mathrm{GPa}$ [31], but the properties of solid wood are not as good as those of fibers. For instance, the tensile strength and modulus of pine wood are just around 5.5 MPa and 6.5 GPa [32]. Thus, wood plastic composites made using cellulose fibers may be able to improve on the mechanical properties of lumber. Beside this, wood plastic composites are more rot- and moisture-resistant than real wood; therefore, WPCs really have the potential to replace the wood products that we use today.

Unfortunately, due to the lack of compatibility between wood flour and the polymer matrix, the mechanical properties are not as good as expected. For example, without any pretreatment of wood or addition of a coupling agent, the tensile strength and modulus of WPC determined in this work are 19.73 MPa and 4.19 GPa. Although the strength of WPC is much higher than timber, the modulus of WPC is only $65 \%$ of solid wood. In addition, the moisture absorption in finished parts is a major concern of wood plastic composites. Therefore, a study of the combined effects of alkali treatment and ultrasound treatment of wood flour on the mechanical properties and water absorption behavior of polypropylene-based wood/plastic composites (WPCs) 
made using the treated wood particulates may help solve these problems.

FTIR measurements indicate, as expected, that alkali treatment of wood helps to remove both hemicellulose and lignin, and there is an increase in the amount of hydroxyl groups on the cellulose surface. Further, this process is promoted by ultrasound treatment. However, as an undesirable effect, alkali treatment lowers the thermal stability of wood particulates. The results of mechanical testing of WPC samples indicate that alkali treatment of wood particulates improves both composite strength and modulus when polypropylene grafted with maleic acid is used as a coupling agent. The strength increase is due to improved adhesion between the fiber and matrix due to improved bonding resulting from the increase in the number of hydroxyl groups, while improved modulus is due to the removal of lignin and hemicellulose that are not as stiff as cellulose. Polarized optical microscopy shows the presence of well-defined polymer crystals on the surface of the modified wood, and this is also responsible for the improved mechanical properties.

Results obtained also conclusively show that the combination of chemical treatment of wood and ultrasound assistance is more effective in improving the mechanical properties of the composites as compared to the use of chemical treatment alone. Moisture absorption experiments indicate that the coupling agent reduces the absorption rate and the alkali treatment reduces the maximum amount absorbed, but 
ultrasound treatment promotes moisture absorption. Table 4-8 shows the comparison of pine wood and WPCs. The economic analysis of the alkali and ultrasound treatment are listed in appendix I

Table 4-8 The comparison of pine wood and $50 \%$ WPCs

\begin{tabular}{|c|c|c|c|}
\hline & $\begin{array}{l}\text { Tensile } \\
\text { Strength }\end{array}$ & $\begin{array}{l}\text { Tensile } \\
\text { Modulus }\end{array}$ & $\begin{array}{c}\text { Equilibrium } \\
\text { moisture absorption }\end{array}$ \\
\hline Pine Wood [32] & $5.5 \mathrm{MPa}$ & $6.5 \mathrm{GPa}$ & N/A \\
\hline $\begin{array}{c}\text { WPC } \\
\text { (untreated, no coupling agent) }\end{array}$ & $19.73 \mathrm{MPa}$ & 4.19GPa & $13.86 \%$ \\
\hline $\begin{array}{c}\text { WPC } \\
\text { (1\% } \mathbf{~ N a O H , ~} \mathbf{2} \% \text { coupling agent) }\end{array}$ & $42.43 \mathrm{MPa}$ & $4.72 \mathrm{GPa}$ & $11.33 \%$ \\
\hline $\begin{array}{c}\text { WPC } \\
(\mathbf{1 \%} \mathbf{N a O H}+\text { ultrasound, } \mathbf{2 \%} \\
\text { coupling agent })\end{array}$ & $45.11 \mathrm{MPa}$ & $5.22 \mathrm{GPa}$ & $13.47 \%$ \\
\hline $\begin{array}{c}\text { WPC } \\
\text { (3\% } \mathrm{NaOH}, \mathbf{2} \% \text { coupling agent) }\end{array}$ & $34.55 \mathrm{MPa}$ & $5.02 \mathrm{GPa}$ & $12.60 \%$ \\
\hline $\begin{array}{c}\text { WPC } \\
\text { (3\% NaOH+ultrasound, } 2 \% \\
\text { coupling agent) }\end{array}$ & $39.88 \mathrm{MPa}$ & $5.88 \mathrm{GPa}$ & $13.66 \%$ \\
\hline
\end{tabular}




\section{RECOMMENDATION FOR FUTURE WORK}

In this work, $1 \%$ and $3 \% \mathrm{NaOH}$ solutions have been chosen to modify wood fibers, and the effects are different on mechanical properties. The $1 \%$ alkali treatment is better at increasing strength of WPC, which the $3 \%$ alkali treatment is more effective in improving modulus of WPC. It would be interesting to know what happens when wood flour is treated with alkali solution of other concentrations. In the early stages of this research, wood flour was treated with $10 \% \mathrm{NaOH}$ solution, and this ruined the properties of the wood. Thus, the suggested concentration of alkali solution in the future work is lower than $10 \%$ by weight.

The ratio of wood in wood plastic composites may vary from $30 \%$ to $70 \%$. Due to the low cost of wood waste, a higher wood content can lower the material cost of WPC. Therefore, making the WPC with a higher ratio of wood fiber $(60 \%$ or $70 \%)$ is recommended.

Compared to polypropylene and wood fibers, the coupling agent is the relatively more expensive material in WPC. In this work, most improvements of mechanical properties of alkali treated WPC happened with $2 \%$ coupling agent. Therefore, adding $4 \%$ and $8 \%$ PP-g-MA may not be necessary. In the future, a study of the effect of lower concentration of coupling agent is recommended.

Bonding behavior of coupling agent is also an interesting aspect for future work, 
using an acid catalyst for promoting the formation of covalent bonding. Thus, the moisture absorption could be further reduced, and better mechanical properties are expected also.

In this work, hemicellulose has been removed form wood fiber, and some lignin is eliminated as well. Removing hemicellulose or lignin alone will help to understand the effect of each component on the wood/plastic composite. 


\section{REFERENCES}

1. J. Markarian (2005), Wood-plastic composites: current trends in materials and processing, Plastics, Additives and Compounding, Volume 7, Issue 5, September-October 2005, 20-26.

2. A. A. Klyosov (2007), Wood plastic composites, Wiley-Interscience, 18-20.

3. R. B. Miller (1999), Wood as an engineering material, Forest Products Laboratory. Wood handbook 463.

4. A.K. Bledzki and J. Gassan (1999), Composites reinforced with cellulose based fibres, Progress in polymer science, Vol. 24, 221-274.

5. A.J. Michell (1989), Wood cellulose-organic polymer composites, Composite Asia Pacific, Adelaide, Australia, Vol. 89, 19-21.

6. J. Gassan, and A.K. Bledzki (1996), Effect of coupling agents on the moisture absorption of natural fiber-reinforced plastic, Angewandte Makromolekulare Chemie, 236, 129-138

7. J.M. Felix, and P.J. Gatenholm (1991), The nature of adhesion in composites of modified cellulose fibers and polypropylene, Journal of Applied Polymer Science; $42,609-620$

8. L. Hua, P. Flodin, and T. Ro“nnhult (1987). Cellulose fiber-polyester composites with reduced water sensitivity, Polymer Comp, 8(3), 203-207.

9. D. Maldas, B.V. Kokta, and C. Daneault (1989), Composites of polyvinyl chloride - wood fibers: IV. Effect of the nature of fibers, J Vinyl Tech 1989, 11(2), 90-99.

10. A. Mukherjee, P.K. Ganguly, and D. Sur (1993), Structural mechanics of jute: the effects of hemicellulose or lignin removal, J Text Inst, 84, 348-353.

11. S. Sreenivasan, I.P. Bahama, and I.K.R. Krishna (1996), Influence of delignificaion and alkali treatment on the fine structure of coir fibers, J Mater Sci, 31, 721-726. 
12. K. V. Sarkanen (1990), Chemistry of solvent pulping, TAPPI J., 73(10), 215-219.

13. P. B. Sarkar (1934), The chemistry of jute lignin, J. Ind. Chem. Soc. 11, 691-700.

14. D. Ray and B. K. Sarkar (2001), Characterization of alkali-treated jute fibers for physical and mechanical properties, J. Appl. Polym. Sci. 80, 1013-1020.

15. S.V. Prasad, C. Pavithran, and P.K. Rohatgi (1983), Alkali treatment of coir fibers for coir-polyester composites, J Mater Sci. 18, 1443-1454.

16. R.K. Samal, S.K. Rout, B.B. Panda, and M. Mohanty (1995), Effect of chemical modification on FTIR spectra. I. Physical and chemical behavior of coir, J Appl Polym Mater, 58(4), 745-752.

17. I.N. Panchev, N.A. Kirtchev, and C.G. Kratchanov (1994), On the production of low esterified pectins by acid maceration of pectic raw materials with ultrasound treatment, Food Hydrocolloids, 8, 9-17.

18. M. Salisova, S. Toma, and T. Mason (1997), Comparison of conventional and ultrasonically assisted extractions of pharmaceutically active compounds from Salvia officinalis, J. Ultrason Sonochem, 4, 131-134.

19. A. Ebringerova and Z. Hromadkova (1997), The effect of ultrasound on the structure and properties of the water-soluble corn hull heteroxylan, Ultrason Sonochem, 4, 305-309.

20. Z. Hromadkova, J. Kovacikova, and A. Ebringerova (1999), Study of the classical and ultrasound-assisted extraction of the corn cob xylan, Ind Crops Prod, 9, 101-109.

21. R. Sun, X.F. Sun and X.P. Xu (2002), Effect of ultrasound on the physicochemical properties of organosolv lignins from wheat straw, J. Appl. Polym. Sci. 84(13), $2512-2522$.

22. R. Sun and J. Tomkinson (2002), Comparative study of lignin isolated by alkali and ultrasound-assisted extraction from wheat straw, Ultrasonic Sonochemistry, vol. 9, 85-93. 
23. C. Petrier, M.F. Lamy, A. Francony, A. Benahcene, B. David, V. Renaudin and N. Gondrexon (1994), Sonochemical degradation of phenol in dilute aqueous solutions: comparison of the reaction rates at 20 and $487 \mathrm{kHz}$, J. Phys. Chem. 98(41), $10514-10520$.

24. T. Seino, A. Yoshioka, M. Fujiwara, K.L. Chen, T. Erata, M. Tabata and M. Takai (2001), ESR Studies of radicals generated by ultrasonic irradiation of lignin solution. An Application of the Spin Trapping Method, Wood Sci. Technol. 35(1-2): $97-106$.

25. G.M. Tan, S. Yasuda and N. Terashima (1985), The Effect of ultrasonic irradiation on delignification reactions. ii. Behavior of lignin under ultrasonic irradiation, Mokuzai Gakkaishi 31(5): 388 -396.

26. A.V. Pranovich, M. Reunanen and B. Holmbom (1998), Sonochemistry of Lignin Model Compounds in Water. Advances in Lignocellulosics Chemistry for Ecologically Friendly Pulping and Bleaching Technologies, European Workshop on Lignocellulosics and Pulp, 5th, University of Aveiro, Aveiro, Port., Aug. 30-Sept. 2, $421-424$.

27. J.E. Laine and D.A.I. Goring (1977), Influence of ultrasonic irradiation on the properties of cellulosic fibers, Cell. Chem. Technol. 11(5): $561-567$.

28. S. Yeh, A. Al-Mulla, R.K. Gupta (2006), Effect of the coupling agent on the properties of PNC-based wood/plastic composites. Journal of Polymer Engineering, 26(8-9), 783-804.

29. X.F. Sun, R.C. Sun, J. Tomkinson, and M.S. Baird (2004), Degradation of wheat straw lignin and hemicellulosic polymers by a totally chlorine-free method, Polymer Degradation and Stability, 83, 47-57.

30. B.F. Tjeerdsma and H. Militz (2005), Chemical changes in hydrothermal treated wood: FTIR analysis of combined hydrothermal and dry heat-treated wood, Holz als Roh- und Werkstoff, 63, 102-111.

31. A. J. Michell and D. Willis (1978), Cellulosic fibers for reinforcement. Appita, $31(5), 347-54$ 
32. W. Burdzik (2004), Grade verification of SA pine-Bending, Modulus of Rupture, Modulus of Elasticity, tension and compression, Southern African Forestry Journal, 202, 21-27

33. R.C. Creese, M. Adithan, and B.S. Pabla; Estimating and Costing for the Metal Manufacturing Industries, Marcel Dekker, August 1992, Cost Engineering Series18, pp. 288

34. http://www.eia.doe.gov/cneaf/electricity/epm/table5_6_b.html 


\section{APPENDIX I ECONOMIC ANALYSIS}

Being a commercial product, cost is always a very important issue. In this work, the $1 \%$ and $3 \%$ alkali treatment required $100 \mathrm{~g}$ and $300 \mathrm{~g}$ sodium hydroxide, respectively, for $1 \mathrm{~kg}$ wood fiber. The commercial sodium hydroxide is around 100 dollars per ton. The direct material cost of a chemical process is usually $35 \%$ of the total cost [33]. Therefore, the $1 \%$ and $3 \%$ alkali treatment add 2.86 and 8.57 cents cost to one kilogram wood particulates. The cost of ultrasound treatment mainly depends on the energy to produce the ultrasound. In this work, $170 \mathrm{~g}$ wood fibers were treated by ultrasound with a 750 watts power source for $30 \mathrm{~min}$. The average retail price of industrial electricity in United States is 6.33 cents per kilowatt-hour in 2008 [34], therefore, the ultrasound treatment cost is 13.96 cents per kilogram of wood particulates. It is much higher than the alkali treatment. Table 1 shows the comparison of pine wood and WPCs with different treatment.

Table 1 The cost of alkali and ultrasound treatment

\begin{tabular}{|c|c|}
\hline & $\begin{array}{c}\text { Treatment cost } \\
\text { (cents/kg wood fiber) }\end{array}$ \\
\hline Untreated & N/A \\
\hline $1 \%$ Alkali treatment & 2.86 \\
\hline $1 \%$ Alkali treatment with ultrasound & 16.82 \\
\hline $3 \%$ Alkali treatment & 8.57 \\
\hline $3 \%$ Alkali treatment with ultrasound & 22.53 \\
\hline
\end{tabular}

